\title{
Participants' beliefs about educational risk and resilience in Energy Express, a summer intervention program for West Virginia's elementary schoolchildren
}

\author{
Lynn G. McMullen \\ West Virginia University
}

Follow this and additional works at: https://researchrepository.wvu.edu/etd

\footnotetext{
Recommended Citation

McMullen, Lynn G., "Participants' beliefs about educational risk and resilience in Energy Express, a summer intervention program for West Virginia's elementary schoolchildren" (2002). Graduate Theses, Dissertations, and Problem Reports. 2473.

https://researchrepository.wvu.edu/etd/2473

This Dissertation is protected by copyright and/or related rights. It has been brought to you by the The Research Repository @ WVU with permission from the rights-holder(s). You are free to use this Dissertation in any way that is permitted by the copyright and related rights legislation that applies to your use. For other uses you must obtain permission from the rights-holder(s) directly, unless additional rights are indicated by a Creative Commons license in the record and/ or on the work itself. This Dissertation has been accepted for inclusion in WVU Graduate Theses, Dissertations, and Problem Reports collection by an authorized administrator of The Research Repository @ WVU. For more information, please contact researchrepository@mail.wvu.edu.
} 


\title{
PARTICIPANTS' BELIEFS ABOUT EDUCATIONAL RISK AND RESILIENCE IN ENERGY EXPRESS, A SUMMER INTERVENTION PROGRAM FOR WEST VIRGINIA'S ELEMENTARY SCHOOLCHILDREN.
}

\author{
Lynn G. McMullen \\ Dissertation submitted to the College of Human Resources and Education \\ at West Virginia University \\ in partial fulfillment of the requirements \\ for the degree of \\ Doctor of Education \\ in \\ Special Education
}

\author{
Gretchen Butera, Ph.D., Chair \\ Van Dempsey, Ph.D. \\ Ruthellen Phillips, Ph.D. \\ Luise Savage, Ed.D \\ John Wells, Ph.D. \\ Diane Woodrum, Ph.D.
}

Department of Educational Theory and Practice

\author{
Morgantown, West Virginia \\ 2002
}

Keywords: AmeriCorps, At-risk, Education, Energy Express, Intervention programs, Qualitative research, Resilience, Survey research

Copyright 2002 Lynn McMullen 


\section{ABSTRACT \\ PARTICIPANTS' BELIEFS ABOUT EDUCATIONAL RISK AND RESILIENCE IN ENERGY EXPRESS, A SUMMER INTERVENTION PROGRAM FOR WEST VIRGINIA'S ELEMENTARY SCHOOLCHILDREN.}

\section{Lynn G. McMullen}

Energy Express is a six-week summer program to promote the school success of elementary school children living in rural and low-income communities of West Virginia. Throughout the course of the program, college student AmeriCorps members provide literacy, art, and recreation activities for multiage groups of 5 to 8 children under the direction of a site coordinator, most often a local education professional. The purpose of this study was to describe the beliefs of Energy Express participants about educational risks faced by West Virginia schoolchildren, and to examine the effects of those beliefs on daily program decisions and interactions with children. Data collection strategies for qualitative case study at one Energy Express site included interviews, observations, document analysis, and focus group interviews with attending children. Qualitative study yielded eight themes portraying participants' definitions, priorities, recruitment methods, activities and beliefs in addressing educational risk. A Participant Beliefs Survey, comprised of a 45-question Likert scale section and a section in which respondents ranked educational risk variables by importance, was also developed for this research effort. Energy Express personnel statewide ( $\mathrm{n}=$ 543) responded to the survey. Principal components analysis of Likert scale responses yielded 4 factors believed to predict educational risk. Analysis of the ranking survey revealed that family and within-child factors were believed to contribute the most strongly to educational risk. 


\section{DEDICATION}

The author wishes to dedicate this dissertation to my husband, Bryan K. McMullen. Your constant love, leadership, encouragement, support, and commitment to my well-being during this very long process have been a shining example of resilience-building. You are my hero!

In thankfulness to my Heavenly Father, to my Lord and Savior Jesus Christ, and to the Comforter and Encourager among us, the Holy Spirit. Bless the Lord, oh my soul, and all that is within me, bless His holy name! 


\section{ACKNOWLEDGMENTS}

The author wishes to acknowledge so many people with gratitude for their patience, prayers, support and encouragement. Thanks to the members of my committee, individually and as a collaborative group. Your commitment to my growth as a professional educator, researcher and human being has been awesome!

Thanks especially to my friend, mentor, and committee chairperson, Gretchen Butera, for cheerleading, direction and expectation of the best. Thanks for being here for me! Van Dempsey provided the inspiration for my dissertation research and modeled both the joys and the rigor of qualitative research. Thanks for allowing me to learn from the best! Thanks to Ruthellen Phillips for allowing me to do doctoral research in the setting of Energy Express-a multifaceted gem of a program, reflecting all of your best efforts on behalf of children in West Virginia. Luise Savage inspired me to jump into the doctoral program in the first place, and was a constant source of encouragement along the way. Thanks for your commitment to special education students at all levels of education! Diane Woodrum is just the sort of special education professor I would like to become- a warm and relational human being committed to professionalism, best practice, and hard work in preparing teachers to impact the lives of special children. Finally, thanks to John Wells for your attention to detail, insistence that I could scale a large learning curve in Technology Education, and encouragement during the doctoral defense. I needed that! I count each of you as a gift from God.

I also appreciate the assistance and support of Kingwood Energy Express for your gracious welcome and openness in sharing your daily routine, thoughts, joys and sorrows with me during the summer of 1999. Faithful site coordinator, collaborative members, VISTAs and AmeriCorps members--You are great human beings, one and all, and I enjoyed the time I spent with you and the friendships that have developed from that experience.

Along the way, there have been lots of others who have supported, encouraged and assisted me in my professional efforts and my life. I count among my friends: Dr. Holly Pae, my first and best friend among those going through the doctoral program with and now ahead of me; Dr. Brenda Wilson; Dr. Joan Henderson; Diane Bonasso; Billie Bonnett; Jim Burton; Melissa Reed; Dan Richason; Ann Dilger; Evan Keeling; Ruth Schneider; and Annette Conti. Your commitment to special education, higher education, and/or Energy Express has been a blessing to me. 
I have enjoyed friendship and prayer from so many others-you each know who you are, as I hope I tell you often how much I appreciate you! I thank my extended family-the McMullens, the Pritchetts, and the Goldsums--for their encouragement and personal support, and all that I have learned about what is true, right and good in life from each of you. Last, and most, I thank Bryan, Joel, Cara, and lan-for their long-suffering in going through this process with me; for keeping me somewhat grounded and out of the ivory tower; and for the joy of sharing life together! You are my greatest treasures! 


\section{TABLE OF CONTENTS}

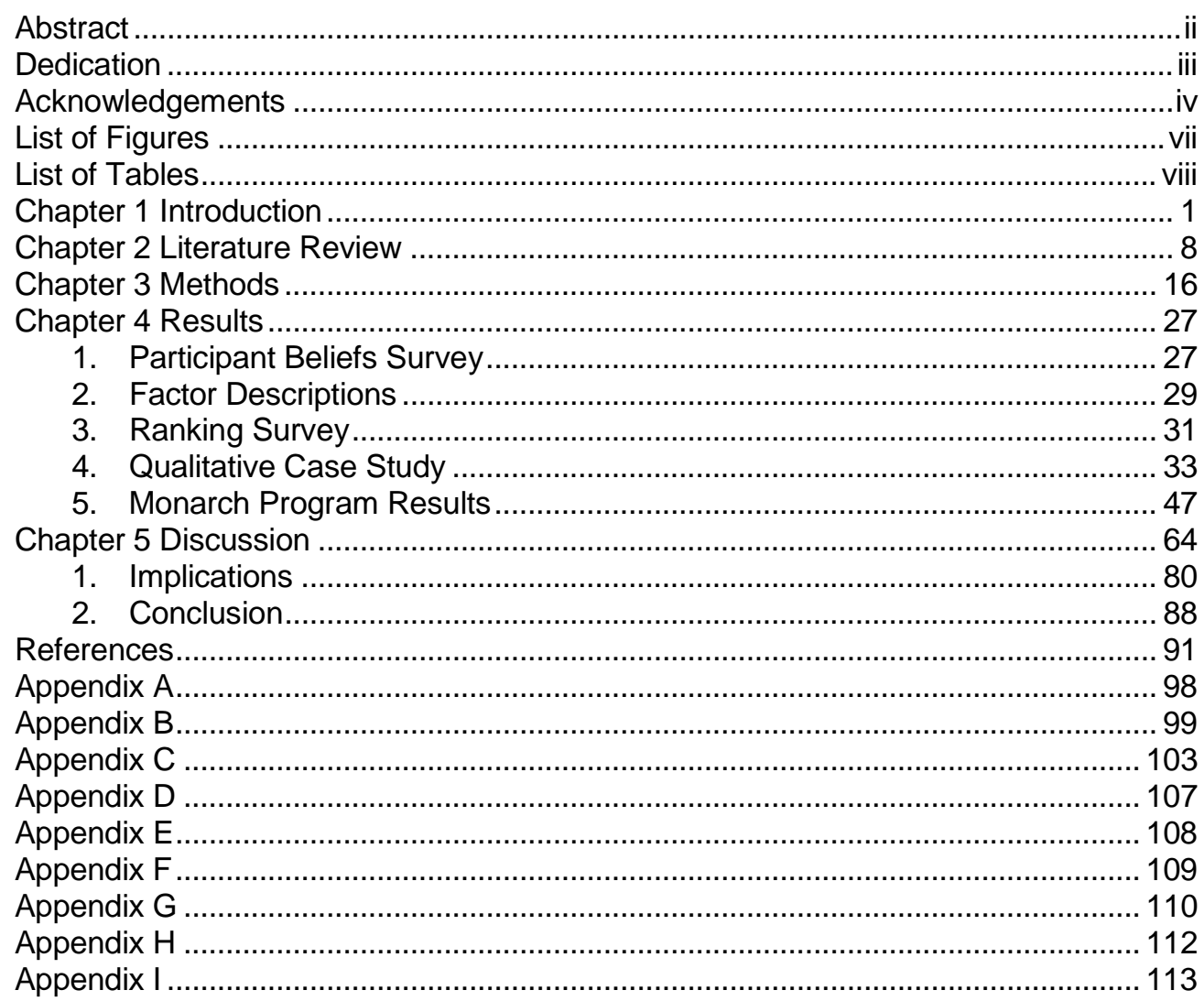




\section{LIST OF FIGURES}

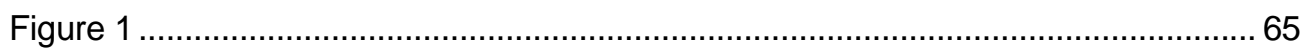




\section{LIST OF TABLES}

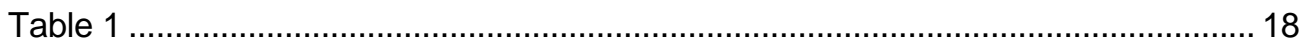

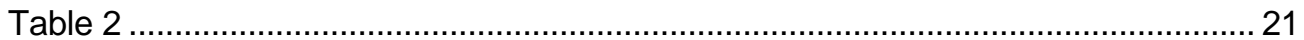

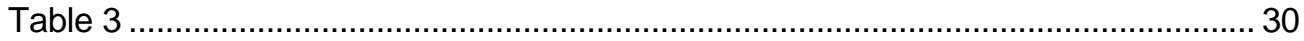

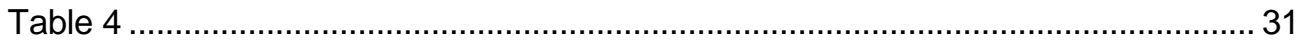

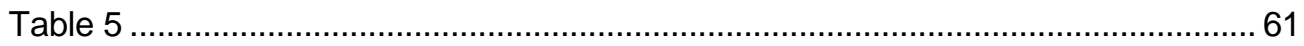

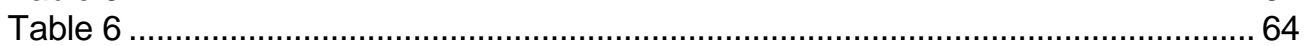

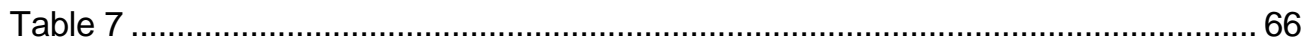

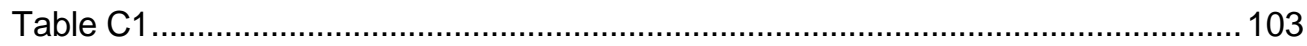

Table C2

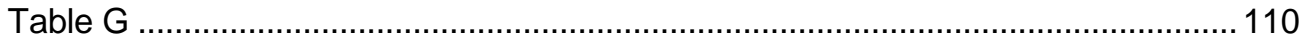

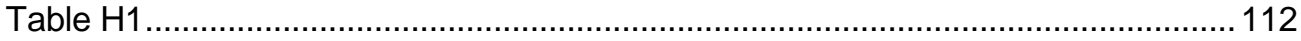

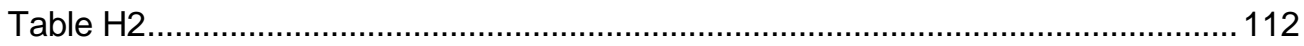

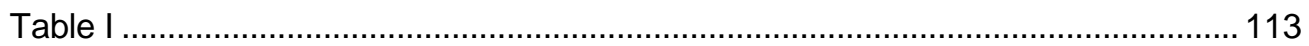


Chapter I

Introduction and Study Rationale

Reading, 'riting and 'rithmetic: Historically and currently, the expressed purpose of educational systems has been to impart knowledge and develop skills in "the three R's." Indeed, the term to educate means "to provide with knowledge or training; to provide training for some particular purpose; to stimulate or develop the mental or moral growth of" (American Heritage Dictionary, 1982, p. 439). While the "three R's" have formed the core of the explicit instruction, compulsory public education in this country has also provided implicit schooling in cultural knowledge and values. In fact, an educated person is one who shows "evidence of schooling" or who is "cultured" (American Heritage Dictionary, 1982, p. 439).

Interestingly, this implicit instruction often centers around our beliefs about two other "R" words--rights and responsibilities. As Thomas Jefferson wrote in 1818, the purpose of the primary education he envisioned for every man was

to give every citizen the information he needs for the transaction of his own business; to enable him to calculate for himself, and to express and preserve his ideas, his contracts and accounts in writing; to improve, by reading, his morals and faculties; to understand his duties to his neighbors and country, and to discharge with competence the functions confided to him by either; to know his rights; to exercise with order and justice those he retains, to choose with discretion the fiduciary of those he delegates; and to notice their conduct with diligence, with candor and judgment; and in general, to observe with intelligence and faithfulness all the social relations under which he shall be placed (Report for University of Virginia, 1818).

While Jefferson "did not believe that schooling should impose political values or mold the virtuous republican citizen" (Spring, 1990, p. 37), he supported the idea that "Popular education should advance the cause of human liberty and freedom by safeguarding the individual's natural rights" (Gutek, p.164). Jefferson and his contemporary, Benjamin Franklin, feared that an uneducated populace could not maintain the freedoms they had gained by the War for Independence which were later specified in the Bill of Rights. With freedom secured, however, Jefferson believed that "If the condition of man is to be progressively ameliorated, as we fondly hope and believe, education is to be the chief instrument in effecting it" (in correspondence to M. A. Jullien, 1818). Later in the nineteenth century, Horace Mann echoed that prevailing belief when he stated that "Education, then, beyond all other devices of human origin, is the great equalizer of the conditions of men--the balance-wheel of the social machinery" (cited in Gutek, p. 185). Access to an adequate education came to be seen as both a citizen's right and a communal responsibility for solving the problems of the society.

From the time of the Civil War and the Emancipation Proclamation through the 1950's, 60's and 70's, education has again been predominantly concerned with making people aware of their rights, safeguarding citizens' rights and extending those rights to ever-increasing segments of society. Individuals such as Catherine Beecher, Booker T. Washington, W. E. B. DuBois, Jane Addams and Alexander Graham Bell advocated for human, educational, and civil rights for African Americans, Native Americans, Asian Americans, Mexican Americans, immigrants, the disabled and other disenfranchised groups. Court rulings, such as the 1954 Brown vs. the Board of Education decision denying the equality of separate educational facilities for minorities, and federal and state laws, such as the recently reauthorized Individuals with Disabilities Education Act both reflect and extend our 
commitment to the educational rights of individuals. In the United States, "Schooling is fundamentally a moral, not a technical, enterprise" (Noblit \& Dempsey, 1996, p. 3).

Jefferson's and Mann's beliefs about the value of education set the course for the development of our universal public education system. Have we, then, achieved Jefferson's vision of public education progressively ameliorating the condition of man? Has Mann's idea of education as "the great equalizer of the conditions of men-the balance-wheel of the social machinery" come into evidence? As educational rights have been extended to disadvantaged groups in this country, have we also ensured, as Mann hoped (cited in Gutek, p. 164) that "all the children within its territory. . . may be well instructed in the rudiments of knowledge, formed to the propriety of demeanor, and imbued with the principles of duty?"

I think we could safely say, "No, not yet." In fact, the National Commission on Excellence in Education (1983) states:

Our Nation is at risk. . . We report to the American people that. . .the educational foundations of our society are presently being eroded by a rising tide of mediocrity that threatens our very future as a Nation and a people. . . .If an unfriendly foreign power had attempted to impose on America the mediocre educational performance that exists today, we might well have viewed it as an act of war. As it stands, we have allowed this to happen to ourselves. . . .We have, in effect, been committing an act of unthinking, unilateral educational disarmament. Our society and its educational institutions seem to have lost sight of the basic purposes of schooling, and of the high expectations and disciplined effort needed to attain them. This report, the result of 18 months of study, seeks to generate reform of our educational system in fundamental ways and to renew the Nation's commitment to schools (p. 5).

In beginning this reform effort, it is valuable to remember that public education is a social practice of society (Skrtic, 1991). In this social practice, each school is organized around the shared beliefs, values, and experiences of its members. In schools, adults such as teachers and administrators may be considered the empowered, decision-making members, and the attending children are the non-empowered members who are developing shared beliefs, values and experiences. Most of the members fit within the established social structure, to greater or lesser degree framing their behavior to the shared values of the school and meeting the criteria determined as adequate for certain levels of education. A smaller proportion of the members do not fit the typical educational pattern nor do they accrue the desired educational benefits from the basic system provided. "Among the many definitions of the term 'at risk,' the most prominent idea expressed is that the term refers to students whose academic achievement is unsatisfactory" (Swanson, 1991, p. 3).

How do we, then, reconcile our beliefs about the value of education for every student with the harsh realities that some students do not learn as much as we want them to learn in the time frames and through the methods we have determined to be effective and efficient for the general population? While in a few cases we examine the system to see where it has failed, we generally narrow our focus, refine our educational processes, and develop alternate educational interventions, programs or systems for those students we have found difficult to teach (Skrtic, 1991; Hixson \& Tinzmann, 1990). Two interesting alternate systems that have been developed to address the educational needs of these difficult to teach children are special education and compensatory education. 


\section{Intervention Programs}

Special education traces its lineage to 1799 when a French physician, Jean Itard, attempted to educate Victor, an 11- or 12-year old boy who had apparently been abandoned in the Aveyron forest. As Victor "was unable to talk and lacked any semblance of socialization," Itard tried many educational interventions and became the first to publish information about his efforts to educate a person with mental impairments (Smith, 1998). From this beginning to the present in which special education services have been mandated by federal law, the special education system has worked from a medical model, premised on the idea that disabilities are inherent in the individual. Diagnostic methods have been developed to identify disabilities (or people with disabilities). Educational remedies or interventions have been prescribed through individualized educational plans to ameliorate the effects of those disabilities for the individual.

Special education programs do, however, have several limitations in addressing the needs of children with educational problems. First, there is wide variability in criteria used to identify disabilities in children (McGrew, Algozzine, Ysseldyke, Thurlow \& Spiegel, 1995). Second, the disability eligibility requirements and screening procedures used can exclude children from receiving the extra educational help that they need or give parents the impression that schools are not willing to help their children (Will, 1986). Third, students who have been deemed eligible for special education services may be stigmatized by special education labels and by physical separation from their peers and regular school activities (Will, 1986). In West Virginia, for instance, students diagnosed with mild disabilities most often receive special education services in resource room pull-out programs or special classrooms within the regular education environment (McLeskey \& Henry, 1999). Fourth, special education programs frequently try to remediate educational failure rather than prevent it in the first place (Will, 1986). Unfortunately, the results are often not what we had hoped. Wood (1994, p. 60) reports that "almost 7 out of 10 special education students drop out, 'age out' (upon reaching their 22nd birthday), are expelled, or leave school with unearned diplomas. Perhaps 1 or 2 out of 10 complete a standard high-school curriculum of any kind."

Compensatory education comes in part from legislation arising from the 1960s' War on Poverty. The rationale for compensatory education came from the work of Allison Davis, an educator, anthropologist, socialpsychologist and sociologist who became "one of the first black Americans granted tenure by a non-historically black academic institution in 1948” (“Allison Davis”, no date). According to Davis, compensatory education was needed to compensate for what he called cultural deprivation, which "refers to the child/adolescent of the nondominant culture being deprived of the human rights and social privileges of the dominant culture manifest in language, educational opportunity, and occupation" (Macaluso, 1996).

Note that from its inception, compensatory education has addressed educational problems from a sociological point of view, as opposed to special education's medical model. It is not surprising then, that compensatory education programs view existing educational problems as originating from the family, community, or culture. This view contrasts with the special education perspective in that the problems are considered to be extrinsic rather than intrinsic to the child. Although some compensatory programs such as Head Start and the Women's Infants and Children (WIC) program seek to prevent educational risk from exploding into educational deficits, most 
compensatory education programs for elementary-aged children still focus on the treatment or amelioration of existing educational problems (Hixson \& Tinzmann, 1990).

\section{Significance of the Problem}

\section{Risk Factors}

A multitude of factors have been identified as contributing to the educational risk of children (Lombardi, Odell \& Novotny, 1990). Carnahan (1994) developed three categories for risk factors: demographic predictors, family predictors, and within student factors. Demographic predictors include low socioeconomic status, minority status, living in the South, and living in an urban environment. Family predictors are single-parent families, large families, having a parent who dropped out of school, or having a parent in jail. Others include being home alone more than three hours a day, having parents who have no high school diploma, and having a sibling who dropped out of school (National Center for Education Statistics [NCES], cited in Chesebro, 1992). Within student factors include academic failure, grade retention, external locus of control for academics, disciplinary problems in school, and truancy or poor record of attendance in elementary school. Other experts include learning disabilities or emotional disturbance (U.S. Department of Education, 1990) and limited English proficiency as within student risk factors (NCES, cited in Chesebro, 1992).

Some authors cite problems inherent in schools and communities as risk factors. Hirsh (1996) sees the lack of a uniform, knowledge-based curriculum as one of the more prevalent causes of educational failure, given the mobility rate (percentages of student transfers during any given school year) of students in our schools. Many experts consider economic disadvantage and its effect on the "intellectual capital" of students to be the bottom line of educational risk. (Lewit, Terman \& Behrman, 1997; Maeroff, 1998; Ralph, 1989; Smith \& Lincoln, 1988). Educational risk, then, is most often operationally defined by those who study or deal with the phenomena across a very diverse population of students with unsatisfactory academic achievement (Swanson, 1991).

\section{Risk in West Virginia}

Children in West Virginia, unfortunately, experience more than their fair share of risk factors. In the nation as a whole, just over $21 \%$ of children live in poverty; in West Virginia, over $30 \%$ of children live in poverty (Behrman, 1997; West Virginia KIDS COUNT, 1998). In West Virginia, the child hunger percentage (the number of children who go to bed hungry on any given night) is between 25 and 35\% (Mink, 1993). For elementary-aged school children, it is not hard to believe that most of these incidents of hunger happen during the summer, when children do not have access to school breakfast and lunch programs. Nationally, only $10 \%$ of families receiving Aid to Families with Dependent Children (AFDC) had some earnings in 1995; in West Virginia, less than 4\% of these families had earnings (Zedlewski \& Giannarelli, 1997). DeYoung and Lawrence (1995) point out that "most chronically poor counties in the nation are located in rural areas, particularly in Appalachia and in the South" (p. 106), and West Virginia is a predominantly rural state, located wholly within Appalachia.

Because of the rural nature of the state, students in West Virginia face challenges other than poverty. Citing the New York State Education Department (1992), Brown and McIntire (1995) note that rural students are often stereotyped as backward and have "lower self-esteem, lower academic achievement and lower post secondary aspirations." 
In the United States, $26 \%$ of families with children were headed by a single parent; in West Virginia, the share of children living in single-parent families increased by 50\% in the 10 years between 1985 and 1995 (O'Hare, 1998) such that by $1990,17.8 \%$ of all West Virginia children lived in single parent families (Rahall, 1990). In 1993, the overall rate of mental retardation (their words) in the nation was 7.6 cases per 1000 population; in West Virginia, the rate was 16.9 cases per 1000 (U. S. Centers for Disease Control and Prevention, 1996). West Virginia, then, becomes an ideal setting for study of the perceived need for, and effects of, programs addressing children at educational risk.

Resilience

There is, however, "the rest of the story." In spite of the overwhelming number of factors present in West Virginia and other low-income settings--risk factors which may, indeed, affect student outcomes--some authors eschew the concept of risk. They make the case that our efforts on behalf of children we believe to be at risk will be negative in orientation or self-defeating from the outset. Swadener and Lubeck (1995), for instance, suggest that we deconstruct the discourse of risk by looking at children and families as "at-promise" instead. They recommend that we focus on discovering and communicating the factors that allow some to become educationally competent in spite of the presence of multiple risk factors. The entire premise of Simeonsson's book Risk, Resilience \& Prevention: Promoting the Well-being of All Children_(1994) is that a "paradigmatic change of emphasis from treatment to prevention" (p. xi) is essential to promote the well-being of children. Danforth and Rhodes (1997) go so far as to recommend the deconstruction of dis-ability, by "seeking, hearing and taking seriously the words and ideas of the persons served by special programs" (p. 363).

\section{Energy Express}

Within this dissertation, we will be able to seek, hear and take seriously the words and ideas of persons served by a special intervention program unique to West Virginia--Energy Express. Energy Express is

a six-week summer program promoting the school success of children living in rural and lowincome communities across West Virginia by:

Providing summer learning experiences focused on reading.

Serving two nutritious family-style meals each day.

Engaging college students in community service as mentors.

Developing strong partnerships involving parents, schools,communities, and state agencies and organizations (Energy Express, 2001, online).

In that the program addresses the needs of children from a global, sociological view rather than from a prescriptive, medical perspective, Energy Express can be considered as a form of compensatory education, although local programs do include students with disabilities in each site. In that most of the attending children are in the primary grade levels, it can be considered to be a preventative rather than a remedial program. In its relatively short history, Energy Express has piloted two sites in the summer of 1994, and expanded each subsequent year with 16 sites in 1995, 38 in 1996, 55 in 1997, 68 in 1998, 76 in 1999, 80 in 2000, and 83 in 2001 (Butera, Bonnett,

McMullen, Pae \& Richason, 1999; S. Harper, personal communication, September 15, 2001).

At each Energy Express site, multi-age groups of five to eight children with an AmeriCorps college-student mentor eat family-style meals and participate in read-aloud, drama, art, and writing activities in a print-rich environment. Children are provided with breakfast and lunch, designed to provide 7/12 of their daily nutritional 
requirements. Weekly activities center around a theme such as self, family, friends and community, and a related book is supplied for each child to take home "for keeps!" Energy Express mentors are themselves mentored by a site coordinator, usually a teacher or school administrator, who helps them design activities and reflect on their work each day. Parents and other community members are invited to contribute their time and abilities in a wide range of activities, from reading aloud to answering the telephone or making special presentations. During the six weeks, children and mentors design and implement a community service project and the mentors complete an additional service project for the community.

Overall, Energy Express' proven efficacy in addressing issues which place children at risk is very promising. In the summer of 1998, for instance, 3,184 children were enrolled in the program, $68 \%$ of whom were recipients of free or reduced lunch during the school year. Energy Express sites provided 143,360 meals to participating children over the course of the program (Butera, 1998). Each of the children received individual attention from mentors and community members and the opportunity to share in literacy activities throughout the program. Seventy percent of the tested Energy Express children maintained or improved their reading achievement over the course of the six-week program as documented by significant differences in pre/post scores on the Woodcock-Johnson Tests of Reading Achievement subtests (Woodcock \& Johnson, 1989). These gains were realized across all ability groups, in that children with Individualized Educational Plans (IEPs) demonstrated gains which were not significantly different from gains of children without IEPs. Energy Express mentors, largely preservice educators, "gained knowledge about their own capacities to assist others, about the challenges involved in facilitating children in learning, and about community service" (Butera, 1998, p. 87).

\section{Statement of the Problem}

As designed by its developers, the Energy Express program in West Virginia seeks to address the needs of children, many of whom are "at risk" for or have experienced educational problems. Because the program has been in existence only eight years to date, there are many questions that have not yet been addressed by research efforts. One aspect of the program that we have not investigated is what participants-state-level and local program developers, local site personnel, and attending children--believe about educational risk factors.

According to Weiss (1995, p.575), even though beliefs are only "sometimes well constructed and coherent" (citing Converse, 1964), "organization theory has long taken for granted that values are one of the bases [sic] for decisions," with the assumption that attention and behavior follow belief. Remembering that, "Schooling is fundamentally a moral, not a technical, enterprise" (Noblit \& Dempsey, 1996, p. 3), participants' beliefs and values form the underpinning of any voluntary endeavor and are fundamental to its success and continuance. As Heclo (1997) states

Value underpinnings are ... framing perspectives through which Americans assign worth and meaning to public policy events and conditions. In recent decades, attacks on national antipoverty policies have shown that value underpinnings are of immense practical importance. Commitments of tax dollars that are not seen to express and enforce values shared by most Americans are highly vulnerable to political attack and public rejection--regardless of what policy analysts might have to say about program effectiveness, costs, and benefits. ... In this sense, antipoverty policies that are not value-based will not work. They will lack the durable, mainstream support from the American public that makes for sustainable policy (p. 141). 
How Energy Express, then, is translated in the individual sites depends on the beliefs and actions of the local site participants and the prevailing social values of the local community. How local participants operationally define and prioritize factors which place children at educational risk affects decisions they make about which children to target for program participation. Beliefs and values reflected in recruitment strategies are also reflected in site characteristics and student outcomes perceived as valuable by site participants. Of particular interest, then, are participants' beliefs about what constitutes educational risk, who is "at risk", and what participants think can or should be done about educational risk.

Personal values and ideologies do not operate in isolation, however. Participants' history, the institution, the community, and the culture co-inform and co-evolve with the participants' beliefs (Weiss, 1995).

Bronfenbrenner's (1979) ecological framework allows us to consider the contextual factors that affect development of human beings and their beliefs. Because the program structure includes participants with varied levels of involvement, Energy Express allows for comparative and multilevel analyses (Bray \& Thomas, 1995), even though data collection opportunities are generally limited to the eight weeks of the program's summer operation. As a summer intervention program for children often considered to be at-risk, Energy Express becomes an ideal setting, then, allowing us to look at how children, parents, program leaders, community members, and school officials view and address educational risk.

\section{Purpose of Study}

Because adults' attitudes toward children affect their own behavior, their interactions with children and children's behavior (Ladd, Birch, \& Buhs, 1999; Montague \& Rinaldi, 2001; Nelson \& Roberts, 2000), this study examines the beliefs of Energy Express participants about factors which present risk of educational failure for children. As a predominantly qualitative study, an answer to the fundamental question, "What is going on here?" (Locke, Spirduso, \& Silverman, 1993, p. 99), or "How does this work?" is sought regarding the translation of Energy Express participants' beliefs into their daily practices. Understanding how local site leaders target children for Energy Express attendance and allocate their resources to address perceived needs of children at-risk is the goal of the study. The questions guiding my research, then, are:

1. How do Energy Express participants define and prioritize children's at-risk status?

2. How do program participants tailor recruitment methods to target those at greatest risk?

3. How do program participants tailor program activities to address risk?

4. What do children attending Energy Express believe about "at-riskness?" 


\section{Chapter II}

Review of the Literature

Literature review in qualitative research takes on a different form and structure than it does in research conducted from a traditional, hypothetical-logical paradigm. Locke, Spirduso and Silverman (1993) describe the purposes of the literature review in both quantitative and qualitative research as

seating the study in the foundational literature of the paradigm, citing works that explain and legitimate the particular methods proposed for use, using scholarly works to create a frame of constructs and theory for the particular area of study, and demonstrating how the proposed research would fit into the ongoing dialogue of science (p. 113).

They also note, however, that "there may be sound reasons not to read" (p. 113) literature that relates directly or closely to the topic for qualitative research. Since the researcher is the primary data collection instrument in qualitative research, it is considered to be more appropriate for the researcher to absorb the participants' world view before acquiring the blinders that knowledge of foregoing research may impose. It is important to note that in this case the research review is purposefully broad. Generally speaking, review of the literature in qualitative research emerges concurrently with discoveries made during the field study (Glesne \& Peshkin, 1992).

The purpose of this chapter, then, is to uncover the constructs that this research intends to examine. Energy Express provides a virtual laboratory for studying the interplay of participant ideologies, interests, and interpersonal interactions in the local Energy Express organization in defining and addressing educational risk. A study of local Energy Express sites can provide meaningful insights into participants' beliefs about and methods of addressing educational risk. According to Weiss (1995, p. 575), “Organization theory has long taken for granted that values are one of the bases for decisions. . 'it assumes that behavior and attention follow belief and attitude" (citing March \& Olsen, 1988). This is important because what educators believe impacts what they do. For example, in studying the use of empirical findings by classroom teachers, Malouf and Schiller (1995) found that teachers' attitudes and beliefs moderate the influence of research on special education practice. Thus, study of Energy Express participant beliefs allows us to confront assumptions about educational risk which are inherent in our educational processes and in ourselves, potentially allowing us to better match educational services and methods with the identified needs of schoolchildren.

In order to disclose the themes that the emergent design of this research will detail, the first section of this literature review examines the historical roots and development of the concept of educational risk. The second section discusses perspectives on risk and limitations of programs developed from these perspectives. The third section proposes that the ecocultural analysis paradigm, based on Bronfenbrenner's work (1979; 1992), is critical for framing observations of a comprehensive case study in which insights are sought from many participant perspectives. In essence, a multilevel case study analysis is proposed to provide insights into participant perceptions of educational risk. The case study also addresses the mirrored concepts of educational resilience and protective factors which incline students to educational success. The final section examines major characteristics of Energy Express that both define and limit the scope of the study. 


\section{Educational Risk: Overview and Historical Roots}

In 1989, John Ralph posed some riveting questions concerning educational risk that have yet to be fully answered. He asks, "Who are the young people "at risk" of school failure? How well do we understand their needs? And what do we know about the link between their learning skills and their at-risk status? (p. 395). The questions that Ralph did not pose are also interesting and have bearing on our understanding of the concept of educational risk. Such questions include: 1) What different conceptions of "risk" have framed our studies of "the students for whom the traditional approaches to organizing and delivering instruction have worked least well"? (Hixson and Tinzmann, 1990, p.1); and 2) How have our conceptions of "risk" changed over time?

According to Hixson and Tinzmann (1990), "Historically, 'at-risk' students were primarily those whose appearance, language, culture, values, communities, and family structures did not match those of the dominant white culture that schools were designed to serve and support" (p. 1). Operational definitions of students likely to experience school problems grew out of anthropological studies conducted by Allison Davis in the deep south in the mid 1940s and his subsequent development of the concepts of "cultural deprivation" and "compensatory education." (Macaluso, 1996). Since significant percentages of the students who were not achieving in schools to the satisfaction of the school system were immigrants, the poor, or from minority groups, from a demographic perspective, these populations were generally seen as disadvantaged. As Davis advanced in renown in the education community, his ideas were sought and incorporated into educational policies developed in the 1960s as part of Johnson's War on Poverty. It was both believed and politically correct, then, to blame school failure on student demographics, including student, family and community characteristics (Richardson, Casanova, Placier \& Guileful, 1989).

Since that time, a variety of "legislation and federally funded 'special,' 'compensatory,' and 'remedial' education programs designed to ensure educational success for these students" have been developed (Will, 1986). "Special" education, for example, came into being in 1975 as the Education of All Handicapped Children Act, public law 94-142, later renamed as the Individuals with Disabilities Education Act (IDEA). For the first time, children with disabilities were guaranteed the right to a free, appropriate public education in the least restrictive educational environment. Determination of eligibility for these services, however, followed multidisciplinary assessment of a student's educational deficits. The appropriate educational program for each student with disabilities was then prescribed by a multidisciplinary team. Although the multidisciplinary team was to provide student information from a variety of perspectives, the student's eligibility for special services depended on his identified educational deficits (Turnbull, Turnbull, Shank \& Leal, 1995).

The Elementary and Secondary Education Act (ESEA) was enacted to provide funding for education programs under Title 1 to compensate for perceived deficiencies in the students' environment. It is important to note, however, that Title 1, like IDEA, was (and is) primarily a funding mechanism, not an educational initiative. The educational programs developed through Title 1 and IDEA are as diverse as the number of schools and teachers who administer the programs nationwide (Anderson \& Pellicer, 1990). Given statistical regression toward the mean for overall evaluation of these very diverse programs, it is not surprising that the National Commission on Excellence in Education (1983) found that we are "A Nation at Risk" of mediocre educational achievement. 


\section{Current Risk Definitions and Programs}

Currently, four approaches are generally used by schools and policy-makers to define educational risk and students affected by the same. These are the predictive approach, descriptive approach, unilateral approach, and the school factor approach.

\section{Predictive Approach}

The predictive approach to risk seeks to determine which children are likely to experience school failure. In the predictive approach to defining educational risk, children with certain life conditions are considered to be at-risk because students in these categories are statistically more likely to drop out of school or be among the lowest achieving groups. Examples of these predictive factors include having low income, having limited English proficiency, being a member of a minority group, or living with only one parent. Intervention programs developed from this perspective include Head Start and English as a second language (ESL) classes (Carnahan, 1994; Hixson \& Tinzmann, 1990).

The predictive approach is based on a deficit view of communities, families, or students. Unfortunately, this view may, in effect "blame" the student's poor achievement on factors over which the student has no control. Consequently, this approach may lower teachers' expectations of student potential, continuing the cycle of poor achievement. As this approach focuses on student and community deficits, it all too easily allows teachers and policymakers to ignore the school's role in student achievement or the lack thereof (Anderson \& Pellicer, 1993, 1990; Hixson \& Tinzmann, 1990; Slavin \& Madden, 1989).

\section{Descriptive Approach}

The identification and eligibility determination of students for special education is part of a descriptive approach to educational risk. The descriptive approach identifies students who are already performing poorly in school who will likely continue to fall behind or eventually drop out. This approach often involves a monitoring and intervention strategy as is often used in school-based assistance teams. If identification of the problem does not occur until a pattern of poor performance emerges, the student's and the teachers' expectations of academic success may have been lowered. Even if started early, typical intervention programs are often "add-on" programs that do not encompass the regular curriculum and may pull the child out of his regular class for part of his instructional day. Some compensatory education and special education programs for students who have been diagnosed as having disabilities follow this "pull-out" model (Anderson \& Pellicer, 1993, 1990; Hixson \& Tinzmann, 1990; Slavin \& Madden, 1989).

Unfortunately, research shows that several common characteristics of compensatory and remedial education programs limit their effectiveness in addressing student needs. First, local central offices often make the decisions on what models to follow in providing Title 1 or remedial programs. Decisions about what model to use are often based on "expediency and economy rather than effectiveness and efficacy" (Anderson \& Pellicer, 1993). Schools have to demonstrate eligibility for compensatory programs such as Title 1 , typically calculated by having a certain proportion of the student body qualifying for free and reduced lunch. Eligibility to actually participate in the school's Title 1 program, though, often depends on the child's level of (poor) achievement. On the other hand, low-income 
and low-achieving students who happen to attend schools with generally more affluent student populations do not even have access to Title 1 programs should they experience educational problems (Anderson \& Pellicer, 1990).

Although schools are mandated to provide children with diagnosed disabilities the special education services they require, no matter where the student attends school, often these services, like Title 1 services, are rendered in the context of "pull-out" programs or separate classes (McLeskey \& Henry,1999; Will, 1986). Lack of coordination between the special program and the regular program can result in fragmentation of the curriculum, such that student learning is actually impeded. Separation from regular class peers may stigmatize students and deprive them of peer role modeling in effective learning strategies and peer support systems (Anderson \& Pellicer, 1993, 1990; Hixson \& Tinzmann, 1990; Will, 1986). In some cases, students may spend inordinate amounts of time working independently on practice sheets in compensatory and remedial programs. Teachers in special programs often have low expectations for their students and many programs have been found to be more effective for "marginal" students than for those with severe learning problems. Finally, students in compensatory and remedial programs rarely seem to "catch up" so they become "lifers" in the programs (Anderson \& Pellicer, 1993,1990; Hixson \& Tinzmann, 1990; Slavin \& Madden, 1989; Will, 1986).

\section{Unilateral Approach}

Hixson and Tinzmann (1990) assert that the third current approach to identification and support of at-risk students is the unilateral approach. In this approach, all children are considered to be "at risk" given the number and complexity of problems faced by young people today. The idea here is that adopting good teaching will benefit all students. While this seems to be a very appealing model, it serves to divert attention from the very real educational problems faced by students for whom the traditional schooling approaches have worked least well and erodes the rationale for change. Hixson and Tinzmann caution that we should be mindful of structural and organizational impediments in American schools and that "to treat people equally does not mean that they should be treated the same" (1990, p.3).

The beliefs that underlie the unilateral approach to problems of educational risk are well-entrenched in American schools and often used to argue against special treatment for any subset of students. In some cases, equity is confused with equality. A previous study gives a brief insight into the belief system supporting this unilateral approach. As Butera, et al. (1996) note, "Practitioners reported their belief that schools must be equitable in their treatment of all students. The practice of making special allowances for students with disabilities was seen as unfair to regular students who must abide by school rules" (p. 85).

\section{School Approach}

Other authors point out that identifying students as at-risk stigmatizes them (Swadener \& Lubeck, 1995; Donmoyer \& Kos, 1993) and subscribe to a fourth approach to identifying students at risk. The school factor approach cites an emerging body of research pointing to school factors as potential causes of "at-riskness." School characteristics that may actually hinder the achievement of students include the use of "inappropriate, limited and rigid instructional strategies; an over-reliance on standardized tests to make instructional and curricular decisions; tracking; and inflexible schedules" (Hixson \& Tinzmann, 1990, p. 3, citing Richardson \& Colfer, 1990). White (1995) targets teacher complacency as fostering complacency toward learning in students at risk. Although this 
approach does not blame the child, the family, or the community for a student's poor academic performance, Hixson and Tinzmann express concern that "making the school solely accountable for responding to conditions in students' lives over which they have little control" may erode students' sense of responsibility for their own achievement and parents' obligation to support and participate in the school's efforts on behalf of students (1990, p. 3).

Although Hixson and Tinzmann's concerns about "making the school solely accountable" for educational risk are likely overstated, the school characteristics listed as hindering the achievement of students seem to be almost entirely within the school's realm of responsibility. It is clearly important to make both individual educators and school faculties aware of the implications of the research for their own teaching styles and school structures. Another challenge to addressing educational risk is the empowerment of personnel to effect needed changes. Pae (1999) notes that

From a change strategy point of view, the bureaucratic structure of schooling may thwart teachers' ability and propensity to make decisions that systematically define the quality of teacher practice. The bureaucracy arranges and defines the teacher's position within the organization in order to maintain a stable environment (p. 198).

Thus, we are still faced with the necessity of a comprehensive understanding of risk to inform our efforts to ameliorate these student risk factors. Probably only an alternative school organizational structure and professional culture stressing collaboration and active problem solving, such as Skrtic (1991) proposes, would dismantle these barriers to achievement and provide all students with excellent and equitable schooling.

\section{Ecological Model}

The approach to defining, ameliorating, and preventing educational risk desired by people who have studied educational risk issues extensively over many years (Chubb \& Moe, 1990; Donmoyer \& Kos, 1993; Hixson \& Tinzmann, 1990; Pallas, Natriello, \& McDill, 1989; Richardson \& Colfer, 1990) continues to emerge. The four currently accepted approaches appear insufficient to guide policy and practice in addressing these problems. Clearly, definitions should move away from labeling or blaming students, families, communities or institutions. Further, in most cases, the ancillary or isolated programs developed to date do little to alter circumstances, school practices, or student outcomes for students "at risk" of educational failure. Instead, Richardson, Casanova, Placier and Guileful (1989) propose a new "ecological" model to explain "riskness" in schools:

It is an interactive view in which the perception of at-riskness is constructed within a particular social or cultural context. The child brings to the classroom a certain number of characteristics that have been shaped by background and personal factors and past experiences in school. This child interacts with a classroom context that includes other children, teacher(s) and materials. In addition, what happens in the classroom is shaped, in part, by school level factors that are often influenced by district level factors. The focus in this approach is not on the child alone, but on the interaction between the child and these nested contexts. (p. 7)

Hixson and Tinzmann (1990) describe this ecological approach as one that "recognizes that education as a process takes place both inside and outside the school itself and is, therefore affected (as opposed to determined) by" multiple personal and contextual variables (p.4). They conclude that, from this perspective, "one regards as at risk the combined characteristics of educational environments taken as a whole in which a significant proportion of students are consistently unsuccessful" (p. 4). They suggest that more multi-tiered ecological analyses of "riskness" 
are needed to "provide a more meaningful data base and perspective for planning new, holistic, integrated, and systemic alterations in the norms of schooling" (p. 4).

Bray and Thomas (1995) developed a framework for the type of multi-level analysis desired for use in comparative education studies. Their insights from different educational literatures concerning multi-level analysis, are instructive. They suggest that "the number of such studies (that build on multilevel research) is much more limited than might be expected or desired," because researchers are constrained by their own perceptions, background and training and because "many fields within the macro-framework of educational studies are rather introspective, . . .with little cross-fertilization from other fields" (p. 488). In the investigation of school effectiveness, for example, they note that "Much of this work has been highly quantitative, and has not taken adequate account of the more qualitative contributions" (p. 488). They conclude that their framework for multi-level analysis "can help identify the perspectives from which educational phenomena have and have not been investigated, and suggest a more balanced and comprehensive approach for future research" (p. 488).

The multilevel analysis has emerged from the work of Bronfenbrenner $(1979 ; 1992)$. Bronfenbrenner's four levels of ecological analysis provide a useful structure for examining the suggested approach to risk management. In Bronfenbrenner's analysis, the relationships between individuals and their environments is considered to be transactional. In other words, change occurring in individuals or in their environments is reciprocal and coevolutionary. In Bronfenbrenner's model, systems as well as individuals are not viewed as static, but as dynamic over time.

The microsystem, mesosystem, exosystem, and macrosystem levels of the ecological analysis are viewed as being nested within each other. The individual, of course, is in the center of the analysis. According to Peck's (1993) summary of the theory, microsystem variables are "a pattern of activities, roles, and interpersonal relations experienced by the developing person in a given setting with particular physical and material characteristics" (Peck, p. 10). The mesosystem involves "the interrelations of two or more settings in which the developing person actively participates" (p. 9). The developing person is not an active participant in the exosystem, but affects or is affected by what happens in exosystem settings such as school board or IEP meetings. Macrosystem influences include cultural or subcultural belief systems and values that form the foundation for "organizational structures, professional practices, and daily interactions that affect the lives of children" (p.7).

In her article advocating the use of Bronfenbrenner's ecological analysis as a framework for disability research, Sontag (1996) examined three research studies which used the framework. In discussing the most comprehensive of the three studies--one by Shonkoff, et. al (1992)--she indicates that the study closely adhered to Bronfenbrenner's model in that parental beliefs and perceptions of the child's impact on the family were both measured. She states, "Bronfenbrenner (1992) strongly urged consideration of the significant others' perception of the properties of the environment" (p. 335).

\section{Building Resilience}

Sontag finds that incorporation of Bronfenbrenner's ecological framework into research efforts would both generate new knowledge about contextual qualities affecting learning processes and influence practice in identifying special education interventions. She notes that "Examining personal attributes such as personality and attitudes may 
help explain both the personal characteristics and the processes influencing development. The developing person would be considered an active agent influencing the interactions encountered in his or her microsystems" (p. 338).

Sontag concludes her article with some advice that would be well worth our heeding in considering Energy Express as the context for this research. She says that

On a final note, this discussion should not be interpreted as supporting a one-sided focus on the negative characteristics of children with disabilities or the disorganization and disarray of their environments. As Bronfenbrenner (1986) elucidated, "For every study that documents the power of the disruptive environments, there is a control group that testifies to the existence and unrealized potential of ecologies that sustain and strengthen constructive processes in society, the family, and the self' (p. 738). Our challenge is to search for the developmental mechanisms and interrelationships that support resilience and positive outcomes for children with disabilities and their families (p. 340).

In short, student resilience mirrors student risk. As Westfall and Pisapia put it, "Resilient characteristics appear to fall into the same general categories as risk factors" (1994, in abstract).

What program aspects have been found to be important for supporting or nurturing educational resilience? In a qualitative study of resilient at-risk youth, McMillan (1992) and colleagues (McMillan \& Reed,1994) interviewed sixty-two adolescents from urban, suburban and rural Virginia about their goals, hobbies, use of spare time, thoughts about school and learning, and views of neighborhoods and homes. Overall themes in the data indicated that internal locus of control and a strong sense of self-efficacy were important for student success. A preliminary literature review for the study (McMillan \& Reed, 1994; Westfall \& Pisapia, 1994) described effective programs for at-risk students as featuring "early intervention, a positive school climate, a central role for the teacher, small class size, and parent involvement” (McMillan \& Reed, 1994, p. 27). Westfall and Pisapia (1994) also list selfesteem and support building, guidance and mental health counseling, social and life skills/vocational education, peer involvement, and easing of school transitions as attributes of successful programs.

\section{Energy Express: Positive charge}

Energy Express includes many of the features described as effective for supporting educational resilience. The mentor's central role is designed to provide a positive climate for elementary-aged children, building student self-esteem and mutual support in small group settings, with both peer and parent involvement. As a summer program with muti-age groups, it can ease school transitions for students moving from one grade level to the next.

The application of Bronfenbrenner's work provides a framework for qualitative case study of Energy Express. A shift in any one of Bronfenbrenner's four levels--whether by attitude change, legislative or judicial ruling, addition or loss of close relationships, or personal development of new skills--has an impact on the child and on

his/her education. So, how might macrosystem variables, such as participant beliefs about educational risk, affect the other ecological contexts and the individual student in Energy Express? How might exosystem variables, such as recruitment strategies developed by site leaders before the program began, influence the microsystem known as the mentor group in Energy Express?

Preliminary research evidence in Energy Express details the transactional relationships between the community and the program (Butera, McMullen, \& Phillips, 2000; Butera, McMullen, Phillips, Webb-Dempsey \& Dempsey, 1998). Energy Express is designed to include many aspects of effective remedial programs and to foster 
student resilience. To create a positive educational climate, Energy Express was designed to be less structured and more interactive than traditional school, focusing on children's creativity. Mentors have a central role in making the program what it is for the children and children often form close bonds with their mentors in just a few short weeks (Butera \& Dempsey, 1999; Butera, Phillips, Harper \& Pae, 1999). Being included in small, multi-age mentor groups in a non-competitive, nongraded environment may allow children to see and become involved with each other in different ways and to develop new support networks. Although guidance and mental health counseling are not offered in the program, participants practice social skills in mentor group interactions, noncompetitive recreation and family-style meals. Finally, community service projects contribute to the development of a sense of self-efficacy for participating children. Energy Express not only includes many aspects of effective programs for at-risk children, it also provides evidence of the validity of ecocultural models of risk and resilience.

Qualitative case studies are particularly appropriate for the examination of comprehensive, multi-tiered programs such as Energy Express. Ecological analysis lets us see how various factors in the program at the state, community or site levels make the educational context either supportive or risky for students. It is the purpose of this study to describe the ecoculture of Energy Express in order to examine participants' beliefs about risk and the role of those beliefs in affecting program decisions and daily interactions among site personnel and children. 


\section{Chapter III}

Methods

The purpose of this study was to examine Energy Express participants' beliefs about the nature of educational risk and to observe how their beliefs played out in the context of Energy Express at one case study site. The study was composed of two parts. In the first part, quantitative research methods were used to describe beliefs of adult Energy Express participants with varying levels of program involvement across the state. A two-section survey, the Participant Beliefs Survey, was constructed as an experimental scale to assess overall beliefs of Energy Express participants about child, family, school and community characteristics that may relate to children's at-risk educational status. Site coordinators, volunteer coordinators, mentors, parents and volunteers participating in Energy Express across the state responded to the survey.

Qualitative methods in the second part of the study addressed the primordial question, "What is going on here?" (Locke, Spirduso, \& Silverman, 1993, p. 99) in relation to participants' feelings, beliefs, ideals, and thoughts (McMillan \& Schumacher, 1997, p. 392) about educational risk and resilience at one case study site. Participants' practices in targeting at-risk children for Energy Express participation and in establishing relationships with those children were examined and described. The research objective for the qualitative section of the study was to describe how participants' beliefs about educational risk relate to their interpretations of Energy Express objectives and activities.

Four questions guided the research for understanding of the overall issues of risk and resilience. These component questions were:

1. How do Energy Express participants define and prioritize children's at-risk status?

2. How do program participants tailor recruitment methods to target those at greatest risk?

3. How do program participants tailor program activities to address risk?

4. What do children attending Energy Express believe about "at-riskness?"

\section{Data Sources}

Adult Energy Express participants across the state were the primary units of sampling for the Likert-scale and ranking surveys. These included site coordinators, AmeriCorps mentors, volunteer coordinators, Volunteers in Service to America (VISTAs) assisting with local Energy Express programs, Energy Express community collaborative members-including county extension agents charged with overseeing local programs--and parents of participating children. Cooperation was initially solicited from site coordinators during the presentations explaining Energy Express evaluation procedures at pre-program training. A cover letter reviewing the information and the request for participation was included with copies of the Participant Beliefs Survey in packets of evaluation materials distributed to the site coordinators at that time. Appendix A provides a copy of the cover letter and Appendix B provides a copy of the Participant Beliefs Survey.

The data source for the case study was selected in collaboration with my adviser and the director of Energy Express. The site selected needed to be a new site for the summer of 1999 to control for history or previous meshing of the values of participants and to allow future longitudinal study. It also needed to be within relatively close proximity as I would be commuting frequently to conduct my research. It could not, however, be so close that I 
might have preconceptions of the site or of participants. The Energy Express site selected to fit these criteria was the Monarch site in Preston County.

\section{Participant Beliefs SurveyLikert Scale}

The Participant Beliefs Survey designed for the purposes of this study was comprised of two parts. The first section of the survey used a 5-point Likert scale response format, considered to be optimal for tapping attitudes and beliefs (Dillman, 1978). The Likert scale was developed, piloted, and administered using methods specified by Daniels and Vaughn (1999, p. 55); McMillan and Schumacher (1997, pp. 296-302); and Wiersma (1995, pp.169210). In this section, respondents indicated their beliefs, ranging from Strongly Disagree to Strongly Agree, about statements concerning educational risk in children.

To develop the Likert scales, a list of 180 preliminary survey items was composed after review of the literature on educational risk and resilience. Survey items targeted child, family, school and community characteristics that are discussed in the literature as contributing to educational risk. The comprehensive list was then reviewed by three education professionals (Gretchen Butera, Ph. D., Luise Savage, Ed. D., and Diane Bonasso, M. A.) to eliminate ambiguous or redundant items and establish content validity (Babbie, 1990, p. 134; Litwin, 1995, p.35). The resulting pilot survey contained 88 items, equally divided among child, family, school and community factors. Sixty-five West Virginia University students in graduate education classes responded to the pilot survey during the first summer school session of 1999. Responses to the pilot survey were analyzed using SPSS Base 9.0 software. Principal components were extracted and rotated to cluster variables, and component factor and item reliabilities were established using SPSS software by fellow graduate student, Melissa Reed. Results were examined to eliminate questions that did not load consistently or strongly in any component group. Using a reiterative process of examination, 45 items were judged as having adequate measurement properties (reliability and validity) and were retained in the final version to be distributed to Energy Express participants.

Survey items were designed to tap participants' beliefs about educational risk factors at four levels-factors inherent within the child, within the family dynamics, within the community, and within the school. Fourteen items included in the final survey sought to elicit participant beliefs about the impact of children's inherent characteristics on academic success. Nine items looked at family characteristics and eight examined community factors that might contribute to educational risk or resilience. Another fourteen items sought to assess beliefs about school factors that augment or diminish a child's educational achievement. Twenty-seven of the 45 survey items targeted participant beliefs about educational risk factors. Eighteen items assessed beliefs about educational success, conceptually the inverse to the underlying question: What do you believe puts children at educational risk? Responses to these 18 items were recoded to match the meaning of the risk questions prior to data analysis.

\section{Participant Beliefs SurveyRanking Scale}

In the second part of the survey, respondents were asked to select five items from an alphabetical list of risk variables they believed had the most impact on children's education. They were then to rank their five selected risk variables from the most to least impacting. A comprehensive listing of 35 variables was developed from topics consistently mentioned in the literature as contributing to likelihood of educational risk. After review by three education professionals (Dr. Gretchen Butera, Dr. Luise Savage and Ms. Diane Bonasso, as described above), the 
list was reduced to 16 items for the pilot study, including a blank for respondents to suggest other variables they felt were critical to a student's educational progress. Like the first section of the survey, the ranking survey was piloted in graduate education classes during the first summer session of 1999. Results of the pilot survey included three alternate suggestions for the variable list, and these were added to the list for the final survey. In addition, two items that were never selected in the pilot survey were eliminated from the list. The final version of the ranking survey listed 17 items from which respondents might select and a blank for other variables the respondent might choose to list or describe. Again, respondents were to select five of the variables that they saw as most directly affecting students' educational risk status, and then rank them from most to least impacting.

The final section of the survey requested demographic information on the respondent's role in relation to Energy Express and the Energy Express site name. See Appendix B for the Participant Beliefs Survey.

\section{Data Collection and Coding}

Ten copies of the survey were distributed to each Energy Express site coordinator during pre-program training, with the request that they respond to the survey themselves and distribute other copies to adults associated with the program at their local site. A cover letter included with the surveys reiterated the request for survey completion and gave explicit directions for its use, return and research purposes. (Appendix A).

Coordinators were also given permission to copy the surveys should they be able to distribute more than the number provided. Mentors, VISTAs, parents, volunteers and Energy Express community collaborative members were specifically mentioned as appropriate survey respondents. Thus, the survey population consisted of a sampling of adult Energy Express participants. The completed surveys were to be returned to the Energy Express central office during the program with other weekly reports.

Descriptions of Sample.

Surveys were returned from 69 of the 76 Energy Express sites across the state of West Virginia in 1999, an overall response rate of almost $91 \%$ at the site level. Surveys were coded by number in the order in which they were returned. Of the 604 coded surveys, 590 respondents indicated their role in relation to Energy Express. Table 1 describes the Energy Express role of respondents.

Table 1

Energy Express Role of Respondents

\begin{tabular}{lc}
\hline \multicolumn{1}{c}{ Role } & Number \\
\hline Site Coordinator & 49 \\
Mentor & 281 \\
Volunteer Coordinator & 44 \\
Parent & 73 \\
Volunteer & 82 \\
Other & 61 \\
\hline
\end{tabular}

Survey data was entered in SPSS Base 9.0 by undergraduate student assistants. Sixty-five surveys contained incomplete responses in the Likert scale survey. Upon examination, missing data appeared to be randomly 
distributed and accidental. When analyzing data using SPSS Base 9.0, missing Likert-scale values were excluded listwise. In 61 cases for the ranking survey, responses were missing (most often when the page had been skipped) or responses were simply checked rather than assigned a rating. When these missing values occurred, the ranking survey was eliminated from analysis. The final database was checked and corrected by both the student assistants and the researcher to ensure data entry accuracy.

Likert Scale Data Analysis

Analysis of Likert scale data began with calculation of individual item means and standard deviations. Because 18 of the 45 items assessed beliefs about educational success, conceptually the inverse to the survey premise about educational risk, responses to these 18 items were recoded to match the meaning of the larger group prior to data analysis. Overall survey response means and standard deviations are tabled separately for the 27 educational risk statements and the 18 recoded educational success statements by item in Appendix C.

Data analysis progressed rapidly to use of multivariate methods, specifically principal components analysis, for reduction of the data. According to Fish (1988) and Thompson (1991), multivariate methods are vital for analysis of data in social science research for two reasons. First, multivariate statistics can be useful in controlling experimentwise Type I error rates - rejecting the null hypothesis when, in reality, the null hypothesis should be accepted because there is no difference between groups due to treatment effects (Keppel, 1991; Wiersma, 1995 ). Second, multivariate methods often

best honor the reality about which the researcher is purportedly trying to generalize since the reality in which social scientists are interested is usually one in which the researcher cares about multiple outcomes, in which most outcomes have multiple causes, and in which most causes have multiple effects (Fish, 1988, p. 347).

Multiple outcomes, multiple causes, and multiple effects are certainly documented in the literature as characteristic of at-risk issues. Therefore, multivariate methods were used to analyze the Likert scale data from the Participant Beliefs Survey. Principal components analysis was selected to discover "which sets of variables in the set form coherent subsets that are relatively independent of one another" (Wulder, 1999, p. 1) and thus reduce the number of dependent variables.

Multivariate statistical analysis methods have only recently come into widespread acceptance in higher education as they were almost impossible to consider before computers became widely available (Litwin, 1995). For this research effort, SPSS Base 9.0 statistical software was selected for data analysis for the following reasons. First, SPSS allowed principal components analysis which was needed for reducing data to manageable constructs. Second, the software, applications guide, and on-line support in using the software were available. Finally, the learning curve for the types of analysis needed, though time-consuming, was manageable.

\section{Variable Construction}

For the initial analysis of the Likert scale data, cases were excluded listwise for missing data values and varimax rotation was selected. Default settings for principal components extraction in SPSS Base 9.0 (eigenvalues > 1, maximum of 25 iterations for convergence) yielded 11 components in 21 rotation iterations for the 45 -item scale. Examination of the rotated component matrix revealed that several of the components contained few variables, or variables that loaded almost equally on several components. Although the percent of variance was fairly evenly 
distributed throughout the eleven factors, the first four components accounted for almost half of the total variance extracted. Each of the remaining factors accounted for less than 5\% of the total variance. Running the principal components analysis several more times with fewer factors selected (10, 9, 8, etc.) showed more distinct differentiation in variation between the first four and subsequent factors.

After determining that the data "fit" a four-factor analysis relatively well, the factor analysis was run again using the 45 items, specifying four factors. Varimax rotation in 25 iterations or less with eigenvalues greater than 1 were again selected as the settings. Missing values were excluded listwise. The rotation converged in nine iterations, using these parameters. The four components cumulatively explained over $35 \%$ of the total variance in factors. Examining internal consistency revealed that the four-factor solution yielded adequate reliability, $r>0.70$ (Litwin, 1995, p. 31).

Results of the 45-item, four-factor analysis were then examined to eliminate items that did not "fit" conceptually with other statements, that did not load together strongly $(<.4)$, or that loaded almost equally well in several factors. Twenty-three items remained for continued factor analysis, maintaining internal reliability of 0.84 . Using the same default settings as before, (eigenvalues $>1$, maximum of 25 iterations, varimax rotation), factor analysis again yielded four factors, which cumulatively explained $45 \%$ of the total variance. The final 23 -item index with four factors is described in the results section.

Respondent roles were included as variables in the data set to examine possible differences in participant attitudes by Energy Express role or by state region. Because the "Others" category of respondents was so diverse in composition (including visitors, volunteers, and county collaborative members for the sites), this category was not compared with the other role categories for differences in attitude.

Because the perimeter of West Virginia (the eastern panhandle near metropolitan Baltimore/Washington, D. C.; the northern panhandle wedged between Cleveland and Pittsburgh; and the western Charleston/Huntington area) is experiencing a growth in urbanization in contrast to the rest of this rural state, Energy Express site names were also included in the data set. To search for differences in attitude due to rural or urban issues, two proxy variables reflecting latitude and longitude of each site, named North/South and East/West, were formed. Each site was then located on a map of the state and assigned a number for its location on a three point scale in each of the two proxy variables. For the variable of latitude (North/South), northern sites were assigned a 1, central locations were given a 2, and southern sites were labeled 3. Likewise for the variable of longitude (East/West), sites in the eastern panhandle and in the eastern counties in the southern part of the state were assigned a 1. Sites in the western counties near the Ohio and Kentucky borders were labeled with the number 3 and central locations received ratings of 2 . 


\section{Ranking Survey Data Analysis}

Of the 604 surveys returned, 543 included responses to the ranking survey according to the directions provided. Responses to the ranking survey were also entered into the SPSS Base 9.0 data set by undergraduate student assistants. Table 2 describes the Energy Express roles of ranking survey respondents.

Table 2

Ranking Survey Response by Role

\begin{tabular}{lcc}
\hline Role & $\underline{\mathrm{n}}$ & $\%$ \\
\hline Site Coordinator & 48 & 8.8 \\
Mentor & 253 & 46.6 \\
Volunteer Coordinator & 43 & 7.9 \\
Parent & 64 & 11.8 \\
Volunteer & 72 & 13.3 \\
Other & 54 & 9.9 \\
\hline
\end{tabular}

Response for the ranking survey was analyzed both by frequency of selection for each item and by importance. After considering the frequency of responses, ranking of each variable by importance was studied. To better reflect beliefs about the importance of the variables overall, coding of the responses was reversed, such that the variables considered to have the most direct effect were assigned five points. Those having less importance were assigned four, three, and two points respectively, while the variable having the least direct effect (of the five selected by each respondent) was assigned one point. The total ranking points represented the sum of all the ranking points assigned to that variable by the 543 respondents. Possible points for each variable totaled 2715 , if all 543 respondents ranked a variable as having the most direct impact (5 points) on children's educational achievement.

\section{Qualitative Instrumentation}

In qualitative research, the researcher becomes the main research instrument as she observes, interviews and interacts with research participants. Rather than attempting to gain the ephemeral concept of researcher objectivity, the research process focuses on the impact of subjectivity (Glesne \& Peshkin, 1992, p. 6; echoed by Lofland \& Lofland, 1995, p. 3). Personal perspectives on the topic, the site and the participants were examined then as they affected the data collection methods selected, the type of questions asked, and the ways findings were interpreted. Lynn's Lens

What personal biases affected data collection and analysis strategies? First, although I elected to pursue a study on participants' beliefs about "educational risk", my personal experiences in life and in schools made me loathe to categorize people. Therefore, use of the term at-risk has been difficult for me, though it is convenient for describing children who have problems with "learning" of the amount and type specified by the school system and/or who have limited attachment to education as defined by the larger culture. Having a long family and personal history as a member and a consumer of West Virginia educational system services, I developed strong beliefs about both positive and negative aspects of the local educational culture. Consequently, my personal beliefs may have blinded 
me to institutional practices and beliefs that hamper children's achievement or support their resilience. It is possible that I discounted or minimized participant beliefs that were not congruent with my own about the value of education. I may have been more likely to believe that educational programs provide equitable opportunities for social and economic advancement than is borne out in the experience of others, and that resilience is more broad-based than it probably is.

Second, my identification with and portrayal of participants whose socioeconomic status differed from my own may have been adversely affected by my "filter" as a member of the dominant (though not the most affluent) culture. Because there were no participants from ethnic minority groups at the case study site, I did not have to confront any personal biases resulting from ethnically-based practices or beliefs during the course of this study.

Finally, from two years of prior experience with Energy Express, I know that I favor the program.

Participants have enjoyed it, children get two meals a day, college students are gainfully employed, reading scores improve, and children with disabilities are included without labels. Therefore, I had to guard against my tendency to overlook or minimize any data that might be critical of the program. Since I have been involved in Energy Express on the state evaluation level, I also had to be aware of interacting with the site as an evaluator rather than as an outside observer.

\section{Strategies for Minimizing Bias}

McMillan and Schumacher (1997, p. 410) recommend use of several strategies to minimize researcher bias in qualitative research. One such recommended strategy is to select colleagues as peer debriefers to facilitate the logical analysis of data and interpretation. Dr. Gretchen Butera, Dr. Holly Pae, and Dr. Brenda Wilson as well as the graduate students involved in Energy Express evaluation served in this capacity for this study.

A second recommended strategy is the use of a field log and journal to provide a chronological record of dates, times, people, and places involved in data collection. This field log and journal was maintained as part of the daily planner for the principal investigator. The journal also provided a record of research decisions made during the emerging research design and a record of ethical considerations which arose from dual roles as independent researcher and experienced program evaluator. Finally, audibility was provided in data analysis by maintaining precise records of data sources to facilitate triangulation of the data.

To enhance design validity, McMillan and Schumacher (1997, p.405) suggest that researchers use a combination of any of nine common strategies. For this study, prolonged and persistent field work by multiple researchers provided breadth and depth in data collection. Use of mechanically recorded data, verbatim accounts, participant language and low inference descriptors from the participants' language was critical to initial data analysis. Participants at the case study site were asked to review observations for accuracy and clarification, and transcripts of interviews were returned to interview participants for member checking. Finally, negative cases and discrepant data were specifically sought in data collection and formal analysis to note exceptions to or modify patterns found in the data. 


\section{Case Study Strategy}

Overall, a case study strategy was pursued in organizing data collection methods. According to Yin (1994), a case study investigates a current phenomenon within its natural context.The case study methodology has often been used when the boundaries between the phenomenon--in this case, participant beliefs about educational risk--and the context (a local Energy Express site) were not distinct. In studying Monarch Energy Express, multiple sources of evidence were used to examine both the phenomenon and the context (Yin, p. 283). Qualitative methods included prolonged observation in the case study site, in-depth interviews of Energy Express participants and document and artifact collection. Opportunities for observation and interviews are listed on the Energy Express program schedule in Appendix D.

This case study was conducted as part of the annual evaluation of Energy Express, under the direction of Dr. Gretchen Butera. For the evaluation effort in 1999, Monarch was one of four selected case study sites. Dr. Butera, Dr. Holly Pae, and doctoral students Dan Richason and I were each the lead investigator for one of the case study sites, and each served as assistant investigators for one of the other case study sites. Doctoral student Billie Bonnett supervised collection of the Woodcock Johnson data and conducted many of the telephone interviews for the evaluation effort. She and graduate students Michael Hoyt and Lisa Palmer assisted in collecting qualitative data at each of the sites, under the direction of the lead investigator for the site. For the Monarch evaluation, Lisa Palmer visited the site four times; Mike Hoyt visited on three occasions; Dr. Butera and Billie Bonnett each visited twice; and Dan Richason and undergraduate student Ann Dilger visited once to make observations and conduct informal interviews. Their transcribed notes were included in the database for the dissertation as well as for the annual Energy Express evaluation.

Undergraduate students Ann Dilger (Emory University), Alexis Butera (University of Washington) and Evan Keeling (West Virginia Wesleyan) entered the quantitative data for the evaluation effort, and transcribed some of the qualitative observation and interview data recorded on cassette tapes. Ann Dilger, who had two years' prior experience with Energy Express evaluation methods, visited the Monarch site on one occasion and submitted a copy of her observations to the lead investigator for inclusion in the qualitative data base.

Some quantitative data were included in the study strategy to aid in description of the broad context of Monarch Energy Express. Quantitative data included analysis of county and school demographics; review of quantitative data collected in the evaluation effort, such as program demographics and child attendance rates, and volunteer hours and activities; and frequency counts of common responses to questions used in interviews.

In addition to using multiple sources of evidence, beliefs held about educational risk by participants with varied levels of involvement in Energy Express were elicited. Interview protocols addressed beliefs held by the Energy Express site coordinator and mentors; community collaborative members who were responsible for planning, implementing, and funding the local site; community volunteers and visitors; parents of participating children; and of the children themselves. Therefore, data analysis examined educational risk on four levels: beliefs of children participating in Energy Express; beliefs of the adults on site; beliefs held by community members; and beliefs held by Energy Express program participants in general.

\section{Participants}


The case study was conducted at Monarch Energy Express in Preston County. The case study site was selected from the listing of new Energy Express sites and recommended for study by program director Ruthellen Phillips. This year's case study provided the foundation for longitudinal data collection at this site for evaluation purposes. As a new site, participants had not been previously informed of Energy Express philosophies or research on the issues of risk and resilience.

Participants for the case study included the children at the site; site mentors; the site coordinator; the VISTA serving as volunteer coordinator; community collaborative members; parents of children attending the site; and community volunteers. During the first weeks of the study, I observed the Energy Express setting and the sequence of activities engaged in by site coordinators, mentors and children at the site. I also interviewed the site coordinator, the VISTA who is in charge of finding volunteers to work at the site, and five of the community collaborative members. As data collection continued, I interviewed and specifically observed the mentors and community volunteers concerning their perceptions of educational risk. Observation of the children's interactions with each other and with the mentors was ongoing throughout the study. During the final weeks of data collection, students with disabilities were specifically targeted for observation in mentor group interactions and the focus group interviews with children from the two older mentor groups were conducted. See Appendix E for the focus group interview guide.

\section{Case Study Data Collection Plan}

I received training in qualitative case study methodology from two classes in qualitative research and two years of experience as a member of the Energy Express evaluation team, under the direction of Dr. Van Dempsey and Dr. Gretchen Butera. For the summer of 1999, Dr. Butera and I trained the other graduate assistants who served as observers and interviewers in the basics of qualitative data collection methods, including participant observation, interviewing, note-taking, recording, organization and document analysis. Data collection strategies for the case studies included participant observation; in-depth, structured interviews of program participants; informal interviews of program participants; and collection of relevant documents and artifacts. Persistent and prolonged field work at the sites contributed to the validity of the design.

Data collection in qualitative research progresses through several phases. In phase 1, the planning phase, the case study site was selected; participants for interview and observation were targeted; surveys, questionnaires, and interview guides were developed; and the sequence and focus for observations was planned. In the beginning data collection period, phase 2, the primary goals were gaining access to the case study site and collecting and recording data. In the basic data collection period, phase 3 , initial data analysis and diagrams were formed as the data collection process continued. In phase 4, data collection closed down and tentative interpretations of the data were made. In the final phase of qualitative research, phase 5, all the data were analyzed and diagrams and descriptions of the findings were formulated.

Observation. Thorough observation and analysis of observation data described both the physical and the social context for the site, and contributed valuable insights about participants' social patterns and values in case study sites. During the course of the program, I observed in the case study site during 18 days of program operation (three times a week for six weeks). Participant observations were also made during the open house and the end-of- 
the-summer mentor celebration. The case study site, then, was personally observed for a total of 76 hours over the course of the program. The children's interactions with the adult program participants and with the other children were the primary focus of the observations. Field notes were taken throughout the observation periods and transcribed in full at least weekly, following methods described by Lofland and Lofland (1995).

Dr. Butera or a second graduate student observed in the case study site at least twice a week, serving as both a second researcher and as a peer debriefer. These second researchers contributed an additional 42 hours of observations and informal interviews to the evaluation and dissertation data bases. Field notes of observations were transcribed on a weekly basis. Data reduction and analysis methods are described following description of interview and document analysis methodologies.

Interviews.Much of the data concerning participants' beliefs about risk-ness was collected via structured interviews conducted at the case study site during the Energy Express program. Adult program participants and child program participants were interviewed using two different interview guides. (See Appendices $\mathrm{E}$ and $\mathrm{F}$ for copies of the interview guides). Sax (1979, cited in McMillan \& Schumacher, 1997, pp. 265-266) listed interviewer variables that influence responses. Female, college-educated interviewers between ages 26 and 50, trained in the behavioral sciences and experienced in interviewing were found to receive and record accurately the most complete responses.

To the extent possible, verbatim accounts using the participants' language were recorded during observations and interviews (McMillan \& Schumacher, p. 406). Interviews were tape-recorded whenever permission was granted to do so. The interviewer took handwritten notes throughout the interviews, in case of mechanical failure, and to record non-verbal communications, reformulated questions, and probes used. Interviewers transcribed their own notes or reviewed the transcripts prepared by paid transcriptionists from interview recordings to ensure accuracy and add other observations of the event that were not recorded previously. Copies of the interview transcripts were returned to respondents for further comment or clarification of responses before the interview data was analyzed (Glesne \& Peshkin, 1992). Data reduction and analysis methods were completed using an accepted reiterative process of interview and document analysis methods (Glesne \& Peshkin, 1992; Miles \& Huberman, 1984).

Interviews with adult program participants. During interviews with local program leaders, questions concerning recruitment efforts were used to determine the interviewee's level of participation in program processes. Some interview questions, including the final adult participant question ("Some children who could have come to Energy Express do not sign up or show up. Why do you think this happens?") were also used as a discussion starter for mentor reflection sessions at the case study site. A second observer and I took thorough notes on reasons given by participating mentors and nonverbal communication forms used during the session, though those reflection sessions were tape-recorded as well.

Focus group interviews with children. During the last two weeks of the program, I conducted two focus group interviews with children from two mentor groups using methods described by Vaughn, Schumm and Sinagub, 1996. Although focus group interview sessions were tape recorded, Lisa Palmer and I also took notes throughout the session. As well as recording child participation in the discussion and as much of the participants' actual statements as possible, both researchers also described nonverbal communications and the setting of the interviews in written 
notes. Of course, I gained approval from the site coordinator and principal of the school to conduct this part of the study and obtained written parental consent for each group member to participate in the discussion.

Documents and artifacts collection. When granted permission to do so, I collected copies of documents produced by the case study site that contributed to my understanding of the site, its demographics and activities, the community, and/or the beliefs of site participants concerning educational risk issues. In addition, I reviewed similar demographic and assessment data collected by the Energy Express evaluation team at other case study sites, and extant data from previous case studies. Artifacts collected included personal documents such as copies of mentor journals, official documents such as copies of site applications, and objects such as pictures or projects made by program participants. Some researchers consider erosion measures (analysis of wear in pathways and materials used in daily interactions) as artifacts for collection (McMillan \& Schumacher, 1997, p. 455), but as Energy Express sites serve multiple purposes over the course of a year, I felt that these would not contribute to my understanding of educational risk issues in the context of Energy Express.

When the information was not otherwise noted, artifacts and documents were identified with a cover sheet describing site name, date, description of the origin of the artifact, and history of its use. Efforts were also made to determine the artifact's authenticity and accuracy and recorded on the cover sheet. In field notes, I analyzed the collected documents and artifacts, using questions based on the focus of my research and methods advocated by Glesne and Peshkin, 1992; McMillan and Schumacher, 1997; and Miles and Huberman, 1984.

Data Reduction and Analysis

The sheer volume of potential data was substantially reduced by the careful preparation of proposed methods and data collection tools such as interview guides. Interview tapes and observer notes were transcribed in full and put in notebooks in chronological order. Transcribed notes from other observers were inserted in the notebooks with the principal investigator's notes, also in chronological order according to the date of observation. Collected documents were also included by date of collection. When all transcriptions, observation notes, and documents had been filed in notebooks, the pages were numbered for ease of reference. These page numbers are included as references in the body of the case study.

Interview, observation, and document data were coded using low-inference descriptors (McMillan and Schumacher, 1997, p. 406). Coded data was then compiled into categories and categories were later united in common themes. To be considered representative of any given theme, coded topics needed to appear in at least three distinct data sources. In this way, data was triangulated across sources. Brenda Wilson, who was at that time a fellow doctoral student trained in qualitative research and experienced in Energy Express evaluation, then read the transcribed field notes and interview data to determine consensus in theme descriptions. In cases of disagreement, consensus was reached by independently seeking additional examples of the theme in the data. I categorized data according to identified themes. Reliability was established by having Brenda read descriptions of data categories and supporting data for each category to validate findings. Themes evidenced by the preponderance of the data were included in the final study report. Implications of data themes for the local site, for Energy Express and for educators in general were discussed. 


\section{Chapter IV}

Results

The results section of this study first describes the sample obtained from the Participant Beliefs Survey, developed for this research effort. Overall survey response means and standard deviations for individual items are briefly reviewed. Factor analysis and multivariate comparisons from the Likert scale section and findings from the ranking section of the Participant Beliefs Survey are described. The qualitative case study from Monarch Energy Express is reported. Finally, findings regarding each of the initial research questions will be reported.

\section{Participant Beliefs Survey}

\section{Site Level Response}

Since 69 of 76 Energy Express sites returned completed Participant Beliefs Surveys, an overall response rate of almost $91 \%$ was accrued at the site level. As the decision to distribute and submit the surveys was made by the site coordinator for each site, a response bias in favor of sites who participate more actively and favorably in Energy Express is probable. However, since the sample constituted almost a census of Energy Express sites, results are believed to be generally representative of Energy Express sites and program participants in regard to key variables that may impact participants' beliefs about educational risk and resilience.

\section{Site Coordinator Response}

Forty-eight respondents identified themselves as Energy Express site coordinators. While the survey asked for no other specifics about site coordinators, Energy Express evaluation data indicates that site coordinators are school professionals-teachers, counselors, or principals—employed in the local county school system. As Energy Express summer programs often use school facilities, it may be assumed that the site coordinators are professionals who are trusted by local school leadership to safeguard and maintain the facilities adequately. In this respect, the site coordinators may not represent school professionals as a whole, but may very well represent school professionals recognized as capable individuals by their peers and supervisors.

\section{Mentor Response}

Each Energy Express site employs between five and eight mentors, so it is not surprising that roughly five times as many mentors (243) as site coordinators (48) responded to the Participant Beliefs Survey. In 1999, an overwhelming proportion of Energy Express mentors (over 96\%) were supported as AmeriCorps members. An overlapping large percentage of these college student mentors are enrolled as education majors in the colleges of their choice. Thus, it may be assumed that the 243 mentors who responded to the Participant Beliefs Survey had graduated from high school, had been attending or were planning to attend college in the near future, had some prior community service experience, and were likely to be preservice educators. As such, these mentors may be considered representative of those college students who engage in community service and have some tolerance for or liking of children.

\section{Volunteer Coordinator Response}

Each Energy Express site designates a volunteer coordinator. Some are directly employed as VISTAs for Energy Express; some are VISTAs borrowed for eight weeks from other local programs; and a tiny percentage are not VISTAs, but are either volunteers themselves or are paid through Energy Express or local funds. As a group 
across the program, volunteer coordinators are not employed as school professionals, and are generally older than the mentors at the sites. Forty-three volunteer coordinators (of a potential 76) responded to the Participant Beliefs Survey.

\section{Parent Response}

Other than the fact that these 64 respondents identified themselves as parents of children attending Energy Express programs in the summer of 1999, no other demographic information is known about these respondents.

\section{Other Response}

These respondents included community collaborative members, adult volunteers, cooks and maintenance workers at local Energy Express sites. They are broadly representative of West Virginia adult residents.

\section{Survey Overview}

Preliminary examination of the original 27 items targeting educational risk in the full 45 -item Likert scale survey revealed that respondents strongly believed that educational problems are associated with incidents of child abuse. They also targeted excessive absences, poorly-trained teachers, lack of a nutritious diet and failure to complete homework as contributing to educational risk. Lack of academic ability, unidentified disabilities and families who move frequently were also considered by many to adversely impact educational endeavors. However, respondents clearly believed that children in small schools received more individual instruction than children in large schools and did not lack educational opportunities.

Eighteen items from the original 45 item survey described Energy Express participants' beliefs about educational resilience. Review of the means and standard deviations indicated that respondents felt that schools with modern instructional technologies did much to build children's educational resilience. Participation in community activities such as Scouts and Little League was also believed to help children in educational endeavors.

Interestingly, respondents clearly disagreed with the idea that attractive children are often good students. They also disagreed with statements implying that children from middle income homes or urban areas had an educational advantage over those from low-income homes or rural areas. (See Appendix $\mathrm{C}$ for response to individual survey items.)

\section{Factor Analysis Procedures}

The Participant Beliefs Survey developed for the purposes of this study sought to tap the beliefs of adult Energy Express participants about the nature of educational risk and resilience. Fowler (1988) notes that when people are asked about subjective states, feelings, attitudes, and opinions, there is no objective way of validating the answers. . Thus, the only way of assessing the "validity" of reports of subjective states is the way in which they correlate either with other answers that a person gives or with other facts about the person's life that one thinks should be related to what is being measured. . the meaning of answers must be inferred from patterns of association (p. 85).

Principal components and common factor analyses have been recommended for exploratory data analysis of survey data (Babbie, 1990; Litwin, 1995; SPSS Base 9.0 Applications Guide, 1999). The purpose of these methods is to

study the correlations among a large number of interrelated quantitative variables by grouping the variables into a few factors; ... the variables within each factor are more highly correlated with 
variables in that factor than with variables in other factors (SPSS Base 9.0 Applications Guide, p. $317)$.

Thus, items within factors developed from principal components and factor analyses of the Participant Beliefs Survey data correlate more strongly with each other than they correlate with items loading on other factors. Analysis of the factor scores reflecting various belief and attitude patterns, however, may be expected to identify factors that are at least somewhat related to one another. As Fowler (1988) suggests, "The most important point to remember about the meaning of subjective measures is their relativity" (p. 96).

Reiterative principal components and factor analyses described in the methods section of this study yielded a parsimonious 23 -item total scale comprised of four factors. The cumulative variance in the 23 -item scale explained by the four factors exceeded $45 \%$. The first two factors account for almost the same amount of variance (13.94\% and $13.1 \%$, respectively). Factors three and four together account for more variance (9.5\% and $8.8 \%$ respectively) than either of the first two factors individually.

Factor Reliability

Results from reliability analysis were used throughout the data reduction and factoring processes to aid in decision-making about items to be retained or omitted from further analyses. Although 16 items were dropped from the original 45 because they loaded below .4, loaded almost equally on 2 or more factors, or did not fit conceptually with the other factor items, 6 items were omitted after examination of "alpha if item deleted" scores. Reliability for the final 23-item scale was calculated as Alpha =.84, good reliability for an experimental scale (Litwin, 1995).

Split-half reliability was also calculated, since the survey was administered only once. Correlation between forms was found to be .64. Equal-length Spearman-Brown reliability was indicated to be .78. Guttman Split-half was .78. In considering the unequal-length Spearman-Brown, split-half reliability was found to be .7876 . For the 12 items in part 1, the Alpha was .76, and for part 2 was .73. Appendix G presents measures of reliability and item loadings for each of the component factors derived from the factor analyses.

\section{Factor Descriptions}

Factor one: personal/school interactions. This eight-item factor indicated respondents' beliefs that educational risk is a complex construct, depending on a combination of variables. Statements loading together for this factor, accounting for $13.9 \%$ of the total variance, related to the belief that the interaction of children's personal deficits and the school's instructional resources predicts a child's educational success or failure. People who score high on this factor believe that children with areas of personal or familial dysfunction are at-risk of educational problems, and that schools can only help these children with well-trained teachers and modern instructional technologies.

Factor two: socioeconomic status. Responses to the seven statements loading in the second factor indicated that adult participants in Energy Express believe that a child's socioeconomic status contributes to educational success or failure. Items in the factor refer to children's readiness to learn and the amount of teacher effort that is required for effective instruction for children of varying socioeconomic levels. Statements concerning how children are valued in educational systems are also included in this factor. 
Factor three: school success. The third factor, comprised of five statements, describes "hidden curriculum" of school success - the student behaviors that schools value as institutions, with set power structures, top-down relationships, and time schedules. Responses imply the belief that certain educational standards are important for teachers and students. Schooling goes well when teachers and students fit the standards or social norms for school interactions. High scores on this factor indicate the belief that students who obey rules, complete homework, are ontime, and have well-trained teachers will be successful in their education. Students with disabilities, who do not as closely "fit" the standards-based model, are not as likely to be successful as students without disabilities.

Factor four: urban/rural. The three statements that remained in the fourth factor relate to the belief that children in rural areas have educational opportunities that are comparable to those in urban communities. The fact that the study was conducted in West Virginia, a predominantly rural state, and that the respondents were almost uniformly West Virginia residents may indicate that people are content with the educational opportunities provided here. Conversely, the factor may betray a lack of familiarity with urban communities and the problems faced by educators and educational systems in large cities.

\section{Multivariate Analysis}

Following development of the factors using principal components analysis, multivariate tests were conducted using the SPSS statistical package to determine if there were significant differences between factor scores based on Energy Express role or location. Factor scores were calculated for the entire scale and for the four factors during the principal components analysis. SPSS returns four different multivariate tests--Pillai's Trace, Wilks' Lambda, Hotelling's Trace, and Roy's Largest Root. The decision was made a priori to use results from Pillai's trace and Wilks' lambda as they are considered to be the most conservative of the four tests. Significant results from these overall multivariate tests are reported in Table 3.

Table 3

Multivariate Tests Results Using Principal Components Factor Scores

\begin{tabular}{lcccc}
\hline Effect & Test & Value & F & Sig \\
\hline Intercept & Pillai's Trace & .995 & 20809.7 & .000 \\
& Wilks' Lambda & .005 & 20809.7 & .000 \\
EW*NS & Pillai's Trace & .065 & 1.656 & .034 \\
& Wilks' Lambda & .936 & 1.669 & .032 \\
\hline
\end{tabular}

Notice that the Participant Beliefs Survey 23-item scale indicated some difference in response by the sample at large and as related to location of Energy Express participants in the state. Respondents from the southern and central parts of the state gave more weight to educational risk items than people in the northern areas or living near major metropolitan centers on the perimeter of the state.

Tests of between-subjects effects provided a second level of analysis, and indicated that significant differences existed, particularly in responses to the full scale and to factor 4 urban/rural variables. Further analysis was indicated to determine differences in response by location and by role. Post hoc tests specifying Tamhane's T2 test in which equal variances are not assumed yielded interesting multiple comparisons. Taking the Participant 
Beliefs Survey in its entirety, significant differences in response were found among all roles. For the full 23-item scale reflecting participant beliefs, site coordinators were more likely than parents or volunteer coordinators to be concerned with educational risk. Mentors were slightly more sensitive to educational risk concerns than parents. Those identified as "others" in the sample were more aware of educational concerns than parents or volunteer coordinators. For the first factor, personal/school interactions, site coordinators and others were more concerned than mentors about child and school interactions that could contribute to a child's educational risk.

Factor two items addressed the status of children in schools. The significant difference in response to these items came from differences between those in the "others" category-generally school and community leaders who were members of the county collaborative--and parents in the response sample.

Factor three uncovered significant differences in response between mentors and parents, volunteer coordinators, and others. As a group, mentors considered the hidden curriculum of student success--variables such as obeying rules, completing homework, being on-time, and having well-trained teachers who could ameliorate children's learning disabilities--as more important than parents, volunteer coordinators or others did. See Appendix $\mathrm{H}$ for statistics describing multivariate post hoc tests.

\section{Ranking Survey}

The second section of the Participant Beliefs Survey asked respondents to rank educational risk variables from those they considered to be most impacting to less impacting. Table 4 describes the rating and frequency of responses marked for the ten most highly rated ranking items, in descending order.

Table 4

Results of Ranking Scale

$\mathrm{N}=543$

\begin{tabular}{|c|c|c|c|c|c|c|}
\hline Variable & $\begin{array}{l}\text { Total } \\
\text { points }\end{array}$ & $\begin{array}{c}\% \text { of } \\
\text { possible } \\
2715 \\
\text { points }\end{array}$ & $\begin{array}{c}\text { Rank by } \\
\text { Importance }\end{array}$ & $\begin{array}{l}\text { Frequency } \\
\text { of Response }\end{array}$ & $\begin{array}{c}\% \text { of } 543 \\
\text { Responses }\end{array}$ & $\begin{array}{l}\text { Rank by } \\
\text { Frequency }\end{array}$ \\
\hline $\begin{array}{l}\text { Lack of home } \\
\text { involvement/discipline }\end{array}$ & 1398 & $51.5 \%$ & 1 & 376 & $69.2 \%$ & 1 \\
\hline Dysfunctional family life & 1224 & $45.1 \%$ & 2 & 349 & $64.3 \%$ & 2 \\
\hline Absenteeism & 1063 & $39.2 \%$ & 3 & 334 & $61.5 \%$ & 3 \\
\hline $\begin{array}{l}\text { Behavior or conduct } \\
\text { disorders }\end{array}$ & 660 & $24.3 \%$ & 4 & 229 & $42.2 \%$ & 4 \\
\hline Learning disabilities & 611 & $22.5 \%$ & 5 & 197 & $36.3 \%$ & 7 \\
\hline Undiagnosed disabilities & 610 & $22.5 \%$ & 6 & 198 & $36.5 \%$ & 6 \\
\hline Inadequate nutrition & 579 & $21.3 \%$ & 7 & 215 & $39.6 \%$ & 5 \\
\hline $\begin{array}{l}\text { Moving frequently during } \\
\text { school year }\end{array}$ & 446 & $16.4 \%$ & 8 & 188 & $34.6 \%$ & 8 \\
\hline
\end{tabular}




\begin{tabular}{lcccccc}
\hline Parent's educational level & 316 & $11.6 \%$ & 9 & 123 & $22.7 \%$ & 9 \\
Poor health & 305 & $11.2 \%$ & 10 & 117 & $21.5 \%$ & 10 \\
\hline
\end{tabular}

Energy Express participants (between 60 and $70 \%$ of respondents) most frequently selected and most strongly rated three variables relating to family life as impacting children's risk status: lack of home involvement, dysfunctional family life and absenteeism. Three other variables among the top 10 related to family backgroundinadequate nutrition; moving frequently during the school year; and parent's educational level—were also included among the most frequently selected responses for educational risk.

Although both the number of points assigned and frequency of response dropped after the first three strongly ranked items, note that the next three variables selected by respondents all related to disability issues. Children's inherent characteristics, such as behavior disorders or other disabilities, were seen as key factors impacting educational risk. Behavior or conduct disorders ranked in both frequency and importance as having more direct impact on educational outcomes than other types of disabilities. Learning disabilities and inadequate nutrition reversed positions in the ranking by importance, with learning disabilities moving up to the fifth-ranked position, and nutrition moving down in importance to the seventh position. Taken together, the importance of variables reflecting disability status outweighed any of the first three variables relating to home environment individually.

The poor health variable can be considered as another risk factor attributable to either the child individually or to the family environment. Conspicuous by their absence in the top 10 list are variables related to school and community factors. Such variables (resource-poor schools; lack of community resources; attending a large school; living in a rural area)--though included as possibilities for selection--were much less frequently selected as affecting educational risk, accounting for less than $9 \%$ of the possible responses.

Only 22 participants selected Other and described additional variables as important considerations in relation to educational risk. Two of these respondents included 2 answers in the blank for Other. While there is no statistical significance in selecting Other and some statements seem to overlap with concepts included in the ranking list, these responses provide valuable insights about participant beliefs concerning children, families and schools in West Virginia. Appendix I lists statements provided as open responses and participant rankings of their own statements.

Interestingly, thirteen of the twenty-two Other responses relate to school, teacher, or administrator deficits. "Favoriteeism" [sic], "not doing work" and "lack of future vision" might be considered as variables in either homes or schools. Two participants specifically mention child abuse as a factor although others may have considered that to be a subset of the dysfunctional family life variable. Similarly, "poor hygiene" might be subsumed by poor health, dysfunctional family life or low-income family as not having adequate facilities. "Living in a housing project" might refer to either the low-income nature of the family or the community/peer/sibling influence factors also suggested by "labels put on children by older siblings". "Lack of teaching of strong moral/social behavior" and "lowered expectations for behavior and academics both at home and school" imply that at least two respondents felt that cultural mores and (declining) social values contributed to lack of academic success. 


\section{Qualitative Case Study}

\section{Energy Express Central Program}

Energy Express describes itself as "a six-week summer program promoting the school success of children living in rural and low-income communities across West Virginia" (Energy Express, 1999). In the model, small groups of five to eight elementary schoolchildren work with college student mentors each day, using a curriculum that encourages reading. Enriching activities in art, drama, community service and literacy are to make reading meaningful in the children's lives.

Energy Express itself has a very short history. According to Dr. Ruthellen Phillips, in 1994, Dr. Belle Zars, employed by the West Virginia University Extension Service, was working to establish the West Virginia Commission for National and Community Service at the capitol. Will Carter, executive assistant to then West Virginia Governor Gaston Caperton, told Dr. Zars about United States Department of Agriculture (USDA) funds available for summer feeding programs for children eligible for free and reduced meals during the school term. Mr. Carter asked if the extension service could do anything to incorporate a meals component to support children nutritionally over the summer into community service projects they were planning. Dr. Zars collaborated with Dr. Phillips to do the needed research, develope the model for Energy Express and apply for the needed funds. The model was successfully piloted at two sites serving a total of 85 children and 13 college student mentors during the summer of 1994. Energy Express's outreach expanded every year, so 76 sites in 38 counties served over 3,400 West Virginia children during the summer of 1999. Thus, Energy Express has been designed to promote educational resilience in rural and low-income schoolchildren of West Virginia, the only state wholly within the economically depressed Appalachian region.

\section{Monarch Energy Express}

The site selected for the case study of risk and resilience in the context of Energy Express is typical of other West Virginia communities. Preston County's population per square mile of 44.8 persons qualifies as between 75\% and 99\% rural, according to the 1990 Census. It has the most miles of unpaved roads of any county in West Virginia. In 1993, between 22 and $26 \%$ of the total county population was considered to be living below the poverty level. In 1996, the county's population of 29,796 had an average per capita personal income (PCPI) of \$14, 202. This PCPI was only $78 \%$ of the state average and $58 \%$ of the national average for the year. The largest industries in the county were state and local government, services, and transportation and public utilities, and between 8.6 and $9.9 \%$ of the 1997 employable population were counted as unemployed. The average annual growth rate for total personal income in Preston County over the past 10 years was only 3.3\%, while the growth rate for the state was 4.6\% and for the nation was 5.9\% (Preston County Data Profile, 1998).

According to the West Virginia Report Cards Trend Data (1998), 5,132 students (spread out over 648 square miles) were enrolled in pre-kindergarten through 12th grade classes and 363 teachers were employed in Preston County schools. Per pupil expenditures for the 1997-98 school year were $\$ 5,686.97$ in the county. The pupil/teacher ratio was 14.5 students per teacher in 1997-98, although the average class size was 22.1 children per class. Six classrooms in the county had split grades during the 1997-98 school year and 362 students graduated from 
the county high school that year. Education professionals in the county averaged 17.4 years of teaching experience and $93 \%$ had advanced college hours or degrees beyond a bachelor's degree.

Monarch's 1999 application to become an Energy Express site reported that Monarch Elementary school in Preston County was a school-wide Title 1 site, and $65 \%$ of the 585 students enrolled were eligible for free and reduced lunch. The school had recently been on a state improvement plan because of low test scores in reading and mathematics. One-third of the children entering first grade were classified as at-risk in one or more objectives on the Metropolitan and Brigance readiness tests administered prior to the 1998-1999 school year. One-third of second grade students scored at pre-primer or primer levels on an individual reading inventory, and 56\% of third graders scored below the instructional reading level on the Standardized Test for Assessment of Reading. Fifty-seven per cent of fourth graders received below average scores on the Stanford 9 Basic Skills tests, and 64\% of fifth graders scored below average on the National Assessment of Educational Progress writing assessment (Energy Express site application, 1999).

Clearly, evidence presented during the application process indicated that members of the Preston County collaborative believed the children of Monarch were subject to many of the factors that contributed to educational risk. Writers of the application, Lydia Constantine and Martha Lazarus, believed that children in Monarch would benefit from Energy Express. In that the site was granted, the state leadership of Energy Express agreed that the program was needed and could be successful in Monarch.

As a new Energy Express site, Monarch presented the unique opportunity to observe the development of a state level program addressing educational risk and resilience as it was translated in a local community, but it was also targeted as a case study site for Energy Express evaluation. As part of the evaluation team and to collect data needed for my personal research effort, I pursued "prolonged and persistent field work" (McMillan \& Schumacher, 1999) by visiting the site 19 times, for a total of 76 hours of personal observation and interviews. I made extensive written notes during my observations and interviews, though some of my personal observations and all of the eleven extended interviews were also recorded on cassette tapes and transcribed in full. Page numbers cited in the case study, especially after direct quotes from participants, refer to pages in my collection of transcribed notes, interviews and documents from the case study site. Evaluation observers often accompanied me on the drive to Monarch to the site visits. Thus, the site was visited on 13 occasions by 6 other undergraduate or graduate level observers for an additional 42 hours of evaluation observation. I was allowed access to data collected by the evaluation team observers during the data analysis phase for my personal research.

Members of the evaluation team met weekly to check observations and discuss emerging themes. Participants from the site_-particularly the site coordinator, Martha Lazarus, and the VISTA volunteer coordinator, Rebecca Bowman-reviewed my case study to ensure accurate representation of observations. Finally, fellow doctoral student and experienced Energy Express observer Brenda Wilson read the transcribed data in its entirety to look for negative cases, discrepant data, and alternative examples of beliefs about educational risk and resilience. Setting: "A Cool Place in the Mountains" for Energy Express

The thirty-minute drive to Monarch, West Virginia, from Energy Express headquarters in Morgantown winds along State Route 7, past Greer Limestone Quarry and through the Preston County communities of 
Masontown and Reedsville. It is uphill all the way to Monarch, as the 20-mile road climbs from Morgantown's 980 feet above sea level to Monarch's 1,863 feet elevation. Preston County, then, accurately bills itself as "a cool place in the mountains", even during these midsummer days.

Monarch is the largest town (population: 3,243) in Preston County, and has served as the county seat since 1818, 45 years before West Virginia separated from Virginia during the Civil War. With a new McDonald's on the right of Main Street and a lovely Civil War-era home restored as a bed and breakfast on the left, the downtown area is an eclectic mixture of banks and small businesses, hardware, antique and craft stores. Historical markers and Victorian-era buildings intermingle with small convenience stores and fast-food restaurants. Turning right just past the county courthouse, visitors stop at the traffic light on the next corner to admire a classic car parked in a restored Esso station, furnished with period pieces from the 1930 and 40's.

After passing both the county high school and a junior high school in the next block, we see a broad, open field dotted with bleachers, pavilions, and concession stands. Though all is quiet today, a large sign proclaims this as the home of the Buckwheat Festival, the Preston county fair. For 59 years, the Buckwheat Festival has celebrated the agricultural heritage of Preston County, particularly growing and milling buckwheat, and traditionally begins on the last Thursday of September. Buckwheat pancake dinners, parades, art and crafts, antiques, exhibits, music, car shows, a carnival, and livestock judging events are all part of the festivities. Last year during the celebration, the volunteer fire department served close to 17,000 orders of buckwheat pancakes with side dishes of applesauce and pork sausage processed at the local high school. Various groups and individuals in the community prepare all year for the festival, probably the largest income-producing event of the year for the county. The historical markers, courthouse, schools and Buckwheat Festival all bespeak Monarch's unique identity as a community.

Directly across the street from the Buckwheat Festival field is the Energy Express site, Monarch Elementary School. The school is a one-story tan building, roughly in the shape of an H, which houses almost 600 students in kindergarten through $5^{\text {th }}$ grades during the school year. Although the main entrance of the school is on the left leg of the $\mathrm{H}$, the AmeriCorps banner over the far right door to the multipurpose room on the right leg proclaims the entry for Energy Express. A small student desk, topped with a sign-in notebook and visitors' badges for volunteers, is just inside the door. The multipurpose room serves as a gymnasium and auditorium during the school year, though bleachers have been collapsed against two walls to give more floor space for the program. A chin-up bar is mounted in one corner and two portable basketball hoops are pushed up against the far wall, next to the door to the sports equipment room. Other doors to the outside are open around the room, for extra light and fresh air.

The left half of this multipurpose room is being used for family style meals this summer. Martha, the site coordinator, has called all the surrounding schools to borrow round tables for the summer. She arranged them in five groupings, one for each mentor group. Each table has a colorful vinyl tablecloth and flowers in vases. Huge banners painted on long reams of craft paper by Martha's daughter welcome the children to Energy Express. Rectangular tables pushed against the far wall are used as serving areas for the meals, and one set of bleachers has been pulled out to provide seating for visitors to the program. Even without air conditioning, the room is light, airy, and pleasant.

Opposite the entry door, an institutional beige hallway leads to the site coordinator's office and mentors' rooms. A large bulletin board portrays the Energy Express logo and theme of the week. Attractive motivational 
posters, left over from school, are displayed at the children's eye level and, later in the program, children's artwork and writing fill the hallway and the perimeter of the multipurpose room. Five mentor rooms are clustered at the end of the hall, and the site coordinator has been given the assistant principal's office to use for the summer in the adjoining hall. Another classroom serves as a supply room, filled with "found" items for craft projects by the county homemaker's club.

First and second grade classrooms are being used as the mentor rooms this summer. Although the teachers have left many of their instructional materials in the rooms and on the walls, some instructional materials--classroom textbooks, computers, and libraries--are generally off-limits to both the children and the mentors. In most cases, the mentors have moved these materials to one corner of the classroom and have covered them in some way to make them inaccessible to the children.

Each mentor room is decorated with a theme, mostly using items the mentors have found or created at home. In chatting with the mentors as they decorate, each comments that they had selected room themes based on personal interests, moderated by their own creative abilities or availability of inexpensive materials. Matt, just out of high school, has chosen a railway theme, and has large cardboard cutouts of railroad crossing signs, a train engine, tunnels and "rocks" to separate the children from classroom materials they are not to touch. The reading area has been made to be a "gold mine" tunneling between two large book cabinets. Leah has a huge drawing of a log cabin covering the "off-limits" area of her room, and blue and green blankets to represent a meadow and stream, with some props such as logs and fishing nets to give it that "outdoor" feeling. Rhoda has a cardboard box with construction paper "flames" and a red light inside to make a campfire for her "Girl's Club" theme. There are bean bags and pillows all around and glow-in-the-dark stars on the ceiling. Mark's room looks like a professional baseball stadium, with a masking tape diamond and bases laid out on the floor, 2 "dug-outs" for reading areas, computer print-outs of baseball team names and logos, and mats to represent the outfield fence. Ruth's room uses an "Arabian nights" theme, and has lots of filmy material pieces hanging from the ceiling and big pillows to make the reading tent. Each room has a door covering related to the room theme that includes the children's names.

\section{Site Coordinator}

Soft-spoken with a ready wide grin, Martha, the site coordinator, is a life-long Preston county resident. She has masters' degrees in both reading and special education and is looking forward to her second consecutive year at Monarch Elementary as a reading teacher. Although she has taught in the county for ten years, she does not yet have enough seniority to avoid being placed on the reduction-in-force (RIF) list annually. As a result, Martha has served in a wide variety of placements countywide as more senior teachers select what are perceived as more desirable

placements. As an experienced educator, the parent of four successful adult children and four adored grandchildren, Martha brings many strengths to her new position. Her principal, Chip Statesman, credits her for getting Energy

Express into the community. He says

The thing with Energy Express, we heard about it specifically, I think it was 2 years ago, and we began the process of trying to become involved and we did not have the key person who desired to take the leadership role. And this past year, as we discussed this, Martha Lazarus came forward and she emerged as the energy that we needed to cause something to take place.... She is what caused it to happen. It was her legwork. She indicated the desire, and the only thing I did was to give Martha a little support. And that was the least that I could do. And because of her energy, 
because of her desire to help children, and her vision of what this program could be, at least within

our school, she caused it to take place. Without her, it would not be a reality (pp. 218-219).

As the site coordinator, Martha is clearly in charge at Energy Express. She has high expectations for behavior, work ethic, and program results for both the mentors and the children. She thinks Energy Express is a "team effort," however. She is very gracious and committed to maintaining open communications and an atmosphere of respect for others. Martha believes that the success of Energy Express this year is pivotal to maintaining the program here in Monarch and engendering support for like programs in smaller, more needy county communities. Mentors

For the most part, all of the Monarch mentors are well-suited for planning learning activities. All, except Matt who will study for the ministry in the fall, are education majors at West Virginia University (WVU). Ruth, Mark, and Leah are in their fifth year of the combined undergraduate/master's program and Rhoda is in her second year. They are acquainted with each other from shared college classes, if not from growing up in Preston County. In some ways, Matt is the "odd man out." He is the mentor least well known by the other mentors and the mentor with the fewest experiences common to the rest of the group. As Leah points out, "Matt was in eighth grade when I was graduating, and what senior even pays any attention to an eighth grader?” (p. 119). Matt is not yet a college student, is not planning to attend WVU, and is not an education major. Matt also has the longest commute time to and from the site, so he is not able to spend as much time at the site or with the mentors in non-structured times.

Ruth is a strong asset to this first-year program as she has had previous experience as an Energy Express mentor in a neighboring county. As the neighboring county is not hosting Energy Express sites this year, Ruth opted to come to Monarch as her grandmother lives two blocks away from Monarch Elementary. Ruth is staying with her grandmother this summer, enjoying easy access to the site and evaluating her grandmother's ability to continue to live alone for her family.

Rhoda's best friends have served as mentors in other counties. These friends urged her to apply as a mentor after a full year of telling her about the experiences they had with Energy Express the previous summer. Mark, Matt and Leah found out about the program by word of mouth from Preston county school district employees or by advertising through the University.

Monarch mentors know Preston County. Although Leah admits to being a little out of touch with the community as she has been living away from home for four years, she and Mark grew up in Monarch. Matt and Rhoda grew up in other Preston county communities. Although Ruth is a Morgantown native, her father is a Monarch native and she made frequent visits to her grandparents' Monarch home throughout her life. These visits and her family's shared experiences have given her some grasp of the history, geography, and political climate of the community.

\section{Volunteer Coordinator}

During the open house, Martha introduced Rebecca, the VISTA volunteer coordinator, as the "spark-plug" of the program, and it is an apt description. A high-energy and high-achieving individual, Rebecca graduated from the high school in the spring and is planning to enter WVU in the fall, looking toward a major in child psychology. Throughout her high school career, Rebecca has had extensive experience as a volunteer in her community and as a 
leader among her peers. Rebecca demonstrates a very clear idea of her job responsibilities and actively looks for ways to extend her capabilities. Her broad base of relationships within the community and her persistent phone calling gain an average of two teen volunteers per mentor room and a community volunteer to read aloud daily. Promise Fellow VISTA

Deborah, who is Rebecca's former volleyball coach, serves as Preston County's AmeriCorps Promise Fellow, a two-year AmeriCorps position to create and foster on-going programs of community development. Although it is not specifically "her job," Deborah is often present at Monarch Energy Express. While there, she provides Rebecca some additional mentoring for her job as volunteer coordinator for Energy Express. Deborah also purchases and prepares the breakfast provisions and transports the lunch foods from the Head Start kitchen in Howesville where she often helps prepare them.

\section{Children at Monarch}

All children participating in Monarch Energy Express attended the elementary school there during the previous school year. Although Preston County's Energy Express is not able to provide transportation this first year, Martha reports that she specifically targeted most of the participating children for Energy Express because of their difficulties in reading. She and the mentors note, however, that although most of the attending children received free or reduced lunch during the school year, they are perhaps not the neediest children in the school's catchment area. Martha assigned children to certain multi-age mentor groups based on her knowledge about the individuals within the groups and how they would interact among themselves and with the various mentors. She feels that her personal knowledge of the children at Monarch is a strong asset to the program's implementation and future development. 


\section{Volunteers}

Teen volunteers are a prominent feature of the Energy Express program in Monarch. Between one and three teen volunteers assist in each mentor group each day. Rebecca solicits the involvement of many high school juniors or seniors that she knows and of family members of all participants (children, mentors, site coordinator, and her own family and friends). Many come consistently on certain days or for certain weeks and participate actively in the program, helping with writing, shared reading, art activities, and recreation as well as sharing meals with the children.

Rebecca also asks a wide range of community members to volunteer for the program. The read-aloud volunteers are almost all specifically trained in oral reading and/or are community leaders. Monarch Elementary's principal, the prosecuting attorney, school board members, county commissioners, the superintendent's wife, the Family Resources Network coordinator, local ministers, a couple of Martha's fellow teachers, and a WVU football player all participated in reading aloud to the students during the summer. Occasionally, groups or individuals make special presentations to the children following breakfast. For instance, the school's music teacher came almost weekly for some musical experiences with the children. On another special day, a group from Mountain's Promise presented a puppet show about environmental issues and the work they do in the county.

Parents are more likely to volunteer "behind the scenes" for special events. A few helped to clean the building before Energy Express started; one or two worked weekly in another building to prepare the foods for the summer feeding program; one made banners for the open house. More parents contributed by making foods for the volunteer appreciation dinner or the open house. Parents, however, are seldom seen integrally involved in the children's activities at Monarch Energy Express. The evaluation team only observes parents directly supporting activities in the mentors' rooms four times throughout the program.

\section{Community Collaborative}

Several key people in Preston County have consistently worked together over the last few years to initiate programs in the county through the Family Resource Network. One person instrumental in finding and applying for various programs is the county grantwriter, Lydia Constantine, a Monarch native who returned to the county to follow the family tradition of county leadership. Lydia claims that her father was one of the last "Boss Hawg's" of Preston County, when county leadership was provided by "the good-old-boy" single political party system. She feels that the responsibilities of county leadership have transferred in recent years from "the good-old-boys" to the Family Resource Network. Lydia notes that during her time living in Chicago and other cities, she became aware of AmeriCorps programs. She was interested in bringing AmeriCorps programs to Preston county to support the college aspirations of community graduates, soon to include her own children. As the county grantwriter, Lydia became aware of Energy Express as she was researching AmeriCorps programs (p.306).

In addition to Energy Express's appeal as an AmeriCorps program, Lydia states that Energy Express appeals to her because it supports children's reading abilities over the summer. She feels that being able to read well is critical for the future development of individuals and for the community as a whole. When she was considering applying for the program, she asked the county's extension agents, the leader of the Family Resource Network, and Monarch Elementary's principal to review the information on Energy Express (p. 307). The principal in turn 
presented the information to Martha and other faculty members and several became involved in planning for the program, though Martha emerged as the driving force in program development.

\section{Preparation for Energy Express}

Although people in the Energy Express state office had on-going contact with the Preston County collaborative and with Martha as the selected site coordinator, I first met Martha after the evaluation training at West Virginia Wesleyan in Buckhannon. Martha said she was glad to meet me, because she was concerned about Monarch's selection as a case study site. I first sought to allay her fears by asking her about her specific concerns and what she thought it meant to be selected as a case study site. I told her about myself and some past experiences with Energy Express, assuring her that the director of Energy Express, Ruthellen Phillips, had recommended Monarch for study as a strong first year site. In talking, we found that we had mutual friends in Aurora, a smaller Preston County community. We made an appointment for the first evaluation team visit on the following Wednesday as the mentors were preparing for the program.

As we talked about Martha's experiences in preparing for Energy Express, she mentioned that they were going to have a problem getting the facility ready for the program. The superintendent of schools had required all service personnel to complete their vacations before July 12, so the janitor promised by the school district to Energy Express would not be available until the third week of the program. I suggested a couple of alternatives, and then reintroduced Martha to Ruthellen, to talk over some other potential solutions.

\section{Energy Express Gets Started}

Evaluation team member Lisa Palmer and I first visited Monarch during the week of preparation before the program. As we entered the multipurpose room, mentors were scrubbing the floor, using huge machines and mops and buckets. Throughout the site, we passed other mentors cleaning in the hallway, bathrooms, and classrooms. Apparently, a satisfactory substitute for the custodian who was to be provided by the school system for Energy Express had not been forthcoming, because Martha and the AmeriCorps personnel were putting in long hours cleaning as well as preparing for the program itself. They had agreed, however, to count their cleaning hours as the start of their community service requirement.

Mentors also completed home visits during this preparation week. As a former kindergarten teacher experienced with home visits, Martha had conducted her own "mini-training" on home visits early in the week before sending the mentors out in pairs or triads. Although some of the children were very shy at first, the visits went smoothly and were completed before the program began, except in the case of some vacationing or late-enrolling children.

I accompanied Ruth on two home visits. Early in the week, Ruth made an appointment by phone for a specific time to visit each family. For the first visit, I drove Ruth several miles out of town, following good directions given by the child's grandfather past several landmarks, on poorly marked rural routes, to a nice split-level home in good repair. Hostas and annual flowers lined both the driveway and the concrete walk to the house. Several children were playing in the large, wooded back yard, as we turned into the three-car wide gravel driveway. One little girl in shorts and a top came into the gravel driveway to welcome us. The child's grandmother came out the 
front door, introduced the little girl as Cara who would be the child going to Energy Express, and invited us into the living room to sit down.

The living room attached to the kitchen, and the entire area looked neat, clean, and in good repair, though the furniture was not new. The kitchen included a microwave and dishwasher, and the living room included a TV/VCR/stereo system. Ruth introduced herself and me to Cara, her grandmother and Cara's aunt who was sitting at the breakfast bar area. The grandmother explained that the aunt had come over from next door to take one of the children to the doctor for an annual checkup, since the grandfather had taken the truck to go fishing early this morning. Ruth named the members of her group, then asked Cara if she knew any of the other children in their Energy Express group. Cara said that she did, though the other children named were a grade behind her. Giving Cara paper and markers she had brought along, Ruth asked her to draw a self-portrait or a picture of a favorite activity or possession. While Cara was drawing, Ruth asked the grandparent for the three dollar insurance fee and answered questions about the program. When Cara finished the drawing, Ruth asked her to tell about the picture and collected it to display in the room the first day. Saying, "I'll be looking forward to seeing you on Monday morning," we left after about a twenty-minute visit (p. 23).

The second visit was to a home only a few blocks from the school. This home appeared to be a basic onestory home, probably about 1000 square feet in area. There might be a half basement or garage under the house, but it was not as large or as well-maintained as the home we visited first. The front yard was very small, and there were slightly rusted Tonka trucks near the road in an area of dirt. There were no decorations and few plants-nothing much to add color to the outside which was beige and brown. Some bicycles and riding toys were in a heap to one side of the front concrete stoop. A five-year-old boy opened the front screen door for us, followed by his older brother, Jonathan, who would be attending Energy Express, and their mother, holding a baby girl. The mother introduced the baby as a child she babysits for, almost all week.

Inside, the small living room had light pink walls with newish dark green carpet. We sat on a new green and white striped couch under the front window. A large TV in an entertainment cabinet, large coffee table and overstuffed chair filled the rest of the room. Jonathan's mother commented that they were getting ready to paint, since one of the children she babysits for took a marker to the walls. I did not see any marker on the walls, but grimy fingerprints were prominent in the hallway in view from the couch. She expressed hope that they could paint when her husband returned from Germany in a couple of days. She reported that he had been gone three weeks this time, with the reserves, "trying to do his part to get things settled down with those European problems" (p. 26) and the boys really missed him.

Ruth followed the same format for this home visit as for the first-offering paper and markers for a drawing to put into her room, commenting on Jonathan's drawing, answering questions and talking about the program and her group. Both visits went very smoothly and I was impressed. Later, Ruth indicated that home visits in Monarch were not difficult for her, other than coordinating a time to meet, getting her car to run, and following the directions to the houses that were not near by. Martha commented in interview that she had provided extra coaching on home visits as she had done many home visits herself as a kindergarten and Title 1 teacher. She felt that home visits were an attractive feature of Energy Express, important for development of mentors' social awareness and good experience 
for future teachers. In informal conversation, other mentors reported that they often knew someone related to the children they visited at home, since they had been life-long Preston County residents and had attended the county high school with some of the children's relatives. None of the mentors reported poor living conditions for the families that they visited, but implied that the families of children in their groups were perhaps only slightly less financially able than their own families.

A Typical Day at Monarch's Energy Express

Arrival and breakfast. Throughout most of the program, adults engage in a flexible pattern of activities at Monarch Energy Express. The site coordinator, volunteer coordinator, and mentors typically arrive at the site before 8 a.m. to set up their projects for the day and, according to Martha, "gather their wits" before parents start dropping off their children between 8:30 and 9:00. As children arrive, they go to their mentors' rooms to spend some time together before lining up to wash hands and go in to the multipurpose room for breakfast at 9:00. Rebecca, Martha and Deborah often work together to get the foods out for breakfast, although occasionally one or the other of the three has to run errands, make presentations to groups, attend conferences, make phone calls or work on other projects during the breakfast set-up time.

The food service sponsor at Monarch, North Central Community Action (NCCA), pays for the breakfast foods, but they do not have personnel or a place to prepare breakfasts. Therefore, Deborah or Rebecca purchases the breakfast foods according to NCCA guidelines that specify a cereal or bread product, a fruit and milk for breakfast. Cereal, muffins, poptarts, cereal bars and bagels are frequent grain choices, and fruit offerings include grapes, apples, bananas, nectarines, and cantaloupe.

North Central Community Action provides the food for several Energy Express sites in the northern part of West Virginia. Community Action Agencies (CAAs) are "nonprofit private and public organizations established in the Economic Opportunity Act of 1964 to fight America's War on Poverty" (Community Action Agencies, online, n. d.). CAAs have five legal mandates: to fight poverty, promote self-sufficiency, feed the hungry, improve social services, and engage the private sector. These mandates seem very similar to Energy Express goals, and the local program seems to be a good match for the agency.

For breakfast, the children, mentors, and volunteers sit around tables colorfully decorated with bright tablecloths and vases of fresh flowers donated by local florists or picked from participants' gardens. Children and mentors bring dishes over to the tables, pass bowls and utensils around, and serve each other. All participants talk quietly (for the most part) during meals--building relationships, fostering oral language, and practicing interpersonal communication and manners. Between 9:20 and 9:30, all help to clear the tables and one child from each group sponges off the surfaces with bleach water, as the rest line up to return to the mentor rooms. Rebecca usually cleans up the breakfast dishes and takes care of any leftovers.

Mentor group activities. Martha and the mentors developed the morning schedule that the mentors generally followed from examples they collected from experienced site coordinators at training. On a rotating schedule throughout the morning, the children in each mentor group engage in a variety of activities. They listen to stories being read by their mentor or a volunteer and have shared reading with another student or mentor. They have a 20-minute recreation period, focusing on non-competitive recreation as Energy Express central suggests. Most 
groups ask to play "cross-over dodge ball". In this activity, children are not "out" when they are hit by the ball, but simply "cross-over" to become a member of the other team. On a daily basis, children work on an art activity; read a poem of the week; contribute to a "word wall" or review writing conventions; and write in journals or about art projects.

Generally, community volunteers arrive during breakfast to join mentor groups or to prepare to read aloud following the meal. After welcoming them to Energy Express, Martha or Rebecca provides them with the read-aloud books selected for the day, a time and place to review the books, and some guidelines about the particular groups they will meet. Martha will often accompany them to their first read-aloud session, to make them feel welcome, answer any questions, and to smooth over any interruptions or distractions. If she is not needed for this, she visits mentors' rooms each day, asking what she can do or get for them to help them during the day. She often models a reading, discussion, or writing activity for the mentors early in the day.

On occasion, the two older groups participate in a pen-pal activity suggested by Rhoda's Energy Express friends in a nearby county. The groups take "Flat Stanley"--a paper doll created to help the group describe their community--on walks to nearby places in Monarch. The children have their pictures taken with "Stanley" at the courthouse, the schools, the historical markers, and the playgrounds in Monarch. On other days, they write about their excursions and the pictures, then send the entire travel packet and "Stanley" on to another West Virginia site. By the end of his travels, "Stanley" will have a complete portfolio describing the places he has been and the people he has "met", including the people and places related to Monarch's Energy Express. This project and others like it demonstrate that the Monarch site implements a "place-based" curriculum (Zibart, 2002), according to central program guidelines.

An additional aspect of "place-based" curriculum relates to community service conducted by all of the mentor groups during the summer. At various times during the program, mentor groups read to residents of a nearby nursing home and planted chrysanthemums and buckwheat around the school. Each group created a special program to present for the open house. Activities at Monarch seem to be nicely paced, with no last minute frantic preparations, and very little "down time" when children are not engaged in valuable projects.

VISTA volunteer coordinator and site coordinator activities. Rebecca and Martha also keep busy throughout the morning. Rebecca cleans up from breakfast, checks to make sure the volunteers are in place and actively involved, answers the phone, takes videos of any special events happening in mentors' rooms, runs errands, and fills in wherever mentors need her. Her major responsibility is making phone calls to line up volunteers, schedule community service projects, and organize the open house, volunteer appreciation dinner and end of the year mentor celebration. On occasion, she takes children home after cleaning up the lunch dishes, returning just in time for mentor reflection and community service hours. 
Martha serves as the Energy Express link to the community. She makes phone calls to arrange newspaper and radio coverage of Energy Express, writes thank you notes to volunteers, orders milk as needed, interacts with parents and community members who visit the program, and talks with children who need to "remember their manners" or exercise better self-control.

Rebecca usually picks up the food from the preparation site at Howesville Head Start around 11:00. She then distributes the food into serving bowls for each mentor group. At noon, the children and mentors wash hands and go back into the multipurpose room for lunch. Assigned children take the bowls to the tables while others distribute styrofoam plates, napkins, and plastic eating utensils as needed. Rebecca, Deborah or Martha distributes cartons of milk to the tables, and the mentor pours cups of water at the table for those who want it. Meals often consist of some sandwich-like main course (burritos, ham and cheese sandwiches, submarines, pitas, sloppy joes, hot dogs, etc.), cooked vegetables or salads, canned or fresh fruit, and milk or water. Most of the time, there is enough food for everyone to be satisfied, although occasionally the food preparer at the Head Start site underestimates the amount needed of certain popular foods, so there is not enough for more than one small portion per child. In such rare instances, the teen volunteers and mentors have declined to eat their portions so that the children may have more.

After lunch, children play with the basketballs and chin-up equipment in the multipurpose room, usually with Matt and Mark's supervision, until they are picked up. Martha and the mentors greet and chat with the parents who come in to get their children. In about the fifth week of the program, the mentors and Martha decide during mentor reflection to eliminate the basketball playing after lunch, as some of the children and parents were lingering for quite a while after the program officially ended. Although a couple of the children were upset with that decision, the mentors were able to get to mentor reflection, to cleaning up their rooms, or to community service a little more efficiently. Rebecca and mentors not directly involved with children or parents start cleaning up the dishes and putting leftover food away.

Mentor reflection. After the children have gone, the mentors spend a few minutes cleaning up their rooms, and then gather for mentor reflection. Mentor reflection happens for a very short time if at all on three days of the week, so that the mentors can fulfill their selected community service projects during a time frame that is acceptable for the organizations they assist. On Mondays and Fridays they generally meet for longer periods. Reflection sessions are lively, with everyone contributing ideas or questions for discussion at some point, though Martha usually brings up the topics and sets the agenda. Much of the reflection time is devoted to "housekeeping" issues: when various activities should be scheduled, who will fulfill certain responsibilities, what materials, supplies or ideas are needed.

Martha and the AmeriCorps members also discuss the children's behavior problems. In one session, Martha and the mentors reviewed philosophies behind and methods of guidance as suggested by Energy Express. They developed standards for Energy Express at Monarch and posted them in the teachers' workroom for a ready reference.

According to the posted standards, discipline methods at Monarch Energy Express evolve from two philosophical statements. First, “We believe all children can be successful.” Second, “A mentor's responsibility is 
for a structured morning filled with varied engaging activities." The standards go on to list the foundation for positive behavior as:

Structure

Relationship with the child

Praise for positive behavior

Positive attitude toward the child (they see you believe in them)

Kids become responsible for their own behavior

The child knows what is expected

The final section of the standards explains development of mentor group rules and consequences for misbehavior:

Clear rules: child generated, posted, referred to often

What happens when rules are not followed

Consistency is the key

Have the child define the behavior (if necessary, seek help from the class)

Peer appraisal of behavior to be modified (how is this behavior keeping us from

getting things done?)

Refer to site coordinator

Monarch's behavior standards closely reflect the information presented during mentor training and in the mentor manual. Although mentors developed classroom rules with their mentor groups during the first week of Energy Express, Rhoda reports that she still had some problems with discipline. She says

If you asked me in the first week, I would have said that there haven't been any problems, but I guess they have gotten so used to me that they found out what my weaknesses are and they are playing on them (p. 138).

In cases of consistent misbehavior, Martha and the mentors determined that they would give the child an oral warning. If the misbehavior continued, the mentor was to remove the child from the activity and company of the other children within the room for a few minutes. Finally, the child would be asked to see Mrs. Lazarus if the behavior continued. Having Martha deal with the behavior problems may have had the effect of protecting the relationship between the children and the mentors to maintain a pleasant atmosphere during the group activities.

In spite of the fact that they did not meet consistently for lengthy mentor reflections, mentors at Monarch seemed to be comfortable with one another. They worked in pairs or as a whole group in their community service projects, and some elected to spend extra time with each other-in the library searching for books, playing tennis, or running out together for fast food or special treats after the children left.

Community Service. As participants in a first year site, Monarch AmeriCorps members did an exemplary job in fulfilling community service requirements. As one evaluator observed, "These mentors WORK!" In her position as Preston County AmeriCorps Promise Fellow, Deborah had already become aware of community needs and contributed suggestions for several projects. Early in the program, the mentors hoped to work with the local Parks and Recreation department to maintain and revitalize some of the county parks. After several phone calls, Mark found out that the time allotted for community service in Energy Express would not mesh with the work hours served by Parks and Recreation, unless the mentors wanted to do their community service starting at 6 a.m. each 
morning. Eventually, the mentors ended up doing several smaller projects for various community agencies—most arranged by Deborah, and one, in particular, initiated by the mentors themselves.

Deborah arranged for Rebecca and the mentors to work at the local food pantry, pick up trash, sort materials for recycling, and test stream waters for Mountain's Promise, another AmeriCorps endeavor in the county that focuses on cleaning up the environment. On one day, they cleaned up fire damage in the Brown building-a historic downtown building that was being renovated by the historical society. All the mentors agreed that cleaning up the Brown Building was the hardest job. Ruth said that Deborah had to find masks for them to wear and the mentors were very glad to have them. They cleaned up glass and soot and dirt and pieces of the floor and ceiling that had burned. She continued

We came out of there looking like coal miners. Rhoda got a nail in her sandal that she wasn't able to see sticking up through all the mess on the floor. She's lucky it didn't go all the way through to her foot! (p. 66).

The mentors' self-initiated project was important to their work. When they went to check out books in the local library, the mentors discovered that the books needed to be arranged alphabetically by author and catalogued in order to be found easily. They determined that they could meet this community need by working in pairs or triads for some of their community service hours. They did similar tasks for some of the school libraries, as well as planting flowers and spreading mulch on the schools' grounds.

Mentors felt that they gained a greater awareness of community needs and opportunities for service in their broad-based approach to community service projects. Fulfilling different service projects in different county contexts not only allowed them some flexibility in their scheduling, but also allowed them to promote Energy Express to many different constituencies in the county.

Special events. Special events also took place in Monarch Energy Express. Besides the excursions with "Flat Stanley" and to the nursing home to read, Mark promised the children in his group that they could design a costume for him one day if they worked very hard to complete their journal writing all week. Of course, he came to lunch that day looking somewhat like Red Skelton as the washer-woman.

On another day, the mentors had "switch day" in which the groups rotated to different mentors throughout the morning for activities. Matt did the read aloud, using different voices, and the shared reading with the children and volunteers. The children made Goop with Rhoda, newspaper hats with Ruth and nature prints with Leah. Mark volunteered to be in charge of the noncompetitive recreation activities for all the groups.

"The ultimate success story" of Monarch's Energy Express, according to Martha, was the open house. All of the children enrolled in Energy Express, their family members and many community leaders--over 150 people-attended the open house. After Martha welcomed everyone, each mentor and group made a special presentation. First, the mentors took turns explaining the main features of the Energy Express program. Then Matt's first and second graders sang and acted out the alphabet song, Chicka Chicka Boom Boom. Leah's group presented a skit they developed together about (Native American) Indians and their house. Ruth's third and fourth graders followed with "Prince Jonathan's Haircut", a play they had written about a prince who gets a haircut and looks much better, according to the princess and her maid, after many adventures with a dragon and a dog. Rhoda's girls acted out a comedic narrative poem called "The Judge". Mark's group presented a magic show, which they developed after 
reading a book describing the tricks behind most magic tricks. At the end of the program, Jonathan, a boy in Ruth's group, read the longest paper he had ever written--a two-page essay about why he liked Energy Express.

The finale of Monarch's Energy Express was a picnic in the park across the street. After breakfast, the children and mentors went to their rooms for their final shared readings and read aloud experiences. Groups took turns to water the chrysanthemums they had planted. They collected final books and art projects to take home, and spent some time working together to straighten and clean the rooms. Late in the morning, everyone went over to the park for a super crossover dodgeball game and special picnic games such as water balloon toss. Volunteers grilled hot dogs for lunch and mentors and children shared hugs and wishes for the remaining part of the summer to be fun when parents picked their children up for the last time from Monarch's first ever Energy Express!

\section{Monarch Program Results}

Monarch's first year as an Energy Express site can be considered very successful. Thirty-five of the forty children who had registered for the program attended each day, and the other five openings for children were filled most of the time. Thus, Monarch had the highest mean daily attendance (93\%) of any of the 76 Energy Express sites in the summer of 1999. Of the 35 children attending throughout the summer, 14 were male and 21 were female. Attending children ranged in age from 6 to 12 years old, and had completed grades from kindergarten through fifth grade. Four Energy Express children (11\%) had Individualized Educational Plans (IEPs) during the school year for speech or mild disabilities. Thirty-two of the thirty-five children were eligible for free or reduced lunch during the school year (Butera, et. al., 1999). All of the registered students were European/American, which is not surprising in Preston County where the entire minority population is less than a quarter of one per cent of the county population (Preston County census, 1990).

Fifty-seven community and youth volunteers contributed a total of 987 hours of work at the site, spending most of their volunteer time reading, writing, and assisting in art and recreation activities with the children (Butera, et. al., 1999). Volunteers spent 191 hours of this time reading one-on-one with the children--almost five and a half hours of reading with each child during the program (6.3\% of each child's time was spent reading individually with a community member or youth helper). Mark, Rhoda and Matt reported on various days that there were so many volunteers, they had almost one adult per child in their rooms.

What do these impressive statistics divulge about Monarch Energy Express participants' values concerning educational risk and resilience in children? What did local Energy Express participants tell us about educational risk and resilience? How did their beliefs inform or guide their actions and affect the local flavor of the program? In what ways did participants' beliefs change or develop over the course of the program? The following qualitative case study themes more clearly inform us of the beliefs of Energy Express participants in Monarch concerning educational risk and resilience in children.

Themes

"If you do what you've always done, you'll get what you've always gotten" (p.315)—Traditionalism and resistance to change yield reluctance to support Energy Express. A computer-generated poster in county grant writer Lydia Constantine's courthouse office aptly summarized this theme. In Preston County, a few hardworking community and school professionals were ready for change in the operating procedures and outcomes of the 
community and schools. These people formed the county collaborative for Energy Express, and they saw the advent of Energy Express as just the starting point for things they wanted to happen in the county. In talking about school cultures, Monarch Elementary School Principal Chip Statesman said

If one is unwilling to admit that there are problems there, then they can't make any change. We make excuses rather than changes. I think all principals and teachers need a chance just to reflect maybe every five to seven years. As they say, the only difference between a rut and a grave is the depth of the rut. Truth and honesty are what bring you out of a rut before it becomes a grave (p. 235).

Lydia Constantine expressed the concern that her own children have become academically stagnant since they moved to Preston County, and that "entire schools in the county remain stagnant" (p. 309). Extension agent Naomi Logan pointed out that "A lot of the old-timers are the ones in the political positions and they are against anything progressive" (p.166), though both she and FRN coordinator Tamara Bethany agreed that the county commission was very supportive of their initiatives. During our interview, Lydia Constantine continued, "There are so many things going on that could go on in Preston county that haven't gone on. It forces me to be the creator of it” (p. 310).

Lydia wanted to generate some far-reaching and long-term changes in Preston County through Energy

Express. She noted

I'd also like to address some of the food preparation and what the kids are used to here. So many around here are into frying everything and we really need to change the medium of cooking here for the community's future health and bring the cholesterol levels down in the population as a whole. Beans and cabbage are okay, and some here eat them almost every day, but they put that pork fat with them and the cholesterol content goes way up. I think we could introduce to the kids alternate ways of eating through the feeding part of the program. I like thematic education, even in nutrition (p. 312).

Both Lydia and Chip mentioned in interviews that they had been interested in Energy Express for several years before they could become involved. From previous experience with AmeriCorps programs while living in the Chicago area, Lydia knew that she wanted to bring AmeriCorps programs to Preston County. When her family returned to West Virginia, she began hearing about Energy Express. She attended Energy Express training the year before, and thought

What a way to get two birds killed with one stone! I could still follow my goal that was to have young people, kids, together with college ... plus the literary programs in this county are run so badly ... but a couple of the extension agents in this county did not want anything to do with Energy Express ... one of those ag[riculture] agents was my husband. I told him we needed to do it, and showed him the numbers-the number of children that were being fed at one site in the county; the number of kids that are two to two and a half years behind in their reading levels, the second graders that are reading at kindergarten or pre-kindergarten levels. I was showing him these numbers and he said, 'Well, we need to do something about it!' (p. 331).

Chip explained that they needed a key person, such as Martha Lazarus, to provide the impetus for the program to become a reality in Monarch. Extension agent Naomi Logan added

Martha was very interested in the program from the get go, before the planning committee ever came together and took a look to see if we could do it. I think that Martha was a big initiator as far as getting other people interested and that may be because she is a teacher here at the school. She was interested in the kids, interested in something happening for these kids and this school that needed this to happen (p. 171). 
With all her energy, however, Martha felt that many county leaders were reluctant to become involved in new programs. In interviews, Martha talked about the number of civic groups that she visited to garner support for Energy Express. Although she noted that she smiled and thanked them for their contributions, she felt like most of the groups gave only a fraction of what they might have offered, if Energy Express had not been new to the county. Throughout the program, Martha urged volunteer coordinator Rebecca Bowman to continue to invite the Title 1 coordinator to serve as a read-aloud so that the coordinator could see the amount of reading that Energy Express encouraged and become invested in the program. The Title 1 coordinator, however, never visited the program.

Extension agent Naomi Logan was also concerned about the reluctance of county leaders to become invested in Energy Express. She asked volunteer coordinator Rebecca Bowman to videotape the mentors and children in action so that she could develop a presentation video of the local program. I reminded her that Energy Express already had a professionally developed presentation video, but she said

We want to make an Energy Express video to take to different civic organizations, to take to different church organizations, to take to other types of volunteer organizations to create an interest on the community level. I know that there is an Energy Express video, but we want one for Preston County because we feel like in order to get the interest that we need, they are going to have to see the positive results that can happen in our county. I'm hoping that they recognize some of the kids or the mentors or some of the activities in the school ... it may not be in the form of a video, just something that portrays the activities ... getting people an idea of what can happen in Energy Express. Whatever works just to sell our story and get people interested (p. 173).

Community collaboration or conflict? The collaborative nature of Energy Express planning caused community leaders to recognize and grapple with many facets of educational risk in determining their priorities for local program location, emphasis, and selection of site personnel. As a program "to build children's school success" Energy Express includes development of a local community collaborative to garner the $30 \%$ financial match and to sustain the program over time. Collaboration, by definition, involves direct interactions between at least two coequal parties, voluntarily engaged in shared decision making, with shared responsibility, resources, and accountability, to achieve a common goal (Friend \& Cook, 1992). Results of collaboration are most often different from what any individual originally envisioned.

In Preston County, collaborative members had to negotiate many difficult decisions to make Energy Express a success locally for its first year, and to keep the possibilities open for expansion of the program in subsequent years. Martha Lazarus, site coordinator, gave the rationale for the location of the first year program. She explained, "Monarch is the county seat and there is a little more prosperity here than in other parts of the county. But we wanted things to go well this year and thought that it might be easier to get started here in Monarch" (p. 80). Lydia Constantine, county grant writer, stated more directly, "Here we're doing Energy Express as a pilot program at Monarch. Why? Because they are the only school in the county that would open the door!” (p. 314).

Collaborative members were well aware, however, that the very success of the program in Monarch could create a barrier to its acceptance in other county communities. Extension agent Naomi Logan compared the establishment of Energy Express with her experience in starting a program to address cooking for diabetics throughout the county. In an interview, she described the attitudinal barriers she faced.

Some of the communities said, 'Why did you do it first in Monarch?' I couldn't really tell them, well, it is the county seat, and I have the facilities I need there to do the program, and I can reach 
the most people there. Some of these small communities, though, they don't make it easy for you to bring stuff to them. They either don't have the facilities, or they want to charge $\$ 40$ for the night to rent the community center or some facility, even for extension programs. But there are some who won't even grocery shop in Monarch. Even the Buckwheat Festival, the county fair, some won't attend because it's in Monarch. ... Monarch is really resented by the other communities. ... People in Aurora say they are always left out of everything and it may be true, but it is just because of the geographics--not any intention to slight anyone. Some of the smaller communities, well, have smaller programs or the people don't even come out when you have a program there, so you can't reach as many people with the information you're trying to give them. It's generational"Well, my grandpa didn't ever like Monarch, and my pa didn't and I don't either." It's a cancer that eats them up-and part of it is political, to "down" Monarch. ... And for this county, you can't win for losing, if you can't convince them of a program's value because it is an idea that came in from outside the county, or from another community in the county. Really leaves you between a rock and a hard place in introducing any new ideas (pp. 166, 167).

Tamara Bethany, primary site contact and coordinator of the local Family Resource Network (FRN), added

Our intent was to pilot the program here and to expand it into other communities in the county, if a community wants it and will do their part to get it ... But we have to be realistic. That local match is not going to be easy for some to come up with. We didn't get the WV Reads grant, and it has been a headache, a barrier to what we wanted to do here. What HAS worked well is that we had a good relationship between several of us prior to the program, so we could call each other and ... remind each other and help each other to keep on track. For next year, we have the support of the existing collaborative, and if we can get the stakeholders in each of the communities involved, we can do it. There are five other communities eligible [for Energy Express, based on poverty levels], and we're hoping to be able to add two next year. The areas of the greatest need have the lowest reading levels, but we may have to look for better funding for them to do it. (p. 146).

County collaborative members also differed about program emphasis and priorities. I asked Tamara

Bethany to describe the child for whom Energy Express is perfect. After pausing a long time to consider carefully, she replied

My initial response would have been the child who is living in poverty, may or may not have a dysfunctional family, but has a low reading level for whatever reasons. On the other hand, I know the needs are not always economical. Maybe it should just be the child who needs that extra shot in the arm of self-esteem, regardless of their economic level (p. 147).

Site coordinator Martha agonized over reaching the neediest children in the area. She wanted very much to have a bus to bring children in, but

The collaborative had basically decided that they needed to do it without buses, even though I thought that we needed buses. I could only fight so much because you can't alienate the rest of the collaborative. Most of them just didn't understand because they don't work with children. They are not working with children on a daily basis, so they don't understand the on-going need (p. 99).

Collaborative members very clearly agreed, however, about the human resources for the new Energy

Express program. In interviews, each collaborative member pointed to an individual in their own lives who mentored them and influenced the course of their lives. Therefore, certain personal characteristics of the site coordinator, volunteer coordinator, and mentors were felt to be essential for optimal program development. Extension agent Naomi Logan, for instance, said that they selected the volunteer coordinator and mentors on the basis of their relationship to the community and their personal characteristics as caring, nurturing people who would be good role models. Both Naomi and Tamara Bethany noted that they wanted someone as site coordinator who was committed to 
the program and a good organizer. County grant writer Lydia Constantine was very clear that they wanted a site coordinator who was "a reading specialist" and a volunteer coordinator who "had good people skills—who was personable" (p 310).

Generally speaking, the collaborative was more than satisfied with the personnel selected. Tamara Bethany, county contact, said

I personally was looking for caring people, who would look at it as more than just a summer job. Not so much their educational background, but the understanding, and empathy to be able to bond with the kids, to connect. We got plenty of applications to choose from, and from reading their resumes you would have thought they walked on water, too. But we did get the cream of the crop! (p. 147).

"It is not always the poorest families that have kids that can't read" (p. 222). Although socioeconomic level was acknowledged as a major factor in educational risk by Energy Express respondents to the Participant Beliefs survey, Monarch's adult participants discounted poverty and focused on reading abilities in addressing educational risk. During interviews, each of the county collaborative members mentioned the lack of financial resources and the prevalence of low-income families in the community in discussing the need for Energy Express. In our interview, Lydia Constantine said, "This is a poor county, but the people are not lacking in willingness. Our biggest challenge has been the money, as there are few large businesses within the county" (p. 311). Tamara Bethany stated succinctly, "Resources are definitely tight— the money is just not there.... We don't even have a school bond in this county, so the Board of Education is strapped for money, too" (p. 149).

In relating her own life history as a teen-age wife and mother living in poverty twenty-five years ago, Tamara reflected, "When you're in a dysfunctional—well, not even dysfunctional, but in low-income circumstances—education is just not valued so much. There are other things that are more important—like day to day survival concerns- that mean more" (p. 146). Mentor Mark was very clear that socioeconomic level contributes to educational risk. He said, "Socioeconomic level, underprivileged kids, less reading, fewer reading materials. No access to reading materials in the home. They just didn't develop the skills that they needed to and so they need extra help to get pushed up to where they should be" (p. 120).

Adult participants in Energy Express in Monarch agreed that there were children in the county with more need for the program than the children enrolled this first year. Site coordinator Martha wanted to have busing to and from the site for that very reason. Ruth, the only mentor with previous Energy Express experience, noted that

The need was not as much here, though they would benefit from the program in reading, and there were certainly a few who needed the nutritional support. ... On the home visits, it was obvious that these were nicer homes and a little more financially able families than at M. D. [her previous Energy Express service site] (p.60).

During various informal conversations, each of the mentors said that children did not seem to "need" the food - particularly breakfast — and that many of the children had eaten before they came to the program in the mornings. In evaluating the program for the future, mentors agreed that it would be better to have children with more need in the program. As an example, Leah described three children she met when she had been riding her fourwheeler over the weekend. She reported that she frequently sees these same children in her neighborhood and that 
she "knows these kids are hungry and they haven't looked at a book all summer. The parents work, there are no cars, so they can't go anywhere all summer" (p. 268).

Mentors were probably not informed about the documentation of need that accompanied applications for Energy Express site programs. Their opinions of the children's needs in Monarch Energy Express were more likely based on their personal observations and relationships with the children. Nevertheless, I was also surprised that so many of the children participating in Monarch Energy Express qualified for free and reduced meals during the school year. The site itself and the children attending Energy Express seemed to be typically middle class. Monarch Elementary school, though not new, was in good repair and had many resources available in terms of books, equipment and an abundance of donated items for the program. Children attending Energy Express were not noticeably small or underweight, and were clean, healthy and well groomed throughout the program. Some wore name-brand clothing and many were able to bring in personal or family CDs for music during breakfast and lunch.

Although Monarch was clearly eligible for Energy Express, the nutritional needs of low-income children were not the focus of the program. Collaborative members considered educational achievement, particularly in reading, and children's personal empowerment as forming the road to a better life. Principal Chip Statesman illustrated this belief, stating

It is not always the poorest families that have kids that can't read ... What really is the critical issue, seems to me, is that we've got to cause parents to be better invested in education for the child, and be able to provide for the education. ... So the value of education has to be within the individual. Until we as adults, the individual adults in this world that have children, teach/cause our children to see that we value education, education is going to be for naught. ... That's what I'm talking about when I'm talking about sacrifice. Until we're willing to give up something to get something of value, then it's worth nothing (p. 222-223).

Focus on the families: Conflicting stories about family values. Adult participants' beliefs about families of children enrolled in Energy Express were operationally defined—and none too consistent. Parents and family dynamics were seen as having a powerful influence on children's educational outcomes, in contributing to risk or in building resilience. Generally, families that spent time with their children, especially in reading and enjoying books, were believed to build educational resilience. Families "that do not value education" and "chaotic" families were seen as significantly contributing to educational risk. Principal Chip Statesman stated, "Apparently people don't have enough time for their kids, don't give enough time with their kids. It's not all people—some, a large majority, larger than I would like to think" (p. 227).

When I asked Martha about the type of child who would benefit most from Energy Express, she said that would be a child whose "parents do not value education, who has been basically left to watch TV hour after hour. They are not taken to the library; they are not read to ... probably three-fourths of the Energy Express population here" (p. 98). In describing the typical child in Energy Express, Martha focused almost exclusively on family issues as she said

The mom works as a maid; the dad is a truck driver. The parents themselves have very low reading and writing skills. They have not traveled anyway; it was big to go to Morgantown for a field trip. The only time that they have been anywhere is field trips at school like to the Pittsburgh Zoo. Whenever the parents or teachers send home notes about anything the parents never answer the notes, never read them. And they can read it, but they just don't bother with it. These parents are trying to solve many living problems, so it is difficult for them to focus on their child's 
educational needs. The family deals with marital and financial problems, always concerned with finding a place to live and if the phone bill can be paid or has been paid. Although the father is currently employed, you figure that the parents are inconsistently employed. This child has an older brother who has been kicked out a couple of times in school and causes a problem to the family. There is no family support network nearby or other support network (p. 98).

Martha also talked about a family that she hoped would send children to Energy Express, whose children failed to appear:

A really chaotic family. We had tried to help them with filling out the papers five times-spent a lot of time trying to get them to fill out the paperwork. And they finally did send them in, but they don't have a phone. The first grade teachers recommended that they come, but the parents didn't really feel strong about it or value education. Leah and Ruth went on the home visit and they said there was so much going on there, it was hard was hard to hear. The mom was there, and some boyfriends were there. It was hard to communicate in the twenty minutes ... just a very chaotic family (p. 99).

Mentors' responses to questions about educational risk and resilience were not as consistent about the impact of family dynamics. When we asked why children come to Energy Express, Mark reported that

Parents encourage kids to come to the program. Parents know that a child's reading skills can affect a child's performance in other subjects as well ... Low-income families may not have books in their homes ... but a main distraction is peer influences on children. Children may make fun of others if they can not read. Children may also get embarrassed if they can not read (p. 41).

Rhoda had a similar perspective. When I asked her what things interfered with children's learning, Rhoda responded

Not feeling like they fit in. I have seen it in this classroom. I have two girls that really don't, I can tell, don't feel like they fit in. And because everybody else will be around this table doing their journals and they will be off in the corner, doing this, head down on the floor, trying not to be nervous, so I think that a lot of it is peer pressure and not fitting in. And the parents' support, I think the lack of that puts them in major risk. Luckily, these girls have that, the support (p. 135).

Leah said that children come to Energy Express because "their parents want them to read better and write better and be better students. This is a way to bring them up to where they should be" (p. 115). However, when asked what things interfere with children's learning, Leah pointed to both the home and school environment. She said

A lot of parents--I grew up in part of the community that had a lot of lower income families and the last thing that those parents wanted was their kids to be better than they are. To grow up better than they are ... I think that teachers, myself included, they say, 'This is my impression of the child and, no matter what, that child is going to fulfill that impression.' I think the parent attitude towards the school. They don't see it as valuable, (but) extraneous to their life (p. 116).

On the other side of the coin, mentors appreciated parents' volunteering in Energy Express and parents of attending children valued the contribution of Energy Express to their children. During mentor reflection, Leah reported that

Ian's mom, Becky, was there and took Roger aside to help him write ... these two got buddybuddy and I swear he didn't make a single disruption for half an hour at least! And I just went, "What's happening here?" She was very good with him (p. 191). 
Martha responded, "She seemed so appreciative of the fact that we needed her. You know what I mean? And I said come back again." Leah rejoined, "She says, 'I have two ADD kids and I know how to handle them.' She says 'I know what's going on"” (p. 191). For her part, Ian's mother said

Energy Express is more like one-on-one ... it's great ... I appreciate it. Anything Matt asks him (her son, Ian) to do, he does. Parents can just do so much ... others can help. Now he wants me to read books to him; sometimes he reads them himself (p. 184).

"Live within the reality of your expectations" (p. 192): Children's behavior and/or disability. Ian, among others, was a frequent topic of mentor reflection, due primarily to his behavior and secondarily to his disability status. Though the county collaborative members who visited the program on occasion never mentioned children's behavior or disabilities as affecting educational outcomes, the site coordinator and mentors talked about these issues on a daily basis, especially during mentor reflection.

Children with attention deficit or attention deficit/hyperactivity disorder (ADD/ADHD) were most frequently discussed. Rhoda related that "we have so many kids that are ADD and that are just completely going wild on us. They don't listen to what we are saying” (p. 138). Early in the program, Matt reported that when he read Where the Wild Things Are ${ }_{2}$ all of the children in his group "turned into little wild things-especially Ian, who had not had his Ritalin" (p. 66). Mentors and the site coordinator also discussed David and his needs throughout the program. Martha noted that David is not the typical child in the program as his family is affluent by Monarch standards, but he would lose some ground over the summer by the fact of his reading problems (p. 99). During one reflection session, Mark's frustration was evident when he stated

Everyday he's disruptive, he won't sit still, he's doing something, and I don't know how. . . I've tried all kinds of things, he just will not listen. The first couple of days this week he was pretty good ... he has deteriorated . . . Read Aloud is the worst. I've tried everything with him; it's difficult for him to focus. ... He needs one on one, he's uncooperative (p.189).

Martha suggested that Mark call David's mother, but Mark said that he had already talked with her, though resulting changes in David's behavior had been short-lived. Martha volunteered to come in to Mark's group during Read Aloud to sit with David, and Mark exulted "That would be great!" at the offer of help. During the last week of the program, the mentors recommended that Martha specifically divide up the ADD/ADHD kids so that no one mentor group would have more than one. Matt and the other mentors seemed to think that there were several children with ADD/ADHD in his group, though Martha said that only Ian had been diagnosed. (p. 268).

Children's behavior also brought them to the attention of the mentors during mentor reflection, to "see Mrs. Lazarus" during the day, or both. During one discussion, a mentor told about a child who was trying to "bully" other children in the group into doing what he wanted to do all the time. Volunteer coordinator Rebecca related her experience with children in Eagle's Nest, a program for high school students to discuss social issues with small groups of middle school students. She reported that three out of eight kids in her group were bullies, and she enjoyed the challenge to work with them. She added, "You could tell that some of the kids didn't get any attention at home, or any guidance at home, that the parents didn't even care" (p. 109). She volunteered to come in to the room to talk with the children about respecting each other's right to make choices. In another incident, Leah sent Roger "to see Mrs. Lazarus" after a series of distracting incidents and several verbal warnings about his noncompliant behavior 
during her reading activities. A few minutes later, Martha returned with Roger, asking the group if they could remind Roger why he was sent out of the room. According to observer Lisa Palmer, some of the answers were: "hitting his head against the table and talking loud, rolling around, putting his fingers in his ears and saying he wasn't going to listen, putting his shoes on his hands and crawling around the floor" (p. 200). Martha thanked the children for helping Roger remember, guided him back to her office, and talked with him about respecting his mentor and fitting in with the group (p. 200).

Throughout the program, Martha encouraged the mentors to develop their relationship with the children to the point that they would want to comply with their mentor. She continually referred to the discipline principles presented at mentor training. During reflection sessions, she often prompted them to consider the needs of children with disabilities. Early in the program, Martha suggested that the mentors try to write for one entire day without using the letter $\mathrm{T}$ to begin to understand the frustration of having a disability (p. 103). Another time she began the reflection session with the quote "Today I will be especially aware and supportive of all those who struggled to succeed" and asked the mentors to respond to that thought in their journals (p. 108).

In a later reflection session, mentors asked Billie Bonnett, a member of the evaluation team who is an experienced behavior disorders teacher, for words of wisdom about their discipline questions. She said

When I go in (your rooms) I don't see a lot of misbehavior. I see the kids. . . I know you're having to redirect them, but I don't think it's anything that any of you can't handle, because it's all being handled very well. Something that I learned a long time ago is: live within the reality of your expectations ... in other words, you know they're going to act up, so don't come in here in the morning thinking that they're going to be perfect today.... Know that they're not and be prepared for it and it's not as rough of a day, because then you're prepared for the fact that this one is going to be like this and this one is going to do this and it's not such a disappointment (p.192).

"The unkindness of inflexibility"(p. 233): Schools and school professionals, though admittedly highly organized, educated and experienced, are not thought to build resilience in students, especially in low income children. Site participants believed that parents whose children do not experience success in school were resistant to attending Energy Express as it is "like summer school." In one instance, on our first visit to Monarch, before the program started, Lisa Palmer and I had been observing Martha, the site coordinator, as she informed Ruth that she had just talked with a parent of two boys registered for the program. According to Martha, the boys had told the parent that they just wanted to have fun this summer, and did not want to do anything like school. The parent told Martha that she should take them off the registration list as the parent would not "force" them to attend (p. 4).

Martha confided that

People see it as summer school, and for six weeks, they just don't want to make the effort to get the kids here- they want to kick back some. And the older kids who have the most reading difficulty are the most reluctant. They don't like school and don't like to read because they can't do it well, and don't want to do anything like school. ... And the parents don't want to fight about it in the summer- they have enough trouble getting them to school during the nine months. Once they come, though, and enjoy Energy Express, I'm hoping they'll start to see school in a different light (p. 8).

Mentor Leah claimed that attitudes of adults were responsible for many learning problems in schools. "This can make the children feel unwanted, those from the lower socioeconomics [sic] that are not made welcome" (p. 108). Leah tried to emphasize the differences between Energy Express and school to her group. She related that 
I have had so many kids say that it is summer school and, no, really it isn't. It is fun hanging out. They argue that it is summer school. I try to stay away from saying how much they are learning because then it would be school again. I feel that a lot of it is the mindset. Sometimes there is some pressure to "improve" them. Make sure they know what they knew before (p.115).

Matt, mentor and son of a local teacher, focused on the differences in group sizes between school and Energy Express, with the benefit of having extra volunteers in the Energy Express groups. He noted that "the number of kids in a classroom can interfere with a child's learning. It's hard when there are 28 kids and one teacher. . .the process of teaching is interrupted because not everyone is on the same page" (p. 131).

Local school professionals who were involved in the program--such as Chip Statesman, principal and county collaborative member/Read Aloud volunteer and Martha Lazarus, Title 1 teacher and site coordinator--found significant differences between "school" and "Energy Express". In discussing the focus group interviews concerning Energy Express that I was to conduct with the children, Principal Statesman accurately predicted that

The kids are going to say, are going to focus on the fun activities, the positive things like that. I don't know if any of them will say, "I really like reading." But without that attitude, without that desire, as I said before, the learning is not going to take off. It's too bad we can't have schools modeled after this (p. 227).

Martha liked the non-competitive social environment of Energy Express. She said that in the school, there are many competitions—-science fairs, social studies fairs, young writers contests, dental health posters, even art or coloring contests. She works with

the poor little guys who don't do any of that kind of thing well. The kids with maybe the higher intellect get all of the glory and recognition and attention and my guys have to try three times as hard to get noticed (p. 100).

Throughout the program, Martha contrasted the "joyful" experience of Energy Express and its focus on one-on-one interactions with the children with the "cattle-herding" feeling of school. She especially enjoyed the family style meals in Energy Express. She contrasted Energy Express family style meals with lunches during the school year in which teachers are

expected to keep them quiet and to hurry them through eating for 15 minutes and there are way too many kids in the cafeteria to watch at one time. You have to herd them through the lunch process, like cattle to the feeding trough, and they don't get the conversation or the pleasant atmosphere or the feeling of being able to relax (p. 140).

Martha was also concerned about the interpersonal dynamics between some teachers and the students in school. She said that she had not invited many of her fellow teachers to participate in Energy Express because she felt that "some teachers will dispense criticisms about Energy Express" (p. 101). She noted that her philosophy of discipline in the context of interpersonal relationship more closely matched Energy Express's policy than it matched the procedures used by some of her colleagues. She asserted she would never be friends with some teachers, because

We have a professional relationship and I can't stop in or correct them on their relationship with the children ... it is the same kids who miss recess every time for any little thing--they are yelled at an awful lot; they belittle them. ... They are giving them a handicap, something to carry with them all their lives to say that they can't do this or they can't do that (p. 101). 
In observing daily school interactions between teachers and students, Martha has wanted "to say to the teachers 'Stop it and realize what you are doing!' but they don't" (p. 101). She had asked Principal Statesman if he could do anything about the poor interpersonal dynamics of some classrooms. Mr. Statesman said he was also frustrated with the poor quality of teacher-pupil relationships. He stated his belief that WVEA should monitor certain teachers that he has confronted because they have been less than kind to children. Unfortunately, WVEA has often indicated that all he can do is to write an improvement plan. Mr. Statesman said he would like to be able to say to certain teachers, "I have noticed you yelling at the kids" or "Why are there so many work sheets here?" (p. 217), and for teachers to have some real incentive to change. He said that

Teachers are truly the leaders of learning in our schools, and we administrators need to encourage them to seek out new strategies, to use better technique in their delivery of instruction.... We need to do this, and as long as our decisions are focused on children, to improve learning for each individual child, we will be successful with whatever decision we make (p. 218).

Mr. Statesman was well aware, however, that often school decisions are not focused on the needs of the children, but on what works for the adults in the setting. He was further concerned that the culture of schools did not allow for much latitude in teachers' expectations of students.

We want to put every kid in the same mold-the same system that you were raised in and I was raised in. Put them all in the same mold. Punch them through the system. But that is changing and we in education are struggling to deal with that ... I'm not trying to say we don't have committed dedicated teachers. WE DO! They will work many, many, many hours here. But, sometimes we work really hard, and not too smart. We need to work smarter. (p. 230).

Returning to the idea of meeting the needs of children, Mr. Statesman expounded on the importance of interpersonal relationships in the school climate, and ultimately in the school success of children.

One of the things that we don't need, that kids don't need, is the unkindness of inflexibility. We need a renewal, if you will, in the schools, and I'm working toward that. We must maintain the standards, but with some flexibility. Mark demonstrated an understanding of that last night when he was talking about playing on a team, as a member of a team. You have to play by the rules, but everyone has to pull their own weight to keep the program going. That internal rapport is what keeps us all focused on our mission. When there is arguing, fussing with one another, when we lose our sense of humor and we're always on each other's case; if we don't treat each other with kindness, we lose what we're trying to accomplish ... The same for teachers. If they don't like what they're doing, they shouldn't be there. If they don't meet the standard, then they should be out. Society has gotten permissive with standards and therefore society has broken down. We have broken wheels in families, in schools maybe, too (p. 234).

“The concept fits with what we want to do for children." (p. 232): Addressing risk by building reading fluency and self-confidence. As we were finishing our discussion about schools and Energy Express, I asked principal Chip Statesman what he wanted to tell me about Energy Express that I had not asked. He responded, "I don't know that I've talked so much about Energy Express other than the fact that I think that it fits. The concept fits with what we want to do for children" (p. 232). Energy Express concepts that received the most praise from local participants were the focus on reading and helping the children in their personal development.

Participants from every program level expressed the belief that fluency in reading helps children build resilience. Grant writer Lydia Constantine said that she had looked over the scores for the schools (the school report cards and SAT-9 profiles) and was "concerned about the effects on society when a population or a significant part of 
the population can't read" (p. 311). She stated that she "knows that though most of the kids graduate from high school, they don't have the reading level they need to be successful" (p. 311). Principal Chip Statesman agreed with her philosophy: "Reading is the critical issue. We're finding that children are struggling to read today. . . It is not at Monarch Elementary School, it's throughout this county, throughout this state, throughout this nation.” (p. 218).

Community members and children attending the program in Monarch understood Energy Express as a program to build reading skills. During the home visit with mentor Ruth before the program started, Cara's grandmother expressed the hope that Cara would become a more fluent reader. She said that Cara needed some extra help with her reading, but that she liked school. "Cara can read, but is very slow in reading, so it is not much fun for her" (p. 22 6/23). In focus group interviews when I asked the children in the oldest groups, "Why do you think people decided to have Energy Express here, in Monarch?" David's answer was representative of the children's responses. He said, "To make sure people are reading during the summer vacation, and getting good food and not eating a whole bunch of junk. Learning" (p.276). I asked children to think about a friend that did not come to Energy Express and asked why it might have been good for the friend to come. "To read better" was the short answer given by most of the children, but Abby gave a thorough answer. She said, "So people here, like Rhoda [her mentor], they can help them write; they can help them read; they can help them get more stuff settled for next year" (p. 285).

Focusing on the benefit to mentors in Energy Express, Lydia Constantine, county grant writer, again mentioned the importance of education for county residents:

People know that they can go anywhere and do anything with a well-rounded education. And that is a blocking point for so many of the people in this county, as well as in other low-income areas. They just don't have the monies to go to school. They just don't have that vehicle for education to take place (p. 222).

When I asked principal Chip Statesman to describe for me the type of child for whom EE is perfect or just especially good, he talked about both reading and self-esteem. He responded

It touches the child that struggles in reading. It does good for that child that maybe reads a little better, but has a self-image problem. It's good for that child who may be able to read somewhatstruggles, struggles with reading — but the support at home is just not there, whether it is for food or for love, for kindness, or for the desire to learn (p. 224).

As we were discussing what Energy Express provided for the children, extension agent Naomi Logan was also clear that both reading and personal development for the children were features of the program. She felt, however, that the individual attention was the most important contribution of Energy Express to the children. Energy Express provided

just that little extra attention from adults, and some reading skills and comprehension. One of the grandest things that is not focused on enough, is what has happened this year with the individual attention given to some of the kids who never get any or not enough. It really gives them a shot in the arm for their personal development. May even change some lives (p. 156).

Naomi went on to describe herself as having been a child who would benefit from Energy Express. From her personal history, she shared

It was not so much that I needed the extra help as far as reading development, but I was a very shy and timid child and $95 \%$ of the time I stood back, I didn't initiate anything. . . I think a program like this really helps those kids simply because it gives them an opportunity because the class size 
is small to interact not only with the mentors, but maybe to start initiating some conversation within this very small group. ... It enables kids to feel better about themselves ... gives them that little extra special attention that sometimes it may take to bring an introverted child into an extroverted child (p. 170a).

When asked to describe each of the girls in her group during the last week of the program, mentor Rhoda also focused on social skills, relationships and self-confidence more frequently than she mentioned reading abilities. Overall, she said, "A lot of the girls are socially not very able. They have no social skills or not much around people their own age, though some relate well with adults or even the volunteers who come in."

The Energy Express success story that Martha shared at the mentors' dinner celebration featured a child's development in both reading and social skills. Martha wrote

When Lynette's mother inquired about Energy Express, she shared with me that Lynette had experienced a difficult year in school due to her extreme shyness. Her mother wanted her to come, however, Lynette was not willing to do so. Lynette's name was put on our list with much reservation. When it was time for Mark Barnabas to make a home visit, Lynette would not respond to his questions and seemed very unhappy about the whole situation. She came the first day with her older sisters who came as volunteers for Energy Express. Lynette was in tears. As time passed each week, her tears eventually turned into a beautiful smile! Her older sisters had other commitments and could not be here for her. She still came. When Mark's class visited Heartland [a local nursing home] to perform a magic show and read to the patients, Lynette was introduced to Roy, an elderly gentleman in a wheelchair. Lynette pulled up her chair beside him and said, "Hi, Roy, I'm Lynette and I'm going to read you a story today." Lynette's face was glowing with a beautiful smile. She read to Roy with love and affection. Mark and I were amazed when we realized that morning the progress that had been made during her time at Energy Express. I left, to check on the other children, with her sweet little voice reading in the background. I knew she would be "just fine." (p. 378)

"One hundred years from now it won't make any difference, except for what I did in the life of a child" ( $p$. 315). Although Lydia Constantine pointed out this poster in her office and claimed it as a family motto for over seven generations, it also well portrayed the Monarch Energy Express prime directive at every level. When I asked Matt what Energy Express was all about, he responded quickly, "It's all about the kids . . letting them know that someone else cares. These kids are the ones that don't stand out in school. It's great to come here and see them participating and standing out" (p. 131).

Principal Chip Statesman emphasized positive relationships between adults and children as essential to the learning process. He related this story about one child attending Energy Express to illustrate his point:

This morning when I came in, a little girl came up and gave me a big hug. The same little girl gave me a big hug last night [at the open house] ... When Dan and I were talking, this little girl came back again and was just standing beside me. And I just reached down, as you would with any child, or your own child, and put my arm around her, and she just took hold of my hand, and we just stood there. When I came out from reading, guess who met me in the hall again? Same kid. So what's that tell you about what this child needs? . . . Sure, she needs love that we're not providing elsewhere in her life. She is evidently getting it here. Now, what does that have to do with reading? I think a great deal (p. 226).

After visiting occasionally over the first three weeks of the program, extension agent Naomi Logan felt that "the interaction of those kids with the mentors is just invaluable." When I asked her to tell me about anything that we had not discussed that she felt was important to know, she responded 
I think that if there is nothing else that happens with the program this year, I just think that the attention that these kids are getting from these mentors and vice versa, I think is unbelievable, is just beyond, far more than what we bargained for. I don't think that it is something that the kids thought would happen. It is certainly not something that we were selling as far as talking about the program. We weren't telling the kids that if you come to EE, you will make friends with whoever, the mentor. ... I think that is just something that happened because of the interest that the mentors have in these kids ... and then the kids in turn just needing, needing and liking, and wanting that kind of attention. It has just awed me. For instance, an example would be like some of the activities--they are sitting in a circle or something and then mentors would be sitting there alone with the kids and the kids will just come up and sit on their lap and just, it is just a bonding thing. . .. I think that is something that is very good and positive that those kids will never forget. And more than likely they will never forget their mentor. I just, the role model aspect of it. I just think that it is wonderful (pp. 175-176).

Efforts to build educational resilience focused on providing good role models in the Energy Express mentoring relationship. As soon as mentors were selected for the Monarch Energy Express program, Mr. Statesman sent each one a welcoming letter. In the letter, Chip reminded them that they would not need experience as much as they needed to remember that they are models in the community, to the kids and to the others who would be watching Energy Express to see how it works (p. 10). Site coordinator Martha asked her daughter to create a bulletin board to welcome the children to the program which proclaimed Energy Express was "Helping children to become capable, connected, and contributing" (p. 93). This bulletin board was prominently displayed in the hallway where the children and mentors would have to pass it several times a day.

Martha expressed her philosophy about how to build resilience to the mentors during a mentor reflection session. She said

I tell children, "Don't be upset, you'll get it." I tell mentors, "Believe in the children. Show it on your face, in your body. Appreciate them for who they are. They have been taught that they are failures. You have to show them that they're not." (p. 262)

Monarch's mentors took the Energy Express philosophy and Martha's instructions to heart. Rhoda translated that philosophy into her interactions with her mentor group. She reported that

Kids need to be told that they can do it. I try and some of these girls I can see that they feel what they can't do. And I am trying to show them ways that they can do it, not the way everyone else is doing it, but they can do different things. Those are two things. They can do whatever they want all day, but I try and respect them and I teach them to respect me. I see that they really respect the people that come into the classroom (p. 134).

Leah took her responsibility to the children very seriously. She noted in her journal that she prayed for them every day. She also shared her primary goal as an Energy Express mentor. She said, "I want to leave and have my kids like their life, reading, and books a little more than before" (p. 108).

Community members also believed that the mentoring relationship was important and would provide lasting benefits to the children. The principal in the middle school where the mentors were doing community service projects told them, "Some day some kid or even adult will come up to you and say, 'Hey, I know you. Remember the summer we read together? You were my mentor!"” (p. 81).

Primary contact and Family Resource Network coordinator Tamara Bethany felt that the mentoring relationships developed within Energy Express could have as profound an influence on children as mentoring 
relationships had in her own early married life. Her own mentors had encouraged her to get her GED and continue with her education, even when she was a young mother with three children. In her own words, "The kids and families don't realize it now, but I think someday they may be able to look back and say, 'That Energy Express mentor really made a difference in my life, and in the direction of my life"” (p.146).

\section{Summary}

The purpose of this study was to capture the beliefs of Energy Express participants in the summer of 1999 about factors that contribute to children's educational risk or resilience, and to see the effects of these beliefs in practice. Initially, four questions guided the research for understanding of the issues of risk and resilience. These questions were:

1. How do Energy Express participants define and prioritize children's at-risk status?

2. How do program participants tailor recruitment methods to target those at greatest risk?

3. How do program participants tailor program activities to address risk?

4. What do children attending Energy Express believe about at-riskness?

An in-depth, multi-level examination of participants' expressed beliefs and practices was conducted in one case study site-Monarch Energy Express--throughout the summer of 1999. Qualitative research methods were used to delve into microsystem, mesosystem, and exosystem level variables to uncover foundational macrosystem variables (Bronfenbrenner, 1979). The case study of Monarch Energy Express provided eight themes describing participants' perceptions of educational risk. Results from focus group interviews with the children at the site contributed to development of the qualitative themes.

The quantitative Participant Beliefs Survey developed for this research effort to tap beliefs from a broader base of Energy Express participants was used to triangulate the findings with qualitative research results. Data from the Participant Beliefs Survey set the case study results in the context of beliefs of the larger Energy Express adult participant population. The Participant Beliefs Survey was comprised of two sections: A section using a 5-point Likert scale on 45 questions to assess beliefs; and a section in which respondents were to select and rank risk factors from a list of 16, according to their relative importance. Four components of educational risk resulted from principal components analysis of the Likert scale responses, and 10 variables were selected by statewide respondents to the ranking survey as the most impacting of variables possibly contributing to educational risk. Keeping in mind that the following oversimplification of case study themes dissipates the richness of understanding accrued from qualitative case study, Table 5 summarizes the results describing perceived contributions to educational risk.

Table 5

Summary of results

Qualitative case study themes

"If you do what you've always done, you'll get what you've always gotten": Traditionalism and resistance to change yields reluctance to support Energy Express.

Community collaboration or conflict?

"It is not always the poorest families that have kids that can't read."

Focus on the families: Conflicting stories about family values 
"Live within the reality of your expectations": Children's behavior and/or disability

"The unkindness of inflexibility" of schools

"The concept fits with what we want to do for children."

“. . . it won't make any difference, except for what I did in the life of a child."

Likert scale principal components factors

Personal/school interactions

Socioeconomic factors

School success

Urban/rural

Ranking scale 10 most frequently/highest ranked variables

Lack of home involvement/discipline

Dysfunctional family life

Absenteeism

Behavior or conduct disorders

Learning disabilities

Undiagnosed disabilities

Ranking scale 10 most frequently/highest ranked variables

Inadequate nutrition

Moving frequently during school year

Parent's educational level

Poor health 
Dandelions

By Solveig Russell

We are dandelions:

We're a thousand million or more;

We are golden stars

Strewn on earth's green floor.

We are buttons of brightness

Holding earth down;

We are royal princes,

Each with a crown.

We are dandelions,

Unnoticed by most who pass;

We are yellow parasols

For small things in the grass.

We are fragrant hassocks

Where fairies and fireflies rest;

We are the joy of children,

Who love us best. 


\section{Chapter V}

Discussion

Children at risk. Are they like dandelions to be ignored or discarded as weeds so environments can be aesthetically pleasing to middle and upper class property-owners and taxpayers? Or are they resilient wildflowers with untapped potential to be cultivated for the sustenance and development of the state's property and tax base? Or do we dehumanize or devalue children by even asking questions about the circumstances of their lives that hinder or empower them (Swadener \& Lubeck, 1995)? The answer to these questions about children's risk status, particularly in a wild and wonderful state replete with both dandelions and children at risk, depends to a great extent on the perspective held by those charged with making a positive difference. Perspective, however, is subject to change over time, moderated by new experiences and understandings received from research and life experience about the world and the systems in which we live.

As explained in the literature review, Bronfenbrenner's ecological analysis $(1979,1990)$ forms the basis for discussion because the study sought to uncover belief systems and cultural or subcultural "assumptions and values that underlie organizational structures, professional practices and daily interactions” (Peck, 1993, p. 26). In Bronfenbrenner's ecology, the developing person affects and is affected by four concentric systems of personal ecology. Macrosystem variables, such as the beliefs about educational risk and resilience which were the focus of this study, encompass "consistencies in the form and context of (the three) lower-order systems" (Peck, 1993, p. 26)-the microsystem, mesosystem and exosystem. Table 6 provides a summary for review of Bronfenbrenner's ecological analysis from Peck (1993, pp. 22-25).

Table 6

Summary of Bronfenbrenner's ecological analysis

\begin{tabular}{|c|c|}
\hline Level & Description \\
\hline Macrosystem & $\begin{array}{l}\text { cultural or subcultural "assumptions and values that underlie organizational structures, } \\
\text { professional practices and daily interactions" }\end{array}$ \\
\hline Exosystem & $\begin{array}{l}\text { does not involve the developing person as an active participant; includes events that affect } \\
\text { or are affected by the micro- or mesosystems. }\end{array}$ \\
\hline Mesosystem & "interrelations of two or more settings in which the developing person actively participates" \\
\hline Microsystem & $\begin{array}{l}\text { "pattern of activities, roles, and interpersonal relations experienced by the developing } \\
\text { person in a given setting with particular physical and material characteristics" }\end{array}$ \\
\hline
\end{tabular}

The importance of using several data sources, data collection methods and investigators-a process known as triangulation — has been explained by many qualitative researchers (Glesne \& Peshkin, 1992; Hammersly \& Atkinson, 1995; McMillan \& Schumacher, 1997). Triangulation "contributes to the trustworthiness of the data" and serves to "increase confidence in research findings (Glesne \& Peshkin, 1992, p. 24). In this case, the congruence or overlap of qualitative themes and quantitative results also served to triangulate the results from the qualitative case study with similar beliefs held by Energy Express participants overall. Figure 1 illustrates triangulation of results and the area of discussion. 


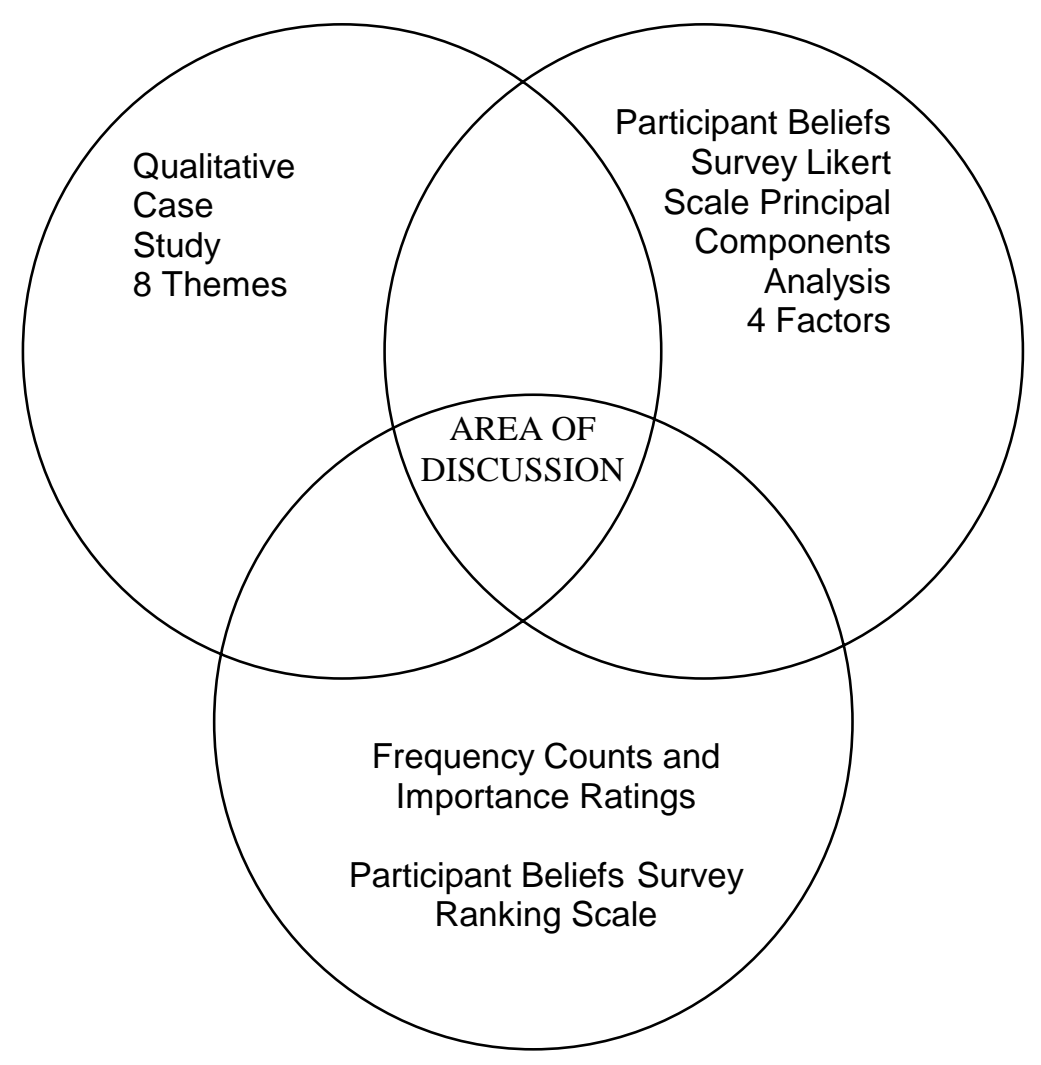

Figure 1. Triangulation of case study, Likert scale, and ranking survey results

Qualitative themes, principal components factors and items ranked as most impacting for educational risk described variables in many different levels of Bronfenbrenner's ecology. Consistencies in study results from the three lower-order levels of Bronfenbrenner's ecology uncovered belief patterns among Energy Express participants at large for the fourth level of analysis-macrosystem variables reflecting "cultural or subcultural assumptions and values" (Peck, 1993) about educational risk and resilience. Study results provided implications for work with children at risk or with identified disabilities in Energy Express as well as for teacher preparation programs. Questions which emerged during the course of the study provided direction for possible future research efforts. Table 7 illustrates the relationship of Bronfenbrenner's ecological analysis, the research questions and qualitative and quantitative data results as a guide for discussion. 
Table 7

Discussion matrix

\begin{tabular}{|c|c|c|}
\hline Level & Research question & Sources \\
\hline Microsystem & $\begin{array}{l}\text { What do children attending Energy Express } \\
\text { believe about "at-riskness"? }\end{array}$ & Qualitative themes $3,5,6,7$ \\
\hline Level & Research question & Sources \\
\hline Microsystem & $\begin{array}{l}\text { How do program participants tailor program } \\
\text { activities to address risk? }\end{array}$ & Qualitative themes $3,4,6,7$ \\
\hline Mesosystem & $\begin{array}{l}\text { How do program participants tailor recruitment } \\
\text { efforts to reach the children at risk? }\end{array}$ & Qualitative themes 5, 3, 7 \\
\hline Exosystem & $\begin{array}{l}\text { How do program participants define and } \\
\text { prioritize children's risk status? }\end{array}$ & $\begin{array}{l}\text { Qualitative themes 2, 5, } 6 \text { and } 7 \\
\text { Participant Beliefs Survey }\end{array}$ \\
\hline Macrosystem & $\begin{array}{l}\text { What do program participants believe about } \\
\text { educational risk/resilience? }\end{array}$ & $\begin{array}{l}\text { Participant Beliefs Survey; consistencies in } \\
\text { the three lower-order systems; qualitative } \\
\text { themes } 1 \text { and } 8 \text {. }\end{array}$ \\
\hline
\end{tabular}

\section{Microsystem Variables: What Do Children Attending Energy Express Believe About "At-Riskness?"}

Focus group interviews conducted with children at the site provided direct access to their ideas about educational risk variables affecting Monarch's Energy Express. Participating children were well aware that Energy Express was provided to address microsystem variables--so that children who needed it could be fed and "to keep kids reading" over the summer. Interviewed children acknowledged that they were participating in Energy Express to build their reading skills since they were "behind in reading". Perhaps typically, however, participating children did not express any concerns about their futures due to reading deficits or any other factors in their lives. Children did not seem to see themselves as at-risk, either in informal conversation or during interviews. Even the child who was legally adopted and changed her name during Energy Express was seen by both children and adult Energy Express participants as an isolated case whose past included abandonment and abuse, but whose future was "of promise" (Swadener \& Lubeck, 1995).

The children's responses to focus group questions did not agree with study findings from the Participant Beliefs Survey representing adult participants' perspective. Children at Monarch Energy Express did not acknowledge the presence in their own lives of any of the risk factors suggested or prioritized by respondents to the statewide survey. Though aware that Energy Express was to provide food and reading activities to "poor" children in their community, none indicated that they were among those who needed the free meals. Even when children noted their own needs to improve in reading, they did not seem to attach any predictive values or long-term concerns to their own reading struggles.

Unlike the adult participants, interviewed children did not mention any disparity between their families' values and the values of either Energy Express or school. Nor did they note behavior problems as contributing to educational risk. In short, children did not seem to consider themselves to be at risk. 
These omissions from the interviews may indicate either a difference in perspective between interviewed children and adult participants or research bias in selection of children to be interviewed. As stated previously, children attending Monarch Energy Express were not those facing the most risk variables in the county. As children, interview respondents may have been unable to verbalize differences in values among various groups, or may have had enough social sophistication to avoid potentially uncomfortable interview topics such as their own educational risk status.

Although interviewed children did not acknowledge their behavior as an indicator of educational risk, current educational practices, especially in special education, are based on principles of behaviorism (Skinner, 1953). In behaviorism, learning is measured as a change in students' behavior as a result of interaction with environmental events, such as teachers, other students, curricula, or classroom climate. Thus, children's behaviorin reading, in peer relationships, or in various social settings - is thought by education professionals to very clearly communicate educational risk. Indeed, since 1997,amendments to IDEA have mandated functional behavior assessment (FBA) and development of a behavior intervention plan for students with disabilities whose behavior places them at-risk of exclusion from their least restrictive educational environment (Gresham, Watson \& Skinner, 2001).

Interestingly, FBA is "a multimethod strategy involving observations, interviews, and review of records [Author's note: much like qualitative research] regarding student behavior" (Gresham, Watson \& Skinner, 2001) to determine the purpose of the behavior for the student. Carr (1994) determined that the functions of behavior typically include gaining social attention, communication or access to preferred activities; avoiding aversive activities or individuals; or internal stimulation. Future studies investigating Energy Express mentors' perceptions about the child's purposes in challenging behavior could provide valuable insights for preparing undergraduate students in effective behavior management strategies for their own children or in schools.

Four of the qualitative case themes provided insight into children's beliefs about "at-riskness." The exceptional attendance rate at Monarch Energy Express and the children's statements that they enjoyed participating in the program lent credence to the idea that "the concept fits with what we want to do for children" (p. 232). As the children acknowledged the program as personally valuable because they were "behind in reading", it seems the children agreed with adult participants that personal reading deficits (theme 7) comprised a risk factor distinct from family socioeconomic status (theme 5).

In structured interviews and casual conversation as part of the qualitative case study, three of the collaborative members named children's personal characteristics of shyness and low self-esteem as microsystem variables contributing to educational risk. Each expressed the opinion during interview that they themselves would have been considered at-risk during their school years, due to their families' poverty compounded by their personal characteristics. Mentors also referred to a child's shyness and low self-esteem as contributing to educational risk during the program, and included children who developed self-confidence during the program in their success stories. According to principal Chip Statesman, the Energy Express "concept fits with what we want to do for children" (p. 232) because the children were given that extra "shot in the arm" (p. 156) of caring attention and selfconfidence during the program. 
If the Energy Express concept fit what the site participants wanted to do for children in terms of building self-confidence, self-esteem, and other resilience factors, the children did not mention any awareness of deficit or growth in these areas. If program leaders, community collaborative members or mentors focused on the families as contributing to educational risk because they "do not value education," the children participating in Energy Express did not. Although respondents to the Participant Beliefs Survey ranked personal and family "deficits" as factors most likely to put children at risk, children attending Monarch Energy Express made no mention of these factors. Simply, children attending Energy Express recognized deficits and needs contributing to educational risk for unnamed others in the community and, to a limited extent, for themselves, but they did not appear to consider themselves to be at risk.

Monarch's final site report indicated that the proportion of children qualifying for free and reduced lunch status was greater in the Energy Express program than for the general population of the school, so at least a few of the interviewed children benefited from the free meals. Exo-, meso- and microsystem observers from the state level program, the county collaborative, and the site personnel all commented on the growth in participating children's reading abilities, self-confidence, and pleasure in academic endeavors. Were the children simply unaware of their own characteristics of risk or resilience? Did they lack the analytical skills for such self-analysis? Or were they reluctant to identify themselves with factors that they related to their social status among their peers in Energy Express? Certainly, children's beliefs about their own educational risk or resilience bear further study beyond the scope of this research effort.

Microsystem Variables: How Do Program Participants Tailor Program Activities To Address Risk?

From its inception, state level (exosystem) Energy Express creators designed program components to address various aspects of educational risk at the meso- and microsystem levels. As site coordinator, Martha made sure that the local program strictly followed Energy Express guidelines for each of the components addressing possible risk factors and Monarch site personnel implemented the program precisely. Language, reading, art and drama activities promoted literacy. Weekly themes were to encourage children to value themselves as individuals, family members, friends, and community and society members. Family style meals provided basic nutrition as well as opportunities to develop language and social skills. Recreation was non-competitive to foster interdependence among children and mentors and to build self-confidence. College student mentors were worthy role models, providing encouragement for reading, engagement with activities, and the desire for advanced educational achievement. Volunteer activities were to initiate commitment to the community's development.

Site personnel wholeheartedly completed Energy Express-prescribed activities, including home visits and community service requirements. As Chip Statesman said, "The concept fit with what we wanted to do for children." Although Martha's personal characteristics assured that exosystem program components would be precisely translated into the meso- and microsystem components of the local program, her training as a former special educator and Title 1 reading teacher brought reading and literacy activities to the forefront of priorities for the local program.

At the microsystem level, program activities had to serve the dual purposes of addressing the children's needs and making a favorable impression on the community to assure continued support for the program, laying the 
groundwork for possible future expansion of the program into other Preston County communities. Thus, Martha and the mentors spent most of the preparation week cleaning the site and making it attractive for both the children and visitors to the program. Throughout her term as site coordinator, Martha and the Preston County Promise Fellow made presentations about Energy Express to the county commission and community associations. During the program, the radio station featured some of the children telling about Energy Express, and the children were taken to the local nursing home to sing, present skits and read to the residents. Influential community members were invited in as readers. Community service projects such as landscaping part of the school grounds and helping to restore a nearby historical building and special events such as the open house also focused the larger community's attention on the program.

To continue the program's impact beyond the parameters of Monarch Energy Express, site personnel devoted as much effort to pleasing community and state-level leaders as to involving parents of participating children. Of course, mentors at Monarch Energy Express fulfilled their program responsibilities to reach out to families. They made home visits, invited families to come in to special presentations, and made phone calls whenever there was a particular problem or need. For their part, parents welcomed mentors into their homes, provided transportation to and from the site for their children, and attended the open house, with many other relatives in tow. A token parent attended county collaborative meetings and later visited a meeting of the county commission to support the program. A few volunteered to help with meals or in preparing for special occasions. On the whole, however, very few parents were involved in the ongoing activities at the site. Nevertheless, it seemed easy for collaborative members, Martha, and the mentors to talk about differences between values of program participants and values of local families.

Monarch's Energy Express provided a better model of central Energy Express tenets than of any beliefs or values held by the local community. Activities in Monarch's Energy Express program did little to promote the sense of Monarch as a unique West Virginia community. Few activities related to Monarch were included during the program, other than planting buckwheat in the school's new flowerbeds (across the street from the site of the Buckwheat Festival), and taking "Flat Stanley" around to nearby community facilities. It seemed that local program participants did not recognize local resources for addressing educational risk or building children's resilience.

At the microsystem level, on-going personal interactions between the adult site personnel and the individual children produced a narrow, de facto definition of children at risk among the adult participants in Monarch Energy Express. On a daily basis during Energy Express, microsystem variables such as the child's ability to follow directions, sit still, and focus were considered by adult site participants to indicate the child's relative educational resilience or risk. Children who cooperated with volunteers, mentors, and site coordinator Martha Lazarus were less likely to be discussed during mentor reflection and more likely to be cited as Energy Express success stories. A child who could follow this hidden curriculum of school success was going to be resilient, or in Martha's words, "just fine!" (Final site report, 1999). Those children who were frequently the subject of concern during mentor reflection because of behavior considered inappropriate or "bad" by the mentors fit site personnel's de facto definition of educational risk. Usually these were students with disabilities such as attention deficit disorder or those least 
compliant with school-like procedures. Interestingly, the school success factor of the Participant Beliefs Survey confirmed the existence of a similar belief among Energy Express participants at large.

During daily interactions with children, mentor beliefs were expressed by the frequency of verbal reminders to individual children about their behavior and by the frequency of visits "to Mrs. Lazarus" by the same children. In many cases in the mentors' planned activities, the social distance between mentors and the children they considered to be at risk was greater than the distance experienced by children cited in success stories. Whether this greater distance was by the mentors' choice or the child's was not clear.

Interestingly, in her book A Framework for Understanding Poverty (1998), Ruby Payne lists certain student behaviors as characteristic of children from generational poverty. These include disorganization, physical and verbal aggression, extreme freedom of speech and sense of humor, lack of procedural self-talk to initiate activities, and work based on whether or not they like the teacher. These characteristics surely describe the behaviors that caused concern to the mentors at Monarch Energy Express. Payne states that generational poverty "has its own culture, hidden rules, and belief systems" (p. 64) and defines it as affecting people who have been in poverty for two or more generations. It is the type of poverty most often associated with educational risk and behaviors perceived as peculiar or disturbing to middle class professionals such as teachers. Clearly, the presence or lack of "school success" behaviors strongly correlated with mentors' concerns about educational risk, and reflected differences in socioeconomic status between mentors and attending children.

Payne (1998) advocates for education as the key to getting and staying out of generational poverty. She notes that

Individuals leave poverty for one of four reasons: a goal or vision of something they want to be or have; a situation that is so painful that anything would be better; someone who "sponsors" them (i.e., an educator or spouse or mentor or role model who shows them a different way or convinces them that they could live differently); or a specific talent or ability that provides an opportunity for them (p. 79).

Monarch's mentors and site coordinator were much more likely to see resilience in terms of achievement in academic (specifically reading) skills than in improvement in social and school success behaviors. Payne (1998), however, recommends that direct instruction be provided so students can learn the hidden rules and choices of the middle class. In this respect, Energy Express with its emphasis on mentoring relationships provides a unique opportunity for addressing the educational risks associated with generational poverty.

During one mentor reflection session, evaluation team member Billie Bonnett pointed out that the mentors needed to "live within the reality of" (p. 192) their expectations of the children's behavior, and recognize how their own attitudes and beliefs affected children's educational risk or resilience. The relative dearth of positive comment about certain children was specifically addressed by Martha as she cautioned mentors to let her "be the bad guy", and to work hard at starting each day fresh with a positive attitude about the child. Martha's purpose in telling her own story—being warned that even rolling her eyes did not show respect to children—was to encourage mentors to monitor their own verbal interactions and body language to deal with children as evenhandedly as possible.

Interestingly, the mentors and Martha rarely talked about ways in which Energy Express could build the social and school success behaviors of attending children. They easily recognized the behaviors that did not 
contribute to children's school success, but did not often name behaviors that could build skills in school success. Visiting collaborative members and principal Chip Statesman frequently mentioned the "shot in the arm" (pp. 147, 156) of self-esteem and personal relationship with the children as possibly the most valuable features of Energy Express. Collaborative members noticed ways in which Martha and some of the mentors instinctively engaged the children in developing positive relationships, such as getting on the child's eye level, giving quick hugs or pats on the back, and playing with the children rather than watching them from a distance. However, Martha and the mentors-as people who grew up with some amount of school success and generally good relationships--did not note these behaviors as the resilience-builders they were believed to be by the collaborative members and this investigator.

Martha's experience with mentoring — somewhat unsuccessfully—mentor Matt demonstrates the site participants' difficulty in conceptualizing and employing resilience-building. In spite of her admonitions to mentors to respect the children, Martha was herself hard-pressed to maintain a positive and even-handed attitude toward Matt. Matt was the youngest mentor from the most rural environment and was the least socially and academically experienced - in many ways, the mentor most like the children who fit the de facto definition of at-risk developed by site leaders.

From the beginning of the program, she and Principal Chip Statesman had concerns about Matt's abilities to be an effective mentor. Martha went daily into Matt's group to model activities and to offer suggestions. At the end of the program, she stated that she had been very disappointed by his lack of skill in managing his mentor group, even though she had spent much more time with him in his mentor group than she had with any of the other mentors. She was concerned that the children in his group did not develop their reading skills as much as they might have with another mentor who was better versed in reading activities. She questioned his relationship with one of the female mentors and the development of his work ethic over the course of the program. In short, she feared that Matt was too immature (as a soon-to-be college freshman) to meet the needs of children at risk, and hoped he would not return as a mentor the following year. Only upon later reflection did she recognize Matt as a possible mentor at-risk, and concede that she could have demonstrated more faith in him by allowing him a little more freedom to succeed or fail on his own.

On his part, if "Success is the intelligent use of mistakes" (Glickman, 1993, p. 91), and Matt was never given the freedom to make mistakes, then it is not surprising that he did not feel like his Energy Express experience was a success. Matt was younger than all the other adult participants except the volunteer coordinator, and not as socially adept as she. He commuted daily from his rural home near another Preston County community nearly 45 minutes away, and cut short his time and opportunities to socialize with the other mentors. Historical divisions and competition among Preston County communities may have influenced him to feel that he was not accepted within the mentor group. As he sensed Martha's growing disappointment in him, Matt withdrew even more, leaving as soon as he was allowed and making it known that activities with his family and friends from his local neighborhood took precedence over spending extra time with the mentors or in preparation for Energy Express activities. Near the end of the six weeks, he stated in informal conversation that although he enjoyed being with the children, he felt that he could never measure up to Martha's expectations of him. 
On the other hand, evaluation team members agreed that Matt was likely to have been considered at least an adequate mentor in other settings. He had very few negative interactions with the children in his group; they loved for him to read to them using all the different voices that he could imitate; and he was consistent in fulfilling all his AmeriCorps responsibilities. He clearly agreed with Energy Express principles on building resilience when he said, "It's all about the kids . . .letting them know that someone else cares. These kids are the ones that don't stand out in school. It's great to come here and see them participating and standing out." In spite of Martha's concerns about him, Matt seemed to realize that "One hundred years from now, it won't make any difference except for what I did in the life of a child." Martha realized later that she may have missed an opportunity to let Matt "stand out" in Energy Express.

If "it won't make any difference, except for what I did in the life of a child", did Energy Express participants at Monarch recognize that "the difference" in educational risk or resilience relates to the child's (or mentor's) social and school success behaviors? In what ways might Energy Express participants build the social and school success skills of children and mentors for whom they want to make a difference? What part did socioeconomic status of both the site personnel and the children play in determining certain children's likelihood of educational risk or resilience? Certainly these questions require more extensive investigation in future efforts. Mesosystem Variables: How Do Program Participants Tailor Recruitment Efforts To Reach The Children At Risk?

Mesosystem variables are those which focus on "the interrelations of two or more settings in which the developing person actively participates" (Peck, p. 25). In this case, the variables center on the interrelations between Monarch's first Energy Express program and participating children's families, the school, neighborhood peers, or other community groups.

As Energy Express has been translated from the state level to local programs, decisions made by county collaboratives definitely impacted the interrelationships between local programs and families, schools and communities. In some cases, collaborative decisions narrowed the definition of populations to be served and altered the central program priorities of the risk factors to be addressed. Recruitment methods then were tailored according to the priorities set by the community collaboratives.

Certainly free or reduced lunch status during the school year and reading level deficits were considered as general indicators of educational risk based on the central program's definitions. Having a large proportion of students facing these risk factors on the microsystem level qualified Monarch Elementary School as a potential site for Energy Express in the first place. However, when the cost of providing transportation to Energy Express was factored in, a part of the program's goal to feed "the poorest of the poor" (Mother Teresa, cited by Gonzalez-Balado \& Playfoot, 1989) was exchanged for building community support for the program. The program shifted from addressing the needs of rural low-income children to addressing the needs of low-income West Virginia children who could most easily access the program.

In Preston County, the site selected had to serve the dual purposes of meeting central program constraints and being highly visible to influential community members to garner support for the program, possibly laying the groundwork for expansion of the program into other communities in the future.

However, deciding that the county's first Energy Express site should be located in the premiere elementary 
school in the heart of the county seat and opting not to provide costly transportation to the site reduced the population of potential participants to those who could attend the program without busing. Monarch, though small, is the most urban of any Preston County community. Local Energy Express decision makers along with respondents to the Participant Beliefs Survey at large therefore did not acknowledge the potential impact of geographic barriers and how they may contribute to educational risk.

Hiring Martha, the school's Title 1 reading teacher, as the site coordinator and leaving recruitment efforts to her had the effect of limiting the potential attendees to those children with whom she had the most direct contact. These children were not necessarily from the lowest income levels, but those who might benefit from additional reading instruction. The decision not to provide transportation made it inconvenient or impossible for the poorer families from more rural locales to attend. The rationale, then, explaining the characteristics of the population of attending children as having reading deficits, but not particularly in need of the food provided at the site became the idea that "It is not always the poorest families that have kids that can't read" (p. 222).

For her part, Martha tried to make the program appealing to all the children of Monarch Elementary school by presentations to classes and information flyers sent home. Nevertheless, the students she was most able to influence to actually register for and attend the program were those who received her help through Title 1. The recruiting process used in Monarch Energy Express may reflect either Martha's bias as a Title 1 reading teacher or her best efforts to reach children who could attend the program consistently and who would benefit from the program. The collaborative's decision not to provide transportation, however, implies that collaborative members felt they needed to narrow their definition of children at-risk as those with reading deficits rather than to expend the bulk of their resources to reach those with the greatest economic need.

In Monarch, recruitment for the program fell almost solely on Martha's shoulders. Although the school administration allowed Martha to use school materials to make flyers and teachers allowed Martha to make presentations to their classes, other teachers did not actively recruit children for the program. Although they were from the local community, mentors could not be involved with recruitment as they were not hired before the end of the school term. Nearby churches and community groups such as the Kiwanis Club or the Family Resource Network were not involved with building participation. Nor were families involved in targeting children for the program or assisted in arranging transportation to the site.

At the mesosystem level, relationships between groups of people are at issue. Recruitment efforts for programs such as Energy Express are affected by relationships between the program or school and the family of attending children. While it may "take a village to raise a child", it is good to remember that the African villages considered in this proverb were often largely composed of extended families. In Monarch Energy Express, the relationship with families was not that of an extended family. As the parents were only occasionally and minimally involved with the program, the relationship seemed to be somewhat distant, though not overtly flavored with negative emotions. In spite of the fact that the site personnel fulfilled all program responsibilities believed to involve 
parents and to establish reciprocal relationships, the site personnel clearly belonged to one group and most of the children and their families clearly belonged to another.

For the most part, efforts made by families of participating children were not recognized as building educational resilience. Energy Express site personnel often focused on the families of participating children as contributing significantly to the children's educational risk. Families were reported to "not value education" or to be more involved with personal problems than with their children's educational success, in spite of the fact that the parents provided transportation to the program, allowing Monarch to have the highest rate of attendance for any site that year. Families also provided the justification for decisions made by the collaborative about the setting of the first program and resources that the community would or would not provide. After all, "It is not always the poorest families that have kids that can't read" (p. 222).

Among Monarch site personnel, children were considered to be "at risk" because of family dysfunction or because families "don't value education." Case study data from the home visits and response to the Energy Express open house, however, did not support site personnel's preconception that families did not value education. Site personnel also credited Energy Express and, to some extent, schools with repairing the damages to children's academic skills and self-esteem caused by parents' supposed disregard of education. Martha and other county collaborative members very explicitly named literacy as "the way out" of all the factors that contributed to a child's risk status: poverty, family dysfunction, lack of social skills, and disabilities. Schools and programs from outside of the local community were considered to have the resources and the responsibility to make up the difference for children's academic deficits. Energy Express and schools were seen as the heroes or helpers, reaching down to "poor" children at-risk, to pull them up academically and socially through reading development.

Believing that families contributed to educational risk rather than to resilience seems to have been common to adult Energy Express participants responding to the Likert scale section of the Participant Beliefs Survey statewide, except, notably, parents. On the survey's ranking items, factors relating to family dynamics such as "Lack of home involvement/discipline" and "Dysfunctional family life" were both the most frequently nominated and the highest total point value given of all the factors believed to contribute to educational risk. On Likert scale items, most survey respondents_-mentors, site coordinators, community members--indicated their belief that "school success" variables were important to addressing educational risk. As a group, however, parents differed from other respondents for these survey items. Parents gave less weight to socioeconomic and school success variables than other respondents did, though they agreed that educational risk was a complex issue, influenced by the interaction of personal and school variables. Parents either did not value the "school success" components as much as other Energy Express respondents did or were not aware that Energy Express and school personnel valued these behaviors. Whatever the source of differences in perspective between adult Energy Express participants and parents of attending children about the educational risk of children, the differences themselves are likely to have formed a barrier to parent involvement and the site's recruitment efforts.

Although Preston County's Family Resource Network (FRN) supported and promoted Energy Express in Monarch, it was not involved in the site's recruitment efforts. Nor did Energy Express have strong bonds with other community-building groups and individuals in Monarch in their recruitment efforts for children at risk. In some 
cases, Energy Express even found itself in competition with other groups for participants and resources. Although community churches did not schedule vacation Bible schools at times that would compete with Energy Express and several ministers came in to read to the children, churches were not highly involved with the program. Children who were very active in other community activities—Little League or Scouts, for example—or who had planned family vacations were not particularly targeted for Energy Express participation. Individual neighborhood children and groups from a nearby day-care center were turned away when they wanted to use the school's playground while the Energy Express children were on the playground for non-competitive recreation. Early collaboration with these existing programs might have contributed to Energy Express' recruitment efforts and strengthened the community's commitment to the program.

Exosystem Variables: How Do Energy Express Participants Define And Prioritize Children's At-Risk Status?

At the exosystem state level, Energy Express sought to foster community development by providing nourishing meals to low-income children over the summer when they would not be in school to receive free or reduced breakfast or lunch. Federal monies were available to states that could demonstrate need for the assistance and present a plan to get food to those who needed it most. At the same time, federal initiatives were supporting "a range of research and development activities designed to improve the education of students at risk of educational failure because of limited English proficiency, poverty, race, geographic location, or economic disadvantage" (AtRisk Institute, online, 2001). Although only a tiny proportion of West Virginia's student population fit the definitions of educational risk because of limited English proficiency or race, the other three risk issues-poverty, geographic location and economic disadvantage—-were pervasive across the state. From the beginning, state level program developers related children's risk status to economic and geography issues and addressed those issues by seeking to provide essential sustenance over the summer.

Considering the rural nature of the state as contributing to nutritional as well as educational risk, Energy Express program developers realized the logistical difficulties and prohibitive costs for transporting large amounts of prepared food to remote locations in the state. They also theorized that it would be difficult for low-income families to get to food distribution sites twice a day. They therefore designed a program that would allow families to come for breakfast and stay through lunch at places accessible to local community members.

As state leaders considered how to make good use of the time children would be together during and between meals, they focused on another educational risk issue: literacy level of the state population. Program developers felt that incorporating simple literacy enrichment activities throughout the morning would help participating children to become more fluent readers and thus more empowered community members. Additional grants were written to employ college student mentors to work with small groups of children on literacy activities and to set an example of the value of education. Energy Express was born! (Personal communication, R. Phillips, 1999).

Energy Express developers at the state level, then, defined and prioritized the risk status for elementaryaged children in terms of: 1) Poverty or economic disadvantage, as demonstrated by lack of food or adequate nutrition over the summer; 2) geography, as a barrier to receiving economic and social support services; and 3) 
literacy and social deficits. Similarly across the state, Energy Express participants defined and prioritized risk factors for elementary-aged children through response to the Participant Beliefs Survey. The primary result of component analysis for the Participant Beliefs Survey defined the complexity of educational risk and prioritized using school resources to address the most severe risk factors. At its simplest, the term educational risk was believed to represent the interaction of a child's personal and familial deficits with the school's ability to ameliorate those deficits.

The second and third factors of the Participant Beliefs Survey confirmed statewide belief among Energy Express participants that socioeconomic status and school success contributed to children's educational risk or resilience. In the fourth factor describing Likert scale results, however, survey respondents differed from central program priorities in considering geography as a barrier affecting children's educational opportunities. Statewide survey responses indicated that educational opportunities for rural children were believed to be comparable to those for urban children. This result may indicate a sample bias. It is possible that survey respondents were so aware of difficulties in accessing resources in more rural locations or of financial constraints for providing transportation to Energy Express sites that they minimized the impact of the state's geography on their local program. Since most of the respondents were from West Virginia's relatively stable and rural population, they also may have had limited experience with the problems of inner city schools or a bias toward educational opportunities with which they were familiar.

Although Monarch site personnel implemented Energy Express precisely as it was designed to address educational risk issues, there is some question whether Preston County collaborative members and Monarch's site personnel defined and prioritized children's risk status in ways consistent with central program priorities. Although the children who attended Monarch Energy Express generally had literacy and social deficits, for the most part they were not the children with the greatest economic need. The program was not located in the Preston County community with the most pervasive climate of poverty or in the more isolated rural communities. Literacy activities were a strong component of the local program, yet social skills development was not considered to be a program goal, in spite of the abundance of discussion among site personnel about the socially unacceptable behavior of certain attending children.

Priorities of site leaders were also divided between serving children with the most severe needs and making the first year's program successful in the eyes of community leaders and potential supporters. Thus, priorities for Monarch's first year of Energy Express seem to have inverted state-level priorities. The local, de facto definition of children at risk included those with deficits in academic skills, specifically in reading, and those who had personal risk factors such as attention-deficit disorder, low self-esteem, or extreme shyness which resulted in social and behavioral problems. Family characteristics and values were also believed to contribute to a child's risk status, and schools and programs such as Energy Express were credited with providing remedies for children's educational and social deficits.

\section{Macrosystem Variables: What Do Program Participants Believe About Educational Risk And Resilience?}

At the macrosystem level, Energy Express participants in Monarch and those responding to the Participant Beliefs Survey statewide recognized educational risk and resilience as complex constructs, involving socioeconomic, familial, and personal factors. Survey results did not support central program developers' opinion that geographic 
barriers contributed to children's educational risk, but indicated that rural and urban children were believed to enjoy equivalent educational opportunities. The decision of Preston County's collaborative not to provide transportation to Monarch Energy Express apparently resulted from a similar belief. Survey respondents and local interviewees agreed that low socioeconomic status was one of the predictors of risk, yet did not see Energy Express as a program primarily designed to address poverty issues. Instead, Energy Express personnel, both in the local program and in the statewide survey, indicated a strong belief that, given the milieu of low socioeconomic status, children were most likely to be at risk due to personal or family characteristics or both.

Personal characteristics that defined a child's risk status included behavior problems, attention deficit/hyperactivity disorder, identified disabilities, and poor reading or social skills. Families were believed to contribute to educational risk because they do not value education or were so involved with family problems such as divorce, substance abuse, and infrequent or inadequate employment that they did not have an awareness of or time for their children's academic needs. Among site personnel and survey respondents, school success skills characteristic of middle class values--obeying rules, completing homework, being on time, and working to full capacity--were considered to be important to building personal resilience in children. Schools and programs like Energy Express which reinforced school success skills were seen as solutions for risk factors related to the child's or family's poor literacy skills or socialization.

For their part, parents and children did not believe that school success variables were as important as other survey respondents believed them to be in building children's resilience. The hidden curriculum of teacher-pleasing behaviors and school success, while important, was not as important to parents and children as to Energy Express site personnel. Interviewed parents and attending children in Monarch did not see children as at-risk, even when they noted concerns about children's behavior, reading deficits, or disabilities. In formal and informal discussions with parents and even some collaborative members, positive relationships were cited as more important than school success for building a child's future and personal resilience. This belief in the value of relationships is also characteristic of the beliefs of the larger American culture. As psychologist Nancy Molitor put it in the wake of the September 11 attacks, "Spending time with people you love creates a resilience" (Condor, January 13, 2002).

What was the source of the difference in perspective concerning children's educational risk or resilience between Energy Express personnel and the families of attending children? Considerations of race are unlikely to be the source of differences in results of the statewide Participant Beliefs Survey, since West Virginia has very little racial diversity in its population (U.S. Census Bureau, online, n.d.). In Monarch, collaborative members, the site coordinator, mentors who applied for service and all children eligible to attend the program were of the same race, so race issues are not likely to have played a part in county or site-level decisions or beliefs.

Response differences in Participant Beliefs Survey results could not be attributed to gender, and Preston County's collaborative included community leaders of both genders. Gender issues were never mentioned and did not seem to be present at the local case study site. In Monarch, one male mentor was considered to be successful while the other was considered to be unsuccessful or at risk. Although certain participating boys in Monarch were more likely than girls to be referred to Mrs. Lazarus for discipline, mentors of both genders referred those children to Mrs. Lazarus. 
The most plausible explanation for the source of difference in belief patterns between Energy Express personnel and the families of attending children is that the beliefs are based, at least in part, on the respective socioeconomic status of participants' families and Energy Express personnel responding to the survey. Although the majority of children attending Monarch's Energy Express received free and reduced lunch during the school year, collaborative members for Monarch's Energy Express, with the exception of the token parent, and the site personnel, with the possible exception of Matt, were all part of Preston County's professional middle class. In a county in which the unemployment rate is high and the school district is the largest employer, teachers are considered to be the more affluent and more powerful community members. Thus, the professional middle class school culture held sway as the dominant culture in Preston County, and families of children targeted for Energy Express participation were more closely aligned with the less empowered, but more pervasive low-income culture.

Discounting differences in socioeconomic status allowed collaborative members to proceed as if Preston County residents who were to benefit from the program shared their beliefs about the importance of education and of summer programs such as Energy Express. The local Energy Express implemented central program components and activities in keeping with school culture priorities and professional middle class values. The collaborative exerted little effort to assure that the local program incorporated parents' values or reflected Monarch's unique characteristics as a community. Thus, the local program assumed more of the characteristics of the Energy Express model and of the school than of the local community. It seemed that the local community was not valued as a resource for building educational resilience of children.

Collaborative members and site personnel consistently talked about families of low-income children as others not like themselves and their families because they "do not value education." When asked to consider individual cases, site personnel acknowledged the impact of socioeconomic and other factors on program attendance and children's academic achievement. Generally, however, site personnel maintained the belief that differences in values rather than socioeconomic constraints formed the basis for families' decisions not to send their children to Energy Express and for children's struggles in schools.

As Martha, three other collaborative members, and three of the mentors discussed their personal histories, it became clear that they were, or were becoming, first generation members of the professional middle class in their families. Through hard work in educational and social service fields and many hours of college credit, they had become the first in their families to move from the working class to their current positions. As Ehrenreich defines them, the professional middle class includes "all those people whose economic and social status is based on education, rather than on the ownership of capital or property" (1989, p. 12). Those collaborative members who were first generation participants in the professional middle class believed they had pulled themselves up by their bootstraps and expected community children to be able to do the same.

County leadership and site personnel's strong belief in literacy and education as the way for upward social and economic mobility developed, then, not just from their positions as educators and preservice educators, but from their personal life experience as resilient adults. Is it possible that some of their decisions about site priorities and their interactions with attending children from socioeconomically disadvantaged families reflected a belief that "if I can do it, anyone can?" Or did their decisions and interactions betray a "fear of falling” (Ehrenreich, 1989) from 
their recently acquired social status? This question is outside of the scope of this study, but is worth considering for future research in West Virginia or in topics related to socioeconomic status and class issues.

The decision not to provide transportation to the Energy Express site illustrates how differences in belief patterns associated with differing socioeconomic status affected the local program. That decision defined a subpopulation within the Monarch Elementary catchment area as those who would be targeted for EE participation. This sub-population included working class--but not necessarily welfare-dependent--children who were experiencing reading problems and could obtain transportation to the program. Although that program-management decision was based on budgeting constraints rather than a conscious effort to exclude poorer children, it reflected at least a lack of awareness of socioeconomic barriers faced by families the program was supposed to involve. At worst, the decision reflected a preservation of the status quo in the distribution of educational opportunities in the county by limiting more rural low-income families' involvement in the program.

\section{Summary}

Middle class professionals who participated as Energy Express collaborative members and site personnel believed that the term at-risk almost always characterized low-income children, especially those with poor social, behavioral and reading skills. Risk factors were most often considered to result from the personal or family characteristics of the child at-risk. Programs such as Energy Express, and, to some extent schools, were thought to mitigate risk factors and to build resilience by addressing the literacy of attending children. Geography of the region was not believed to provide a barrier to program attendance for the more rural low-income families in the state, though the cost of providing transportation was acknowledged as a budgeting constraint for local programs.

On the other hand, children attending Energy Express and their parents applied the term at-risk to people other than themselves, even when they acknowledged economic constraints and children's reading or behavior problems. Although potential geographic barriers to program participation were not mentioned either in interviews or in the Participant Beliefs Survey by parents or children, it remains to be seen whether geographic or economic constraints prevented the attendance of nonparticipants.

Numerous hypotheses for the differences between families' and program personnel's perspective about educational risk bear investigation beyond the parameters of this study. Children who participated in focus group interviews may have been over-eager to give the "right" answers to interview questions, or they may have been simply too young or naïve to be aware of their own, their family's, or their community's needs or risk factors. Perhaps interviewed children implicitly recognized socioeconomic class differences and avoided identification with lower income groups as they were striving for acceptance by peers or mentors that they perceived to be of more affluent socioeconomic classes. Or did they accrue enough protective factors from their families, the community, the school, their Energy Express experience or other sources to consider themselves to be resilient rather than at risk?

It is difficult to hypothesize about parents' beliefs about educational risk from this limited research effort. Of course, families relate with children in a greater variety of settings and for significantly more time than Energy Express or school personnel do, and therefore, have a broader understanding of their children's abilities and disabilities than is possible for Energy Express personnel (or teachers) to develop. Families are also concerned with an individual child's growth and development over a life-time rather than with the academic success of groups of 
children in six weeks or even a school year. Perhaps parents are more tolerant of or better able to judge a child's educational risk factors because they focus on the big picture rather than on the immediate concerns. It may be that families define success differently than the ways that most public schoolteachers define it.

In placing significantly less value on school success variables, it is possible that the hidden curriculum of school success simply remained hidden to parents, even in adulthood. If school success variables are part of the culture of public schools, but not of families in the community, then schools can no longer be considered a public institution. Either school professionals need to "cross borders" to make the schools more representative of or responsive to the culture and values of families in the community, or families have to make the effort to cross borders to succeed in school. It seems logical that the better informed and educated professionals should have the responsibility to cross borders.

Parents most likely represented the minority perspective of lower socioeconomic status groups on the Participant Beliefs Survey. It is possible that differences in socioeconomic status resulted in different assessments of the value of education in general. Education as the way to the professional middle class is a lengthy and costly process, and West Virginia in general and Preston County in particular does not currently offer many employment opportunities for middle class professionals. The county school district is the largest employer of professionals, yet even excellent teachers with years of experience and seniority are subject to losing their jobs or being transferred into less valued jobs due to cutbacks in the school system. In economic conditions such as these, young people from working-class or welfare-dependent families have little incentive for graduating from high school or for finding ways and means to attend and graduate from college. Perhaps we as education professionals need to reevaluate our assumptions about education as THE way to upward socioeconomic mobility within the community, and consider other possibilities for young people to become self-sufficient.

Future research efforts might seek to expand understanding about relationships between programs for lowincome families and the families themselves. Given the lack of transportation and the exceptional attendance rates of Monarch Energy Express, parents seemed open to new possibilities such as Energy Express and committed to their children's opportunities for development and socialization. However, the paucity of parent involvement in the program itself is of concern.

Limited parent involvement may reflect long-standing and almost invisible barriers between low-income families and schools. Schools and school professionals were not thought to build resilience in students, especially in low income children, because of the "unkindness of inflexibility." Programs such as Energy Express need to be aware of the downside of close association with institutions such as schools which are driven by schedules and measurable achievements rather than by relationships among participants and natural growth. The inflexibility of institutions, bureaucracies, and certain school professionals may provide substantial barriers to families' involvement with programs such as Energy Express.

\section{Implications}

As is typical in qualitative research, more questions have been discovered than have been answered in the course of this study (Pugach, 2001). Questions, observations and ideas which emerged during this investigation are 
discussed as implications for educational practice and teacher preparation in general, then, more specifically, for practice in Energy Express and special education.

\section{Implications for Educational Practice/Teacher Preparation}

Study results indicate that the impact of beliefs and social class differences on our understanding of educational risk and our interactions with children, families and educators is great! However, conspicuous in its absence from Participant Beliefs Survey results and in its superficial acknowledgement in the case study is the idea that study participants might identify school or teacher factors as contributing to educational risk. I consider this omission as evidence of a limitation to the study. We educators are a powerful group in West Virginia communities, and we maintain that position by accentuating our attributes and minimizing our foibles and inadequacies. As it is unlikely that we as educators never contribute to educational risk, I propose that we examine and continuously monitor our own beliefs about children, adults, and our current educational practices, in spite of lack of results from this study necessitating such self-examination.

Beliefs about children, adults, and education. Is education something we do to, for, or with children and families? This study supports existing research indicating that teacher expectations become "self-fulfilling prophecies" for children's risk or resilience. To the extent that our relationships with children and parents demonstrate unilateral and unequal relationships, we are likely to be limiting parents' involvement and unwittingly contributing to our own belief in the child's educational risk. To the extent that our relationships with children and families demonstrate reciprocity and parity, we are likely to be promoting educational resilience by our beliefs in the abilities of children and families.

Educators on the front lines of instruction, then, need consistent and regular opportunities for selfexamination of their beliefs and expectations for individual children. Are children able or disabled, dependent or independent, decision-making individuals or victims of circumstances? Do we subscribe to the prevailing educational folklore that low-income families don't value education? Do we hold fellow teachers and ourselves accountable for our stated expectations of children's potential? Do we see children, especially children from lowincome families, as resilient wildflowers, springing forth with unexpected brilliance, or as at-risk weeds, interrupting our plans by invading territory that we wished to reserve for others?

We also need opportunities for reflection about our own abilities, roles and responsibilities as adults and educators. Energy Express trains mentors to believe that they are making a difference in the lives of children. Is that belief just the AmeriCorps' party line, the idealism of youth, or are college student mentors really able to make a difference? What do we teachers believe about our own abilities to teach children? Can we make a difference in the life of any child or just in the lives of compliant, sociable, attractive children? Are we able to compensate for children's identified disabilities or less than ideal family situations or are the risk factors too great? If we believe the risk factors in a child's life are insurmountable, should we pass responsibility for the child to special programs or other agencies, or just accept the results for children as they are?

In higher education, we need to examine our own beliefs about children, teaching, education, and schools as institutional bureaucracies, especially as they relate to current realities of public school instruction. We specifically need to grapple with the constructs of individualized and child-centered education, which seem to be increasingly 
difficult to provide in public schools bound by layers of bureaucracy, institutionalization, and legal requirements. When teachers are faced with accountability for (often conflicting) presidential, congressional, legal, gubernatorial, legislative, teachers union, school district, community, administrative, and personal demands, is it possible to provide truly child-centered instruction? If it $i s$ possible, we need first to model student-centered instruction in higher education settings, and seek or develop school structures to facilitate provision of such instruction within the public schools. Then we need to teach pre-service teachers and assist in-service teachers to develop ways to prioritize and balance the requirements of their superiors with the needs of students to retain conscientious teachers and prevent teacher burnout. If it is not possible to develop student-centered instruction given current school structures, we need to be on the frontlines of developing new school structures or advocating for reasonable changes to make schools more person-centered and less institutional environments.

Awareness of class issues. In states or school districts where teacher employment opportunities are filled by seniority systems, newly-hired teachers are unlikely to be placed in well-stocked, state-of-the-art schools in affluent suburban communities. Other teachers opt for employment in programs such as Teach for America (DarlingHammond, 1994; Ness, 2001; Shapiro, 1993) that specifically place teachers in low-income schools. Thus, to be adequately prepared for the realities of these initial job placements, education majors, public school teachers, and administrators need to become aware of differences in priorities and values related to socioeconomic status of school personnel and the school's student population.

Instruction in socioeconomic class, race and gender issues should be included in higher education coursework for pre-service educators. Opportunities should be provided for education students to take the initiative in crossing (socioeconomic class) borders in resource-poor, low-income schools. Energy Express can provide some opportunities; more are needed in college and university preparation programs, especially in West Virginia and other relatively poor states. Practicum/student teaching placements should include settings such as University-related professional development schools in which education majors may observe and practice state-of-the-art instruction with relatively plentiful resources. However, to adequately prepare pre-service educators for likely initial employment placements, experiences in the public schools should also include work in lower-income, resource-poor schools, challenging pre-service teachers to relate with and meet the educational needs of students who face multiple factors of educational risk, including lack of educational resources.

As teachers, we have a choice about crossing borders of race, gender, family, community, and socioeconomic class differences to invite students, parents and communities to engage in education. Public school children do not - they are automatically expected to conform to the assigned school's culture because they are required to be in our domain. In what ways can teachers cross the borders to facilitate children's translation of the differences between the school's predominantly middle-class professional culture and their own family culture?

One expert on crossing social class borders, an executive director of a major food distribution network, suggests that "What matters is the quality of relationships with other people. Do people feel safe? Do people feel valued? Do people feel respected? Do people feel honored? Do people feel seen and heard?" (Erickson, 2002, p. 18). As an initial step, teachers at all grade levels should be allowed some time for reflection and professional discussion with colleagues about beliefs and social class issues, perhaps as part of the requirements for continuing 
education units. Kindergarten and elementary teachers would benefit from frequent visits to students' homes, communications with family members and informal meetings with parent groups. Mentoring programs in which middle school, junior high and high school teachers meet informally with students and families and commit to seeing and hearing their students as individuals should be promoted and refined. Ideally, the divisions between teachers and students or families would be replaced by mutual commitment to the child's future and well-being.

Mentoring relationships. Mentoring relationships are a feature of programs such as teacher preparation, 4$\mathrm{H}$, Scouts, nursing, teaching and ministerial studies. Thus, aspects of Martha's interactions and relationship with mentor Matt provide valuable insights into what works and what does not in mentoring relationships. Martha's methods in mentoring Matt—observing Matt, explaining to Matt, and modeling for Matt—are standard practice in teacher preparation programs. Are the methods we use to prepare future teachers "best practice" or does the definition of best practice need to move toward more reciprocal relationships and mutual accountability among teachers from the beginning of professional life? What would happen if we asked cooperating teachers to teach with practicum students rather than explain to or model for them? It seems that a co-teaching practicum would be especially beneficial in special education since special educators are being asked more frequently to come into general education settings to modify or deliver instruction in inclusive settings.

Even at the end of the Energy Express program in Monarch, Martha's methods with Matt more accurately demonstrated the greater than/lesser than relationships of superiors and apprentices than the reciprocity that is the basis of equal or collaborative relationships. In teacher preparation programs, university supervisors are supposed to move in their relationships with practicum students from their initial role as teachers and supervisors to professional peer relationships by the end of the practicum experience. Exactly how are teachers and practicum students supposed to recognize when the time has come or the change in relationship has occurred? Can or should every relationship move from supervisory to mentoring within a set amount of time?

Positive inter-relational behaviors. Programs such as Energy Express and teacher preparation depend to some extent on positive reciprocity between people for their success. However, the hidden curriculum of school success remains hidden, even in adulthood, for some teachers, mentors, and adults in general. If those who are supposed to help or teach children they believe to be at-risk do not understand how to verbalize and model school success variables, children--especially children with disabilities--are not likely to absorb these behaviors incidentally to become children of promise. Thus, school success constructs may need to be brought to the forefront of preparation-explicitly taught, modeled, discussed and practiced. Training in building positive relationships and relational behavior management is likely to be needed, in Energy Express, teacher preparation, and other programs based on mentoring relationships, to assist learners to overcome factors contributing to educational risk.

To some extent, children's struggles with the hidden curriculum of school success relate to awareness, knowledge and application of: 1) positive, pro-social, inter-relational behaviors, and 2) differences in the ways families and schools work. Families are smaller social units with some flexibility in choice of activity and use of time. Institutions such as schools, on the other hand, involve large numbers of people and limited flexibility in activity choice and use of time. Understanding the usefulness of pro-social behaviors and the differences between families and institutions can help children to experience school success. 
Helping children to develop school success behaviors may allow them to cross borders into the school's dominant culture, but will it help them develop the resilience needed throughout their school career and life? The concept of resilience subsumes the constructs of flexibility and versatility, yet public institutions such as schools are largely prevented from practicing and modeling these constructs. Multi-layered and complex educational hierarchies with competing demands on teacher time and methodology, rule-driven rather than relationship-driven systems and schedules, emphasis on teacher accountability and zero tolerance policies leave schools mired in bureaucracy, with few options for solving student problems and limited flexibility to consider mitigating circumstances. If we want West Virginia children (and perhaps the state in general) to develop "the ability to recover quickly from illness, change, or misfortune" (American Heritage Dictionary, 1982, p. 1051), we need to decide how this ability is to be developed, and by whom.

Certainly children we believe to be at-risk need a variety of methods and personal resources to solve problems they face, and several resources are available. What resources can or should schools provide to children atrisk? As educators, what responsibility do we have to children to teach those problem-solving methods and to promote awareness of available resources? Since other social service agencies are responsible for addressing some educational risk factors, how can we more effectively interface with them and continue their efforts in wrap-around services? Are families responsible for developing resilience? If so, how can we support their efforts? At the very least, we educators could become as vocal about praising families' resilience-building efforts as we are about blaming families for children's educational struggles because we believe they do not value education. Questions such as these are outside the scope of this research effort, and possibly fit more neatly in the domains of philosophers and policy-makers, but they definitely need to be considered as we seek to improve the lives of children.

Higher education priorities. During interviews, Preston County collaborative members almost uniformly indicated a strong belief that community members are resistant to change, and thus reluctant to welcome or support new programs or efforts such as Energy Express within the community. The community's resistance to change was attributed by various collaborative members to: lack of awareness of problems or of beneficial programs; lack of resources; valuing tradition more than innovation; contentment with the status quo of educational opportunities; or having "a lot of the old-timers ... who are against anything progressive" in positions of political power. A sign in grant-writer Lydia Constantine's office stated the dilemma in short: "If you do what you've always done, you'll get what you've always gotten" (p. 315)

Considering current economic conditions in West Virginia and the brain drain we experience because of the paucity of professional jobs available in the state (Herald-Dispatch, online, 2002) we in higher education also need to examine our values and practices for educating young West Virginians. If we are satisfied with what we have gotten from our efforts, then we need to maintain the status quo. However, if we are dissatisfied with educational results in our state, we may need to do things differently.

\section{Implications for Energy Express}

As a program targeting low-income children, Energy Express is well-conceived to address many different aspects of educational risk, providing adequate summer nutrition, engaging literacy activities, and the opportunity to develop supportive relationships with college student mentors. The fact that the program addresses many risk factors 
is especially valuable, given recent research that the number, rather than the type, of risk factors generates the child's personal risk (Gerber, 2001). However, since programs such as Energy Express take place in schools and utilize school personnel, they may be perceived as an extension of the school culture. Energy Express may have to distance itself from schools and the school culture to involve families and to reach the children for which it was intended. Energy Express supporters may become more explicit in helping children to overcome their risk factors by taking advantage of their resilience factors.

Crossing borders with families. By emphasizing home visits, community service, and parent representation on the collaborative, Energy Express has made a good effort to bridge the gap between schools and the community. However, additional efforts are needed if family involvement is desired for the program. Possibilities for bridging the gap between program goals and families include having greater parent representation on the collaborative, recruiting more parents than county officials to participate as readers and arts/crafts instructors, and emphasizing the unique, positive characteristics of the community in activities. The family theme week in particular could feature parents as guests to talk about activities that their families do together such as watching videos or certain television programs, fishing, gardening, hunting, and attending church or community sports events. Parents could also talk about how reading helps them in their daily life or in their jobs.

Crossing borders with the community. A place-based curriculum including the unique characteristics of the local community is one of the central features of the Energy Express program. In Preston County, however, collaborative members and site personnel seemed almost embarrassed to talk about the local community or to search for resources from within the community. Even the community's 30\% match for Energy Express was initially to come from an outside source-a grant that was not forthcoming (p. 311).

Energy Express collaboratives and site personnel might interrelate more actively with other community resources and programs to address the needs of the community's children. Churches, community recreational programs and neighboring children's facilities might be informed of the program's needs and time constraints so that they could contribute to the volunteer pool or at least arrange their schedules to avoid competing for resources. Church-based organizations might provide demonstrations or assistance with reading and with musical, dramatic or craft productions. Community recreational programs could provide demonstrations or schedule activities to meet the needs of Energy Express participants. Neighboring businesses might allow tours or provide an employee to talk about what they like about the community, criteria for available jobs, or their ideas to build the community.

Relationships with mentors. Interviewed parents, children and Preston County collaborative members believed that the opportunity to develop supportive relationships with college student mentors is perhaps the most valuable aspect of Energy Express. The impact of positive relationships on children's resilience should be utilized to full advantage. Mentors should be encouraged to talk with children about their own reasons for attending college and about challenges in their own lives that they have overcome to get to college. Mentors' relational skills should be valued more than their ability to teach reading skills, and relational skills should be explicitly taught in mentor training and modeled by site coordinators throughout the program.

The small groups, engaging activities, and enthusiastic college-student mentors in Energy Express provide an ideal setting for children to learn appropriate social and school success behaviors. Therefore, children believed to 
be at-risk due to identified disabilities, attention deficit/hyperactivity disorder, or poor development of social, behavioral and school success skills might be specifically targeted for Energy Express participation. Children with the most obvious need for development of pro-social behaviors should be assigned to mentors with the best relational skills, not necessarily the best academic or organizational skills. Mentors should talk about school success and appropriate social behaviors during Energy Express activities, sharing examples from their own lives in which demonstrating respect, maintaining self-control, and complying with rules or an authority's request had positive results.

Literacy immersion or direct skills instruction? Children attending Energy Express undoubtedly benefit from nutrition provided throughout the summer. Most increase in their overall reading abilities, their enjoyment of literacy experiences, and their relationships with mentors (Butera, 2001). Energy Express participants identified as receiving special education services during the school year demonstrate results on the program's evaluations similar to those for participants not so identified. However, in spite of the program's overall success, each year's evaluation effort reveals a subset of children (around 25\%) who do not demonstrate maintenance or growth in word recognition or reading comprehension, according to Woodcock-Johnson tests administered at the beginning and end of the program.

Energy Express evaluation efforts to date have not been able to discover differences between the Energy Express participant majority demonstrating at least reading maintenance and the minority that do not demonstrate reading level maintenance. Disability status, family income level, race and gender do not account for the difference in Woodcock-Johnson test results, nor has this research effort been able to discover factors accounting for the difference in reading. Future research efforts could provide insight into the differences between these two groups and inform Energy Express personnel, school administrators and educators about relative benefits of literacy immersion/whole language or skill-based instruction for certain students

\section{Implications for Special Education}

Behavior management. In the Participant Beliefs Survey, Energy Express site personnel statewide indicated their belief that within-child factors such as disabilities contribute strongly to educational risk. Of most concern across the state were behavior or conduct disorders. On the local level in Monarch, site personnel often categorized frequently misbehaving children as $\mathrm{AD} / \mathrm{HD}$ and children's behavior was an almost constant topic of mentor reflection. Site personnel seemed much more confident about working with children's academic needs than with behavior management for mentor groups or for individuals.

These results imply that special education should focus research efforts, development of educational practices and training of preservice teachers to classroom and behavior management concerns. Special educators should be well-prepared to manage behaviors of their own students and to provide inservice opportunities describing effective behavior management strategies or consultation for regular educators.

Identification of disabilities. Perhaps typically of community educators and adults, site personnel did not differentiate between academic or behavior problems as resulting from disability status, family environment, lower socioeconomic status or a child's willful behavior. On the other hand, special education law and philosophy demand that a child's need for intervention must be caused by an identifiable disability, and the disability must not be related 
to other educational risk factors such as socioeconomic status. In West Virginia especially, socioeconomic risk factors are so pervasive that it must be difficult indeed to identify children as having disabilities unrelated to their income status. The current system of identification of disabilities involves a time-consuming and costly process, which seems to be both artificial and not entirely accurate. So, children who struggle with academics or behavior but do not meet the criteria for a specific disability identification are excluded from special education services that would benefit them.

Energy Express personnel did not differentiate between causes of academic or behavior problems, but welcomed knowledge of effective behavior management and learning strategies. Pragmatically, students with behavior or academic problems in West Virginia would be better served by eliminating the involved identification and labeling process and focusing on the design of effective strategies to meet individual educational needs.

Interactions with family. Although special education laws mandate opportunities for parent involvement in their children's educational planning, parents—especially those from low-income homes or minority groups—have not been as engaged with the process as the law intended. Results from the Participant Beliefs Survey and case study themes indicate that Energy Express site personnel, perhaps typically of other adults or education professionals in the state, believe that family factors are largely responsible for educational risk. It is likely that this belief pattern represents a substantial barrier to parity in relations between educators and parents.

Methods for securing parent involvement with special education processes have been left to the imagination of local school districts or individual teachers, and innovative methods to enhance family involvement have not been widely adopted. Although Energy Express has not been satisfied with the level of parent participation achieved to date, the program is experimenting with methods to increase parent involvement. Special education should watch for positive trends and results from Energy Express efforts, and consider adoption of Energy Express methods to achieve more equitable and reciprocal relationships with parents.

Exclusion. If factors inherent within the child or his/her family are to blame for a child's at-risk status, mentors or teachers cannot be held accountable for poor achievement. Responsibility for children's learning (or blame for their lack of learning) then must be transferred to others who have some special knowledge, wisdom, curricula, setting or at least monies for empowerment, such as special education or Title 1. Indeed, these thought patterns represent the philosophy that led to the provision of special education and Title 1 in the first place.

Unfortunately, the downside of that same philosophy is that it leaves teachers feeling inadequate to develop high achievement in children with risk factors in their lives. Although many schools include the idea that "Every child can learn" in their mission statements, adherence to that mission statement does not often appear in practice. Thus, even when children with disabilities are physically included in instructional groups or classrooms, they may be excluded from the high expectations teachers have of other children.

The implication for special education is that we need to be aware of, monitor, and adjust our own beliefs and attitudes about children with disabilities and their families. We may need to go the second mile with children and families to gain the appropriate education we desire for them, whether it is situated in the regular or the special education setting. 
Inclusion. The concept and practice of inclusion of students with disabilities in school settings has been debated hotly in recent years. Inclusion of children with disabilities in other settings has not drawn nearly so much consideration, though children typically spend over two-thirds of their time outside of school. Thus, the experience of Energy Express site personnel can be instructive in considering questions related to inclusion of students with disabilities in non-school or extracurricular programs.

Over the history of Energy Express, the proportion of children with identified disabilities attending the program each summer has been comparable to the proportion of students with disabilities in the host schools. Furthermore, children with disabilities are fully included in all Energy Express activities throughout the program day. Though most of the children included in Energy Express have had only mild disabilities, in some instances children with more severe disabilities have also participated fully in the program with extra support from family members or school personnel.

Should schools make more efforts to include students with disabilities in extracurricular programs? In what ways might children with disabilities be specifically included or accommodated in various public programs? How might children with disabilities be more readily included in private pre-schools, 4-H, scouting, church groups, community sports, music groups, or plays?

Current thinking in higher education and among West Virginia school districts is that teachers require specialized training to work with students with disabilities. Can or should college student mentors be expected to include children with pronounced disabilities in their mentor groups? Can we expect college students serving as mentors to make appropriate accommodations for students with disabilities without any additional training? In what ways should college students be trained, what supports should be provided, and what modifications or accommodations can reasonably be made to include children with disabilities? As they continue to grapple with the inclusion of children with disabilities in local Energy Express programs, Energy Express leaders will be able to serve as examples of inclusive practices for other short-term programs and education professionals.

\section{Conclusion}

At least part of the success of Energy Express is due to mentors' belief that they can make a difference in the lives of children they spend time with, even without specialized knowledge, extensive teaching experience, or an abundance of instructional resources. Is that belief as strong among teachers with years of experience and/or with specialized knowledge of disabilities? How do teacher's beliefs about their personal efficacy affect their perceptions of children with disabilities, their engagement with students, their relationships with parents, and their use of methods to motivate students? Such questions are outside the realm of this research effort, but are appropriate pursuits for future research efforts.

Time spent and books read during the course of this research project have allowed me to examine my own assumptions and beliefs about educational risk, socioeconomic class, and disability issues in the context of Energy Express. The effort involved in seeking understanding of these issues and discussions with various committee members and other professionals have expanded my awareness of the concerns facing West Virginia policy makers, educators, families, and children believed to be at-risk who may very well surprise us by their resilience. I have come to believe, more than ever before, that what we believe about children and expect from them is likely to come 
to pass. Therefore, as Marva Collins says, "The first thing we are going to do in here, children ... is an awful lot of believing in ourselves" (1990, p. 22). May we ever expend ourselves, believing in children and helping them to believe in themselves. 
Please enjoy a poem shared with me by a consummate education professional and friend, Jeanie Dotson of Dunbar Middle School, Fairmont, West Virginia, in an e-mail dated March 17, 2002.

Mud puddles and dandelions!

When I look at a patch of dandelions, I see a bunch of weeds that are going to take over my yard. My kids see flowers for Mom and blowing white fluff you can wish on.

When I look at an old drunk and he smiles at me, I see a smelly, dirty person who probably wants money and I look away.

My kids see someone smiling at them and they smile back.

When I hear music I love, I know I can't carry a tune and don't have much rhythm so I sit self-consciously and listen. My kids feel the beat and move to it. They sing out the words. If they don't know them, they make up their own.

When I feel wind on my face, I brace myself against it. I feel it messing up my hair and pulling me back when I walk.

My kids close their eyes, spread their arms and fly with it, until they fall to the ground laughing.

When I pray, I say thee and thou and grant me this, give me that.

My kids say, "Hi God! Thanks for my toys and my friends. Please keep the bad dreams away tonight. Sorry, I don't want to go to Heaven yet. I would miss my Mommy and Daddy."

When I see a mud puddle I step around it. I see muddy shoes and dirty carpets.

My kids sit in it. They see dams to build, rivers to cross and worms to play with.

I wonder if we are given kids to teach or to learn from?

No wonder God loves the little children!!

"Enjoy the little things in life, for one day you may look back and realize they were the big things."

I wish you mud puddles and dandelions! 


\section{References}

Allison Davis. (No date). In Stamp on Black History [Online]. Available: http://library.advanced.org/10320/Davis.htm [1999, June 12].

American heritage dictionary (2nd. ed.). (1982). Boston: Houghton Mifflin Co.

American Psychological Association. (2001). Publication manual of the American Psychological Association ( $5^{\text {th }}$ ed.). Washington, DC: Author.

Anderson, L. W. \& Pellicer, L. O. (1990). Synthesis of research on compensatory and remedial education. Educational Leadership, 48(9), 10-16.

Anderson, L. W. \& Pellicer, L. O. (1993). A new lease on learning. The American School Board Journal, $\underline{180}(6), 27-30$.

At-Risk Institute. (2001). The National Institute on the Education of At-Risk Students (At-Risk Institute). The U. S. Department of Education Office of Educational Research and Improvement (OERI). Retrieved March 18, 2001, from http://www.ed.gov/offices/OERI/At-Risk/

Babbie, E. (1990). Survey research methods ( $2^{\text {nd }}$ ed.). Belmont, CA: Wadsworth Publishing Co.

Behrman, R. E. (Ed.). (1997). Statement of purpose. In The future of children: Children and poverty, 7(2), inside front cover.

Bray, M. \& Thomas, R. M. (1995). Levels of comparison in educational studies: Different insights from different literatures and the value of multilevel analyses. Harvard Educational Review, 65(3), 472-490.

Press.

Bronfenbrenner, U. (1979). The ecology of human development. Cambridge, MA: Harvard University

Bronfenbrenner, U. (1992). Contexts of child rearing: Problems and prospects. Child and Youth Care Administrator, 5(1), 59-64.

Brown, D. W. \& McIntire, W. G. (1995). Leadership in rural special education. Rural Special Education Quarterly, 14(2), 17-24.

Brown v. Board of Education, 347 U.S. 483 (1954).

Bureau of Business and Economic Research, West Virginia University. (1998). Preston County Data Profile, 1998 [Data file]. Available from Bureau of Business and Economic Research Web site, http://www.be.wvu.edu/serve/bureau/online/cdp1998/preston.pdf

Butera, G. (2001). Energy Express evaluation 2001. Morgantown, WV: West Virginia University.

Butera, G. (1998). Energy Express evaluation 1998. Morgantown, WV: West Virginia University.

Butera, G., Belcastro, R., Friedland, B., Henderson, J., Jackson, C., Klein, H., et al. (1996). Suspension, discipline, and disabilities: Perspectives from practice. Special Education Leadership Review, 77-89.

Butera, G., Bonnett, B., McMullen, L., Pae, H., Richason, D. (1999). Energy Express evaluation, 1999. Morgantown, WV: West Virginia University.

Butera, G. \& Dempsey, V. O. (1999). Kiwis and kids, communities and connections: The lessons of Energy Express on bridging policy and community discourses. Journal of Community Psychology, 27(5), 599-614. 
Butera, G., McMullen, L., Phillips, R., Webb-Dempsey, J. \& Dempsey, V. (1998, April). Building community on behalf of West Virginia schoolchildren and their families: Energy Express. Paper presented for American Educational Research Association Annual Meeting, San Diego.

Butera, G., McMullen, L., \& Phillips, R. (2000). Energy Express: Connecting communities and intervention on behalf of schoolchildren in West Virginia. Journal of Research in Rural Education, 16(1), 30-39.

Butera, G., Phillips, R., Harper, S. \& Pae, H. (1999, April). The lessons of Energy Express for service learning. Paper presented for American Educational Research Association Annual Meeting, Montreal.

Carnahan, S. (1994). "Preventing school failure and drop-out." In Risk, resilience \& prevention: Promoting the well-being of all children, R. J. Simeonsson, ed. Baltimore: Paul H. Brookes Publishing Co. 103-123.

Carr, E. (1994). Emerging themes in functional analysis of problem behavior. Journal of Applied Behavior Analysis, 27, 393-400.

Chesebro, J. W. (1992). Communication apprehension and self-perceived communication competence of at-risk students. Communication Education, 41(4), 345-360.

Chubb, J. E., \& Moe, T. M. (1990). Politics, markets and American schools. Washington, DC: The Brookings Institution Press.

Collins, M. \& Tamarkinc, C. (1990). Marva Collins' way. New York: Jeremy P. Tarcher/Putnam.

Condor, B. (2002). Not as many Americans worry now. Chicago Tribune. Reprinted in The Dominion Post, (2002, January 13), p. 3-E.

Converse, P. E. (1964). The nature of belief systems in mass publics. In D. E. Apter (Ed.). Ideology and discontent (pp. 206-261). New York: Free Press of Glencoe.

Danforth, S. \& Rhodes, W. C. (1997). Deconstructing disability: A philosophy for inclusion. Remedial and Special Education, 18(6), 357-366.

Daniels, V. I. \& Vaughn, S. (1999). A tool to encourage "best practice" in full inclusion. Teaching Exceptional Children, 31(5), 48-55.

Darling-Hammond, L. (1994). Who will speak for the children? How "Teach for America" hurts urban schools and students. Phi Delta Kappan, 76(1), 21-34.

DeYoung, A. J. \& Lawrence, B. K. (1995). On Hoosiers, Yankees and Mountaineers. Phi Delta Kappan, 77(2), 104-112.

Dillman, D. A. (1978). Mail and telephone survey: The total design method. New York: Wiley \& Sons.

Donmoyer, R. \& Kos, R. (1993). At-risk students: Portraits, policies, programs, and practices. Albany, NY: State University of New York.

Education of All Handicapped Children Act of 1975, 20 U.S.C. § 1400 et seq.

Energy Express. (2001). Purpose. [Online]. Available: http://www.ext.wvu.edu/nrgxpress/ [2002, May 10].

Energy Express site application. (1999). Morgantown, WV: West Virginia University Extension, Energy Express. Publishers.

Ehrenreich, B. (1989). Fear of falling: The inner life of the middle class. New York: HarperCollins 
Erickson, J. (March, 2002). The up side. Guideposts, 62(1), 18.

Fish, L. J. (1988). Methods, plainly speaking: Why multivariate methods are usually vital. Measurement and Evaluation in Counseling and Development (21), 130-137.

Fowler, F. J. (1988). Survey research methods: Applied social research methods series, vol. 1. Newbury Park, CA: Sage Publications.

Friend, M. \& Cook, L. (1992). Interactions: Collaboration skills for school professionals. White Plains, NY: Longman.

Gerber, M. M. (2001). The essential social science of behavioral disorders. Behavioral Disorders Journal of the Council for Children with Behavioral Disorders, 27(1), 12-20.

Glesne, C. \& Peshkin, A. (1992). Becoming qualitative researchers: An introduction. White Plains, NY: Longman.

Glickman, C. D. (1993). Renewing America's schools: A guide for school-based action. San Francisco: Jossey-Bass, Inc. Publishers.

Gonzalez-Balado, J. L. \& Playfoot, J. N. (Eds.). (1989). My life for the poor: Mother Teresa of Calcutta. New York: Ballentine Books.

Gresham, F. M., Watson, T. S. \& Skinner, C. H. (2001). Functional behavioral assessment: Principles, procedures, and future directions. The School Psychology Review, 30(2), 156-172.

Gutek, G. L. (1991). Thomas Jefferson: Advocate of republican education. In Cultural foundations of education: A biographical introduction (pp. 148-171). New York: MacMillan.

Hammersley, M. \& Atkinson, P. (1995). Ethnography: Principles in practice. New York: Routledge.

Herald-Dispatch. (2002). Home for good. [Online]. Available: http://www.wvhomeforgood.org/ [2002, May 20].

Heclo, H. H. (1997). Values underpinning poverty programs for children. The Future of Children: Children and Poverty, 7(2), 141-148.

Hirsch, E. D. (1996). The schools we need and why we don't have them. New York: Doubleday.

Hixson, J. \& Tinzmann, M. B. (1990). Who are the at-risk students of the 1990s? [Online]. North Central Regional Educational Laboratory. Available: http://www.ncrel.org/sdrs/areas/rpl_esys/equity.htm [1999, May 8].

Individuals with Disabilities Education Act. (1998). 20 U.S.C.S. sections 1400 et seq.

Jefferson, T. (1818). Correspondence to M. A. Jullien. [On-line]. Available: http://www.geocities.com/Athens/6529/notebook/jefferson_quotes.html [1999, May 5].

Jefferson, T. (1818). Report for University of Virginia. [On-line]. Available: http://www.geocities.com/Athens/6529/notebook/jefferson_quotes.html [1999, May 5]. Inc.

Keppel, G. (1991). Design and analysis: A researcher's handbook. Englewood Cliffs, NJ: Prentice-Hall,

Ladd, G. W., Birch, S. H., \& Buhs, E. S. (1999). Children's social and scholastic lives in kindergarten: Related spheres of influence. Child Development, 70, 1373-1400. 
Lewit, E. M., Terman, D. L. \& Behrman, R. E. (1997). Children and poverty: Analysis and recommendations. In The Future of Children, 7(2), 4-24.

Locke, L. F., Spirduso, W. W., \& Silverman, S. J. (1993). Proposals that work: A guide for planning dissertations and grant proposals (3rd ed.). London: Sage Publications.

Lofland, J. \& Lofland, L. H. (1995). Analyzing social settings: A guide to qualitative observation and analysis. (3rd. ed.). Belmont, CA: Wadsworth Publishing Company.

Lombardi, T. P., Odell, K. S. \& Novotny, D. E. (1990). Special education and students at risk: Findings from a national study. Rural and Special Education 12,(1), 56-62.

Litwin, M. (1995). How to measure survey reliability and validity. Thousand Oaks, CA: Sage Publications, Inc.

Macaluso, A. M. (1996). Allison Davis and the historical development of his sociological concepts: "Cultural Deprivation" and "Compensatory Education". [On-line]. Abstract from: Dissertation Abstracts International On-line. April 15, 1999. Accession No: AAI9623436. Martin's Press.

Maeroff, G. I. (1998). Altered destinies: Making life better for schoolchildren in need. New York: St.

Malouf, D. B. \& Schiller, E. P. (1995). Practice and research in special education. Exceptional Children, $61,414-424$.

Mann, H. (1969). Lectures on education, reprint of the 1855 edition. New York: Arno Press.

March, J. G. \& Olsen, J. (1988). The uncertainty of the past: Organizational learning under antiquity. In J. G. March, Decisions and organizations (pp. 335-358). New York: Basil Blackwell.

McGrew, K. S., Algozzine, B., Ysseldyke, J. E., Thurlow, M. L., \& Spiegel, A. N. (1995). The identification of individuals with disabilities in national databases: Creating a failure to communicate. The Journal of Special Education, 28(4), 472-487.

McLesky, J. \& Henry, D. (1999). Inclusion: What progress is being made across states? Teaching Exceptional Children, 31(5), 56-62).

McMillan, J. H. (1992)._A qualitative study of resilient at-risk students: Review of literature (Report No. UD030698). Richmond, VA: Metropolitan Educational Research Consortium. (ERIC Document Reproduction Service No. 389 779)

McMillan, J. H. \& Reed, D. F. (1994). Resilient at-risk students: Student views about why they succeed. Journal of At-risk Issues, 1(2), 27-33. [Online abstracts] Available: http://www.dropout prevention.org/AtRisk/Fall94.htm [1999, May 10].

McMillan, J. H. \& Schumacher, S. (1997). Research in education: A conceptual introduction (4th ed.). New York: Longman.

McMillan, J. H. \& Schumacher, S. (1999). Research in education: A conceptual introduction (5th ed.). New York: Longman.

Miles, M. B. \& Huberman, A. M. (1984). Drawing valid meaning from qualitative data: Toward a shared craft. Educational Researcher, 13(5), 20-30. 
Mink, P. T. (1993). Children's initiatives in the budget reconciliation. Congressional Record, Daily ed., 29 Jul 1993, p. H5507-5516.

Montague, M. \& Rinaldi, C. (2001). Classroom dynamics and children at risk: A follow-up. Learning Disability Quarterly, 24(2), 75-83.

National Center for Education Statistics. (1990). Statistics of the state school systems. U.S. Bureau of Education. Washington, D.C.: Author.

National Commission on Excellence in Education. (1983, April). A nation at risk: The imperative of educational reform. [Online]. Washington, D. C.: U. S. Government Printing Office. Available: http://www.ed.gov/pubs/NatAtRisk/index.html [1999, May 5].

Nelson, J. R., \& Roberts, M. L. (2000). Ongoing reciprocal: Teacher-student interactions involving disruptive behaviors in general education classrooms. Journal of Emotional and Behavioral Disorders, 8, 27-37.

Ness, M. (2001). Lessons of a first-year teacher. Phi Delta Kappan, 82(9), 700-701.

New York State Education Department. (1992). Rural education issues and strategies. New York.

Noblit, G. W. \& Dempsey, V. O. (1996). The social construction of virtue: The moral life of schools. Albany, NY: The State University of New York Press.

O’Hare, W. P. (1998). Making KIDS COUNT. Statistical Bulletin, 79 (3), pp. 2-7.

Pae, H. (1999). Effects of faculty senate's site-based management practice on restructuring schools to facilitate inclusion. Unpublished doctoral dissertation. Morgantown, WV: West Virginia University.

Pallas, A. M., Natriello, G., \& McDill, E. L. (1989). The changing nature of the disadvantaged population: Current dimensions and future trends. Educational Researcher, 17-22. Co.

Payne, R. K. (1998). A framework for understanding poverty (Rev. ed.). Highlands, TX: RFT Publishing

Peck, C. A. (1993). Ecological perspectives on the implementation of integrated early childhood programs. In C. A. Peck, S. L. Odom, \& D. D. Bricker (Eds.), Integrating young children with disabilities into community programs: Ecological perspectives on research and implementation. (pp. 3-15). Baltimore: Paul H. Brookes Publishing.

Pugach, M. (2001). The stories we choose to tell: Fulfilling the promise of qualitative research for special education. Exceptional Children, 67(4), 439-455.

Rahall, N. J. (1990). Early Childhood Education and Development Act of 1990. Congressional Record. Daily ed., 18 Apr 1990, p. E1060-1061.

Ralph, J. (1989). Improving education for the disadvantaged: Do we know whom to help? Phi Delta Kappan, 70, 395-401.

Richardson, V., Casanova, U., Placier, P. \& Guileful, K. (1989). School children at-risk. Philadelphia: Falmer Press.

Richardson, V., \& Colfer, P. (1990). Being at-risk in school. In J. L. Goodlad \& P. Keating, (Eds.), Access to Knowledge: An Agenda for Our Nation's Schools. (ERIC Document Reproduction Service No. ED337509). 
Sax, G. (1979). Foundations of educational research. Englewood Cliffs, NJ: Prentice-Hall, Inc.

Shapiro, M. (1993). Who will teach for America? (ERIC Document Reproduction Service No. ED376146).

Shonkoff, J., Hauser-Cram, P., Krauss, M. W. \& Upshur, C. (1992). Development of infants with disabilities and their families: Implications for theory and service delivery. Monographs of the Society for Research in Child Development, 57(6, Serial No. 230).

Simeonsson, R. J. (1994). Risk, resilience \& prevention: Promoting the well-being of all children. Baltimore: Paul H. Brookes Publishing Co.

Skinner, B. F. (1953). Science and human behavior. New York: Free Press.

Skrtic, T. M. (1991). The special education paradox:Equity as the way to excellence. Harvard Educational Review, 61(2), 148-206.

Slavin, R. E. \& Madden, N. A. (1989). What works for students at risk: A research synthesis. Educational Leadership, 46(2), 4-13.

Smith, R. C., \& Lincoln, C. A. (1988). America's shame, America's hope: Twelve million youth at risk. Chapel Hill, NC: MDC, Inc.

Smith, T. E. C. (1998). Introduction to the special series. Remedial and Special Education, 19(4), 194-195.

Sontag, J. C. (1996). Toward a comprehensive theoretical framework for disability research: Bronfenbrenner revisited. The Journal of Special Education, 30(3), 319-344.

Spring, J. (1990). The American school, 1642-1990: Varieties of historical interpretation of the foundations and development of American education. (2nd ed.2.). New York: Longman.

SPSS Base 9.0 Applications Guide. (1999). Chicago: SPSS Inc.

Swadener, B. B. \& Lubeck, S. (Eds.). (1995). Children and families "at promise": Deconstructing the discourse of risk. Albany, NY: State University of New York.

Swanson, M. S. (1991). At-risk students in elementary education: Effective schools for disadvantaged learners. Springfield, IL: Charles C. Thomas Publishers.

Thompson, B. (1991). Methods, plainly speaking: A primer on the logic and use of canonical correlation analysis. Measurement and Evaluation in Counseling and Development (24), 80-93.

Turnbull, A. P., Turnbull, H. R., Shank, M. \& Leal, D. (1995). Exceptional lives: Special education in today's schools. Columbus, OH: Merrill.

U.S. Census Bureau. (No date). American Factfinder. Available:

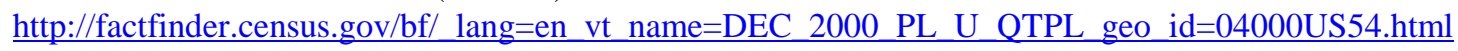

U.S. Centers for Disease Control and Prevention. (1996). State-specific rates of mental retardation--United States, 1993. Morbidity and Mortality Weekly Report, 45(3), 26 Jan 1996.

U.S. Department of Education. (1990). To assure the free appropriate public education of all handicapped children. Twelfth annual report to Congress on the implementation of the Education of the Handicapped Act, p. 100. Washington, D.C.: Government Printing Office.

Vaughn, S., Schumm, J. S., \& Sinagub, J. (1996). Focus group interviews in education and psychology. Thousand Oaks, CA: Sage Publications. 
Weiss, C. H. (1995). The four "I's" of school reform: How interests, ideology, information, and institution affect teachers and principals. Harvard Educational Review, 65(4), 571-592.

Westfall, A. \& Pisapia, J. (1994). At-risk students: Who are they and what helps them succeed? (Research Brief \#17). Richmond, VA: Metropolitan Educational Research Consortium. (ERIC Document Reproduction Service No. ED 411 341)

West Virginia KIDS COUNT. (1998). Children's Defense Fund: Washington, D.C.

White, L. M. (1995). Complacent teachers: Students at risk. Journal of At-risk Issues, 2(1). [Online abstracts]. Available: http://www.dropout prevention.org/AtRisk/Summer95.htm [1999, May 10].

Wiersma, W. (1995). Research methods in education: An introduction. (6th ed.). Boston: Allyn and Bacon.

Will, M. C. (1986). Educating children with learning problems: A shared responsibility. Exceptional Children, 411-415.

Wood, R. L. (1994). A different sort of handicap. National Review, 46(17), p. 60.

Woodcock, R. W., \& Johnson, M. B. (1989). Woodcock-Johnson tests of achievement, revised. Boston: Riverside Publishing Co.

Wulder, M. (1999). Principle components and factor analysis. In Multivariate Statistics: A Practical Guide, [Online]. Available: http://www.sbg.ac.at/geo/idrisi/geostat/tutorial/multivariate_statistics/pca_fa.html [2000, Jan. $1]$.

Yin, R. K. (1994). Discovering the future of the case study method in evaluation research. Evaluation practice, 15(3), 283-290.

Zedlewski, S. \& Giannarelli, L. (1997). Diversity among state welfare programs: Implications for reform. New Federalism: Issues and Options for States, series A (A-1).

Zibart, R. (2002, April 28). When the community is the classroom. Parade Magazine, p. 16. 
Appendix A

Cover Letter Requesting Survey Completion

June 15, 1999

Dear Site Coordinators,

As a member of the Energy Express evaluation team for the past several years, I have been granted permission by Dr. Ruthellen Phillips to perform my doctoral research on educational risk and resilience in the context of Energy Express. I would appreciate your help in completing the enclosed survey as part of my research. I have included 10 copies of a survey on beliefs about educational risk and resilience with your site evaluation materials in this envelope. Please complete one survey yourself, ask each of your mentors to complete the survey, and distribute the rest of the copies to volunteer coordinators, collaborative members, volunteers, parents or others who are involved with your Energy Express program. I can use as many as you can distribute with limited incovenience to yourself to find out more about educational risk and resilience among children in Energy Express. If you need additional copies, please feel free to request more or copy as many as you need. If possible, please complete the surveys as soon as possible and send them in with the weekly evaluation packet. Thanks for your help.

Sincerely,

Lynn McMullen

Doctoral student in special education 


\section{Appendix B}

1999 Participant Beliefs Survey

The statements on the following pages concern important mentoring and child issues which you either currently face or may face in the future. Your point of view regarding these issues is crucial to our understanding of Energy Express for future programming. Please indicate the extent to which you agree or disagree with each of the following statements by circling the appropriate number. The information that you provide will be treated confidentially. Please be sure you answer every question.

Site name:

Your role (please circle one): Site coordinator

Mentor

VISTA

Volunteer

Other (please describe):

Strongly disagree 1
Undecided or neutral 3

1. Children with attention deficit/hyperactivity disorder (AD/HD) fail to achieve their full potential.

2. Educational problems are associated with low-income homes.

3. Children with health problems are at-risk for educational failure.

4. Failure to complete homework limits educational achievement.

5. Teachers who share the cultural heritage of their students understand their students' needs better than other teachers do.

6. Urban communities provide more opportunities for children to learn than rural communities.

7. Children with two parents at home have an educational advantage.

8. Rural children face extra challenges in school.

9. Children with inexperienced teachers are educationally "at risk".

10. Children in small schools receive more individual instruction than children in large schools.

11. Children's appearance affects teachers' perceptions about their abilities.

12. Unless you give lots of practice, children with learning disabilities will fail to master educational concepts.

Agree Strongly agree

4

5

$\begin{array}{lllll}1 & 2 & 3 & 4 & 5\end{array}$

$\begin{array}{lllll}1 & 2 & 3 & 4 & 5\end{array}$

$\begin{array}{lllll}1 & 2 & 3 & 4 & 5\end{array}$

$\begin{array}{lllll}1 & 2 & 3 & 4 & 5\end{array}$

$\begin{array}{llllll}1 & 2 & 3 & 4 & 5\end{array}$

$\begin{array}{lllll}1 & 2 & 3 & 4 & 5\end{array}$

$\begin{array}{lllll}1 & 2 & 3 & 4 & 5\end{array}$

$\begin{array}{lllll}1 & 2 & 3 & 4 & 5\end{array}$

$\begin{array}{lllll}1 & 2 & 3 & 4 & 5\end{array}$

$\begin{array}{lllll}1 & 2 & 3 & 4 & 5\end{array}$

$\begin{array}{lllll}1 & 2 & 3 & 4 & 5\end{array}$


Strongly disagree

1
Disagree

2
Undecided or neutral 3
Agree

4
Strongly agree

5

13. Child abuse contributes substantially to risk of educational failure.

14. Children with excessive absences need extra help to succeed in school.

15. Children who lack opportunities to participate in activities such as 4-H, Little League or Scouts fail to achieve their full potential.

16. Children from urban areas are better prepared for academic activities than rural children.

17. Children in schools which lack instructional resources are at-risk of academic deficits.

18. Children with cognitive impairments are not as valued in the school as other students.

19. Children from families who move frequently are at-risk of educational failure.

20. Children from single-parent homes are at risk of educational problems.

21. Good students are often attractive children.

22. Children from middle income communities are easier to teach than children from low-income communities.

23. Children in small schools lack educational opportunities.

24. Having well-trained teachers assures children of academic success.

25. Children who have unidentified disabilities are at-risk of educational problems.

26. Children with behavior disorders do not follow instructions that would make them successful students.

27. Teachers who live in the community are more likely to help children after school than teachers who commute to school.

28. Children who attend neighborhood schools do better academically than children who are bussed to school.

\section{1}

2

3

4

5

1

2

2

3

\section{4}

5

1

2

2

3

4

5

1

2

3

4

5

1

2

2

3

1

2

3

4

5

5 
$\begin{array}{ccc}\text { Strongly disagree } & \text { Disagree } & \text { Undecided or neutral } \\ 1 & 2 & 3\end{array}$

29. Schools that have modern instructional technologies help students succeed in their education.

30. Children with poor personal hygiene are at risk for educational problems.

31. Children from low-income communities need more instructional help than children from other communities.

32. Good students are on time for school.

33. Educational problems are associated with incidents of child abuse.

34. Children who lack academic ability are often shy about participating in class.

35. Children with learning disabilities fail to achieve their full potential.

36. Children who participate in extracurricular activities do better in school than children who do not participate.

37. Children with attention deficit/hyperactivity disorder (AD/HD) are $t$ risk for educational problems.

38. Children who obey rules will be successful in school.

39. Children with cognitive impairments require lots of practice to master educational concepts.

40. Children from middle income homes are more "ready" to learn than children from low income homes.

41. Children with educational problems often have undiagnosed learning disabilities.

42. Children who lack a nutritious diet are at risk for educational problems.

43. Participation in activities such as 4-H, Scouts and Little League builds children's problem-solving abilities.

44. Completing homework is a hallmark of a good student.

45. Children with poorly-trained teachers are at risk of school problems.

Agree
4

Strongly agree

5
1

3

4

5

1

2

2

1

2

2

3

4

5

1

1

2

3

$\begin{array}{ll}4 & 5 \\ 4 & 5\end{array}$

2

3

5

1

2

3

1

1

2

1

2

1

1

$\begin{array}{lllll}1 & 2 & 3 & 4 & 5 \\ 1 & 2 & 3 & 4 & 5\end{array}$


Place a checkmark by the five factors that you think have the most effect in causing children to be "atrisk" for educational failure. Then number those five factors from 1 to 5 , with 1 having the most direct effect and 5 having the least direct effect. (Factors are listed in alphabetical order, for your convenience). Thank you!

\section{Absenteeism}

Attending a large school

Behavior or conduct disorders

Being a "Latch-key" child (a child staying home alone for extended periods)

Dysfunctional family life

Inadequate nutrition

Lack of community resources (libraries, medical care, Scouts, 4-H, Little League, etc.)

Lack of home involvement/discipline

Learning disabilities

Living in a rural area

Low-income family

Moving frequently during the school year

Parent's educational level

Poor health

Resource-poor schools

Single parent family

Undiagnosed disabilities

Other: (please list or describe)

Now we need to know just a bit about you!

\section{Site name:}

Your role (please circle one): Site coordinator

VISTA

Parent Volunteer

Other (please describe): 


\section{Appendix C}

Survey Response Means And Standard Deviations

Table C1

Overall Survey Response Means and Standard Deviations for 27 “Risk” Statements

\begin{tabular}{|c|c|c|c|c|}
\hline Item \# & Statement & $\underline{\mathrm{n}}$ & $\underline{\mathrm{M}}$ & $\underline{\mathrm{SD}}$ \\
\hline 1 & $\begin{array}{l}\text { Children with attention deficit/hyperactivity disorder (AD/HD) } \\
\text { fail to achieve their full potential. }\end{array}$ & 597 & 2.77 & 1.07 \\
\hline 2 & Educational problems are associated with low-income homes. & 599 & 2.88 & 1.15 \\
\hline 3 & $\begin{array}{l}\text { Children with health problems are "at risk" for educational } \\
\text { failure. }\end{array}$ & 601 & 3.17 & 1.05 \\
\hline 4 & Failure to complete homework limits educational achievement. & 602 & 3.78 & .94 \\
\hline 8 & Rural children face extra challenges in school. & 602 & 2.81 & .95 \\
\hline 9 & Children with inexperienced teachers are educationally at-risk. & 600 & 3.04 & 1.12 \\
\hline 12 & $\begin{array}{l}\text { Unless you give lots of practice, children with learning } \\
\text { disabilities will fail to master educational concepts. }\end{array}$ & 601 & 3.5 & .96 \\
\hline 13 & $\begin{array}{l}\text { Child abuse contributes substantially to risk of educational } \\
\text { failure. }\end{array}$ & 603 & 4.08 & .90 \\
\hline 14 & $\begin{array}{l}\text { Children with excessive absences need extra help to succeed in } \\
\text { school. }\end{array}$ & 604 & 3.98 & .737 \\
\hline 15 & $\begin{array}{l}\text { Children who lack opportunities to participate in activities such as } \\
\text { 4-H, Little League or Scouts fail to achieve their full potential. }\end{array}$ & 604 & 2.85 & 1.05 \\
\hline 17 & $\begin{array}{l}\text { Children in schools which lack instructional resources are at-risk } \\
\text { of academic deficits. }\end{array}$ & 600 & 3.54 & .896 \\
\hline 18 & $\begin{array}{l}\text { Children with cognitive impairments are not as valued in the } \\
\text { school as other students. }\end{array}$ & 599 & 2.91 & .99 \\
\hline 19 & $\begin{array}{l}\text { Children from families who move frequently are "at risk" of } \\
\text { educational failure. }\end{array}$ & 601 & 3.70 & .96 \\
\hline 20 & $\begin{array}{l}\text { Children from single-parent homes are at risk of educational } \\
\text { problems. }\end{array}$ & 600 & 2.87 & 1.03 \\
\hline 23 & Children in small schools lack educational opportunities. & 601 & 2.40 & 1.05 \\
\hline
\end{tabular}




\begin{tabular}{|c|c|c|c|c|}
\hline Item \# & Statement & $\underline{\mathrm{n}}$ & $\underline{\mathrm{M}}$ & $\underline{\mathrm{SD}}$ \\
\hline 25 & $\begin{array}{l}\text { Children who have unidentified disabilities are "at risk" of } \\
\text { educational problems. }\end{array}$ & 600 & 3.70 & .86 \\
\hline 26 & $\begin{array}{l}\text { Children with behavior disorders do not follow instructions that } \\
\text { would make them successful students. }\end{array}$ & 598 & 3.25 & .94 \\
\hline 30 & $\begin{array}{l}\text { Children with poor personal hygiene are at risk for educational } \\
\text { problems. }\end{array}$ & 600 & 2.90 & 1.00 \\
\hline 31 & $\begin{array}{l}\text { Children from low-income communities need more instructional } \\
\text { help than children from other communities. }\end{array}$ & 596 & 3.06 & .98 \\
\hline 33 & $\begin{array}{l}\text { Educational problems are associated with incidents of child } \\
\text { abuse. }\end{array}$ & 596 & 3.30 & .97 \\
\hline 34 & $\begin{array}{l}\text { Children who lack academic ability are often shy about } \\
\text { participating in class. }\end{array}$ & 601 & 3.78 & .91 \\
\hline 35 & $\begin{array}{l}\text { Children with learning disabilities fail to achieve their full } \\
\text { potential. }\end{array}$ & 598 & 2.84 & 1.04 \\
\hline 37 & $\begin{array}{l}\text { Children with attention deficit/hyperactivity disorder (AD/HD) } \\
\text { are at risk for educational problems. }\end{array}$ & 599 & 3.63 & .87 \\
\hline 39 & $\begin{array}{l}\text { Children with cognitive impairments require lots of practice to } \\
\text { master educational concepts. }\end{array}$ & 594 & 3.56 & .74 \\
\hline 41 & $\begin{array}{l}\text { Children with educational problems often have undiagnosed } \\
\text { learning disabilities. }\end{array}$ & 601 & 3.35 & .85 \\
\hline 42 & $\begin{array}{l}\text { Children who lack a nutritious diet are at risk for educational } \\
\text { problems. }\end{array}$ & 600 & 3.83 & .75 \\
\hline 45 & $\begin{array}{l}\text { Children with poorly-trained teachers are at risk of school } \\
\text { problems. }\end{array}$ & 599 & 3.85 & .84 \\
\hline
\end{tabular}


Table C2

Overall Means and Standard Deviations for 18 "Resilience" Statements

\begin{tabular}{|c|c|c|c|c|}
\hline Item \# & Statement & $\underline{\mathrm{n}}$ & $\underline{\mathrm{M}}$ & $\underline{\mathrm{SD}}$ \\
\hline 5. & $\begin{array}{l}\text { Teachers who share the cultural heritage of their students } \\
\text { understand their students' needs better than other teachers do. }\end{array}$ & 601 & 3.20 & 1.08 \\
\hline 6. & $\begin{array}{l}\text { Urban communities provide more opportunities for children to } \\
\text { learn than rural communities. }\end{array}$ & 600 & 2.70 & 1.06 \\
\hline 7 & $\begin{array}{l}\text { Children with two parents at home have an educational } \\
\text { advantage. }\end{array}$ & 601 & 3.24 & 1.12 \\
\hline 10 & $\begin{array}{l}\text { Children in small schools receive more individual instruction than } \\
\text { children in large schools. }\end{array}$ & 604 & 3.94 & .98 \\
\hline 11 & $\begin{array}{l}\text { Children's appearance affects teachers' perceptions about their } \\
\text { abilities. }\end{array}$ & 601 & 3.30 & 1.05 \\
\hline 16 & $\begin{array}{l}\text { Children from urban areas are better prepared for academic } \\
\text { activities than rural children. }\end{array}$ & 602 & 2.49 & .88 \\
\hline 21 & Good students are often attractive children. & 598 & 2.14 & 1.07 \\
\hline 22 & $\begin{array}{l}\text { Children from middle income communities are easier to teach } \\
\text { than children from low-income communities. }\end{array}$ & 601 & 2.48 & 1.02 \\
\hline 24 & $\begin{array}{l}\text { Having well-trained teachers assures children of academic } \\
\text { success. }\end{array}$ & 600 & 2.99 & 1.125 \\
\hline 27 & $\begin{array}{l}\text { Teachers who live in the community are more likely to help } \\
\text { children after school than teachers who commute to school. }\end{array}$ & 601 & 3.18 & 1.07 \\
\hline 28 & $\begin{array}{l}\text { Children who attend neighborhood schools do better } \\
\text { academically than children who are bussed to school. }\end{array}$ & 602 & 2.73 & .95 \\
\hline 29 & $\begin{array}{l}\text { Schools that have modern instructional technologies help students } \\
\text { succeed in their education. }\end{array}$ & 601 & 3.76 & .81 \\
\hline 32 & Good students are on time for school. & 600 & 3.09 & 1.06 \\
\hline 36 & $\begin{array}{l}\text { Children who participated in extracurricular activities do better in } \\
\text { school than children who do not participate. }\end{array}$ & 600 & 3.21 & 1.03 \\
\hline 38 & Children who obey rules will be successful in school. & 601 & 3.17 & .98 \\
\hline
\end{tabular}




\begin{tabular}{clccc}
\hline Item \# & Statement & $\underline{\mathrm{n}}$ & $\underline{\mathrm{M}}$ & $\underline{\underline{\mathrm{SD}}}$ \\
\hline 40 & $\begin{array}{l}\text { Children from middle income homes are more "ready" to learn } \\
\text { than children from low-income homes. }\end{array}$ & 602 & 2.76 & .99 \\
43 & $\begin{array}{l}\text { Participation in activities such as 4-H, Scouts and Little League } \\
\text { builds children's problem-solving abilities. }\end{array}$ & 600 & 3.89 & .75 \\
$44 \quad$ & Completing homework is a hallmark of a good student. & 601 & 3.51 & .99 \\
\hline
\end{tabular}


Appendix D

1999 Data Collection Schedule

Week of June 6: VISTA training in Charleston and Morgantown. Lynn attends with Gretchen and Ruthellen and conducts interviews.

Week of June 13: Mentor and site coordinator training at West Virginia Wesleyan. Lynn attends and presents information to site coordinators, interviews mentors and observes proceedings.

Week of June 20: Energy Express preparation week. Lynn makes first visit to the site to assure/interview site coordinator and gain access to the site. Observations of mentors preparing site and rooms, individually and collaboratively. Observations of the physical setting. Accompanied Ruth on home visits.

Week of June 28: Energy Express program actually starts. Two days visiting the site, meeting the mentors, VISTA, volunteers and children participating in the program. Dr. Butera visits site with me the first time (Wednesday). Observational data. Data collection focus on site participants--names, groups, characteristics, abilities, etc.

Week of July 5: Three days observation at the site. Preliminary interviews with site coordinator and selected mentors. Preliminary interviews with volunteers and VISTA. Data collection focus on site coordinator roles and responsibilities and child-mentor interactions.

Week of July 12: Three days observation at the site. Interviews with selected mentors, volunteers, and community collaborative members. Data collection focus on child-mentor and child-child interactions.

Week of July 19: Three days of observation at the site. Interviews with selected parents, community collaborative members and volunteers. Data collection focus on child-child interactions and volunteers' roles and responsibilities.

Week of July 26: Three days of observation at the site. Interviews with selected parents, community collaborative members and volunteers. Focus group interviews with the children. Data collection focus on children with disabilities. Attendance at (amazing) Open House and luncheon with the mentors at site coordinator's home.

Week of Aug. 2: Three days of observation at the site. Final interviews with selected parents, mentors, the site coordinator, community collaborative members and volunteers. Data collection focus on site coordinator-mentor interactions and final (closure) activities such as home visits. Attendance at end-of-program celebration for mentors at Morgantown restaurant. Attendance at end-of program picnic/field day for children. 


\section{Appendix E}

Interview Guide for Adult Energy Express Participants

Interview guide for adult participants (primary contacts, site coordinators, mentors, volunteers, VISTAs, building principals, etc.) from each case study site

Name: Site: Date:

"Hello. I am Lynn McMullen. I am gathering data for my dissertation about Energy Express. I feel your insight as a site coordinator (primary contact, community collaborative member, driving force behind the program) is crucial to understanding how it works. May I have about 45 minutes of your time to ask you a few questions? I would like to tape record our conversation to ensure accuracy when I am compiling data. I also need to make sure you understand that:

1. Your participation is entirely voluntary and you do not have to respond to every question.

2. Your responses will remain anonymous and confidentiality will be maintained.

1. Demographic data:

Tell me something about yourself (Probes: What is your position with Energy Express? How many years have you been in this role? Are you a community member or from another area? How long have you lived around here?)

1a. What do you do during the school year? (Probes: How long have you been doing that? What other jobs or positions have you had during your career? What is your educational background?)

2. Describe the type of student that will benefit the most from the Energy Express experience--the type for whom Energy Express is especially good.

3. Describe some children that you are really, really glad that they have come to Energy Express this year (and tell why).

4. Describe some children that you think should not necessarily be here (and tell why).

5. Describe some children that you know of who are not here, but you wish could have come. (Probe: What are some likely reasons they didn't get to attend EE this year?)

6. What did you do to recruit kids to come to EE? (Probes: What persons or what efforts have been the most helpful to you in targeting children? What classes or which persons do you get a good response rate from? Who doesn't really understand what Energy Express is, and makes outlandish suggestions of children who should come? Give me an example of this...)

7. How did you generate a waiting list to fill in for no-shows? How did you decide who to contact first?

8. How well do you think your recruitment efforts pulled in the children you would like to be able to come to Energy Express?

9. What are some alternative recruitment strategies or activities that you might like to try?

10. Once you know children are coming to Energy Express, how do you decide which children should be in which mentor groups? What are some of the things you think about when assigning a child to a certain group?

11. Some children who could have come to Energy Express do not sign up or show up. Why do you think this happens?

Thank you for taking your time to talk with me. I'm sure your insights will prove to be most helpful. 


\section{Appendix F}

Interview guide for focus group interviews with the children

Site:

Mentor:

Date:

First names and ages of focus group children:

Questions:

1. How many years have you attended EE here?

2. What was best about coming to EE this year? What did you like the best?

(Probes: The mentors? The food? The books? The activities? The site itself? The hours?)

3. What was not so great about coming to Energy Express this summer?

(Probes: The mentors? The food? The books? The activities? The site itself? The hours?)

4. What is Energy Express supposed to help you with? What is the program supposed to do for you?

5. Why do you think people decided to have Energy Express here?

6. What did you gain from coming to EE this year?

7. Tell me about some of your friends who didn't come to Energy Express that it would have been good for them to come. (Why would it have been good for them to come?)

8. Some of your friends from school probably didn't come to EE this year. What do you think are some reasons they didn't come?

9. What will you tell them about or show them that they'll be sorry they missed? 


\section{Appendix G}

Participant Beliefs Survey Factor Analysis

Table G

Factor and Item Loadings from the Factor Analysis of the Participant Beliefs Survey

Item

Factor (Proportion of variance accounted for; $\alpha$ factor reliability)

Loading

Factor 1: Personal/School Interactions $(13.9 ; \alpha=0.75)$

39 Children with cognitive impairments require lots of practice to master educational concepts.

25 Children who have unidentified disabilities are "at risk" of educational problems.

14 Children with excessive absences need extra help to succeed in school.

37 Children with attention deficit/hyperactivity disorder (AD/HD) are at risk for educational problems.

13 Child abuse contributes substantially to risk of educational failure.

45 Children with poorly trained teachers are at risk of school problems.

29 Schools that have modern instructional technologies help students succeed in their education.

34 Children who lack academic ability are often shy about participating in class.

Factor 2: Status_(13.1; $\alpha=0.76)$

22 Children from middle income communities are easier to teach than children from lowincome communities.

21 Good students are often attractive children.

40 Children from middle income homes are more "ready" to learn than children from low-income homes.

2 Educational problems are associated with low-income homes.

31 Children from low-income communities need more instructional help than children from other communities.

30 Children with poor personal hygiene are at risk for educational problems.

18 Children with cognitive impairments are not as valued in the school as other students. 
Factor 3: School success $(9.5 ; \alpha=0.67)$

38 Children who obey rules will be successful in school.

44 Completing homework is the hallmark of a good student.

24 Having well-trained teachers assures children of academic success.

35 Children with learning disabilities fail to achieve their full potential.

32 Good students are on time for school.

Factor 4: Urban/rural $(8.8 ; \alpha=0.71)$

6 Urban communities provide more opportunities for children to learn than rural communities.

$\begin{array}{lll}8 & \text { Rural children face extra challenges in school. } & .76\end{array}$

16 Children from urban areas are better prepared for academic activities than rural children. 


\section{Appendix $\mathrm{H}$}

Post Hoc Tests

Table H1

Tests of Between-Subjects Effects

\begin{tabular}{llcc}
\hline Source & $\begin{array}{l}\text { Dependent } \\
\text { Variable }\end{array}$ & F & Sig. \\
\hline Corrected Model & Full Scale (23 items) & 1.490 & .021 \\
& Factor 3 & 1.482 & .023 \\
Intercept & Factor 4 & 1.865 & .001 \\
NS & Full Scale (23 items) & 42865.284 & .000 \\
Role & Factor 4 & 5.071 & .007 \\
EW*NS & Full Scale (23 items) & 2.895 & .014 \\
\hline
\end{tabular}

Table H2

Tamhane's T2 Multiple Comparisons

\begin{tabular}{|c|c|c|c|c|}
\hline $\begin{array}{l}\text { Dependent } \\
\text { Variable }\end{array}$ & Fixed Factor (I) & Fixed Factor (J) & $\begin{array}{c}\text { Mean Difference } \\
\text { (I-J) }\end{array}$ & Sig. \\
\hline \multirow[t]{5}{*}{ Full Scale } & Site Coordinator & Parent & .1563 & .001 \\
\hline & & $\begin{array}{l}\text { Volunteer } \\
\text { Coordinator }\end{array}$ & .1381 & .005 \\
\hline & Mentor & Parent & $8.127 \mathrm{E}-02$ & .036 \\
\hline & Parent & Other & -.1326 & .003 \\
\hline & $\begin{array}{l}\text { Volunteer } \\
\text { Coordinator }\end{array}$ & Other & -.1144 & .016 \\
\hline \multirow[t]{2}{*}{ Factor 1} & Site Coordinator & Mentor & .1991 & .040 \\
\hline & Mentor & Other & -.1966 & .018 \\
\hline Factor 2 & Parent & Other & -.2018 & .017 \\
\hline \multirow[t]{3}{*}{ Factor 3} & Mentor & Parent & .3677 & .000 \\
\hline & & $\begin{array}{l}\text { Volunteer } \\
\text { Coordinator }\end{array}$ & .3254 & .000 \\
\hline & & Other & .3052 & .009 \\
\hline
\end{tabular}


Appendix I

Participant Beliefs Ranking Survey—Voluntary Responses

Table I

Other Responses Described

\begin{tabular}{|c|c|}
\hline Ranked & Description \\
\hline 3 & "Favoriteeism" \\
\hline 2 & Non-compassionate teachers \\
\hline 4 & Subject not taught in an interesting manner \\
\hline 3 & School environment not conducive to learning \\
\hline 4 & Lack of adult role models and support \\
\hline 5 & Abuse \\
\hline 5 & Burnt out teachers \\
\hline 5 & Child abuse \\
\hline 5 & Children get "labeled" by teachers \\
\hline 5 & Labels put on children by older siblings \\
\hline 5 & Lack of future vision \\
\hline 5 & Lack of good teaching \\
\hline 5 & Lack of parental involvement in developing a reading environment \\
\hline 5 & Lack of teaching of strong moral/social behavior \\
\hline 5 & Living in a housing project \\
\hline 5 & Lowered expectations for behavior and academics both at home and school \\
\hline 5 & Not doing work \\
\hline 5 & Poor hygiene \\
\hline 5 & Poor principal \\
\hline 5 & Poor teachers \\
\hline 5 & Teachers \\
\hline 5 & Teachers who are not doing their jobs \\
\hline 5 & Uncaring teachers \\
\hline 5 & Unenthusiastic teachers/administrators \\
\hline
\end{tabular}




\section{Lynn McMullen \\ 1617 Edgeway Drive \\ Fairmont, WV 26554 \\ (304) 367-1369}

\section{PERSONAL DATA}

Date of Birth: Sept. 17, 1954

Marital Status: Married

Three Children: Joel, 17

Cara, 13

Ian, 7
SSN\# 460-08-5801

Husband's Name: Bryan K. McMullen

\section{EDUCATION}

Spring, 2002

1994 to present

1993

1990

1972-1976

B. S. Ed. (1976)

B. S. Sp. Ed. (1976)
Dissertation Defense: “Energy Express Participants' Beliefs Concerning Educational Risk and Resilience"

Doctoral program, Special Education, West Virginia University Minor in Technology Education

Committee members: Dr. Gretchen Butera, chair; Dr. Luise Savage, major area; Dr. Diane Woodrum, major area; Dr. Van Dempsey, research skills; Dr. Ruthellen Phillips, Energy Express director; and Dr. John Wells, minor area. Admitted to candidacy: May, 1999.

Graduation date: August, 2002.

M. A. in Special Education--Learning Disabilities

West Virginia University, Collaborative Consultation program

Permanent WV Teaching Certificate issued Aug. 1990

Credits earned from Fairmont State College

University of Texas at Austin

Elementary Education--Reading Specialization

Special Education--Mental Retardation, K-12

\section{WORK EXPERIENCE}

1993-2002: $\quad$ University supervisor of undergraduate and masters level practicum students in special education-mild disabilities

2002: $\quad$ Research assistant for Energy Express longitudinal study

2000-2001: $\quad$ Visiting Instructor, Educational Theory and Practice, West Virginia University Teaching Special Education Methods for undergraduates and masters level students; supervising masters level practicum experiences 
Summer, 2000: Instructor for Special Education Methods (301) for first cohort of the Behavior Disorders project (masters level); Member of Energy Express evaluation team

Spring, 2000: Counselor II for students with disabilities, Fairmont State College under the direction of Dr. Tim Rice

Summer, 1999: Member of Energy Express evaluation team, qualitative data analysis dissertation research—survey of practitioners' beliefs about educational risk issues.

1998-1999: Independent evaluator for technology grant at Dunbar Middle School, Fairmont, WV (unpaid experience).

Summer, 1998: Member of Energy Express evaluation team Sole responsibility for quantitative evaluation of reading improvement using reading subtests of the Woodcock Johnson Tests of Achievement Revised, and JMP statistical analysis program. Additional responsibilities included telephone interviews of Americorps members and assistance in qualitative data analysis. Co-teacher of C\&I 391/SPED 381 Effective Inclusion in Elementary and Middle Grades Science, with Dr. Eric Pyle.

Fall, 1997: $\quad$ Co-teacher of Advanced Educational Studies (Foundations) course in Ethnography in Education, with Dr. Van Dempsey

Summer, 1997: Member of Energy Express evaluation team Responsibilities included qualitative and quantitative data collection, data analysis and presentation of results.

1993: $\quad$ Facilitator of off-campus seminar class in collaborative consultation (Special and regular educators) under direction of Dr. Luise Savage.

1987-1993: Full-time mother, tutor, adult Sunday school teacher. Substitute teacher in Marion County schools 1 year. Homeschool educator for 1 year.

1980-1987: Teacher and assistant administrator under the direction of Dr. William Pritchett, Fairmont Christian Academy. Responsibilities included instruction of kindergarten, elementary classes, and secondary English, Spanish, algebra, geometry, and journalism classes. I also scheduled classes, conducted teaching seminars, selected curriculum and interviewed teacher applicants.

1976-1980: Initial teacher of special education resource classes, Rivesville High School, grades 7-12. Junior high cheerleaders' and Bible Club faculty adviser/sponsor. Church treasurer for two years. 
1972-1974: $\quad$ Sales clerk and stock person, Jester Center Store, University of Texas, Austin

1971-1972: $\quad$ Summer file clerk--2 summers, Texas Water Rights Commission

\section{PUBLICATIONS}

Butera, G., McMullen, L. \& Phillips, R. (2000). Energy Express: Connecting communities and intervention on behalf of schoolchildren in West Virginia. Journal of Research in Rural Education, 16(1), 30-39.

Butera, G., Klein, H., McMullen, L., \& Wilson, B. (1998). A statewide study of FAPE and school discipline policies. Journal of Special Education, 32(2), 108-114.

Butera, G., McMullen, L., Phillips, R., Webb-Dempsey, J. \& Dempsey, V. (1998). Building community on behalf of low-income West Virginia school children: Energy Express. Paper presented for American Educational Research Association Conference, San Diego, April 16, 1998.

Butera, G., Belcastro, R., Friedland, B., Henderson, J., Jackson, C., Klein, H., McMullen, L. \& Wilson, B. (1996). Suspension, discipline and disabilities: Perspectives from practice. Special Education Leadership Review. 77-89.

Butera, G., Henderson, J., \& McMullen, L. (1996). IEP's, students with behavior problems and school discipline policies: A collision course. Paper presented for American Council on Rural Educational Services, San Antonio, Oct. 29, 1996.

\section{PRESENTATIONS}

April, 2002. "Energy Express Participants' Beliefs Concerning Educational Risk and Resilience.” Doctoral Defense.

March, 2001. Enhancing teacher partnerships: Innovations in professional skills development. American Council on Rural Special Education, San Diego.

November 6, 1998. Science inclusion in a climate of reform. West Virginia Council for Exceptional Children, Charleston. Presented with Dr. Eric Pyle.

October 17, 1998. IGOs and effective inclusion of students with disabilities. West Virginia Teachers of Science State Association conference, Snowshoe. Presented with Dr. Eric Pyle.

April 16, 1998. Building community on behalf of low-income West Virginia school children: Energy Express. Paper presented for American Educational Research Association Conference, San Diego. Presented with Dr. Gretchen Butera, Dr. Van Dempsey, Dr. Ruthellen Phillips and Dr. Jaci Webb-Dempsey. 
March 7, 1998. Building health and reading skills among low-income, rural schoolchildren:

Energy Express. Ethnography in Education conference, Philadelphia. Presented with Dr. Van Dempsey, Dr. Ruthellen Phillips, Dr. Jaci Webb-Dempsey.

October 29, 1996. IEP's, students with behavior problems and school discipline policies: A collision course. Paper presented for American Council on Rural Special Education, San Antonio. Presented with Dr. Gretchen Butera and Joan Henderson.

January, 1996. Presentation to the college faculty about suspension and students with disabilities research.

April 26, 1996. West Virginia teachers and administrators speak out about suspension. National Association of Social Workers. Substituted for Dr. Gretchen Butera, with Holly Klein.

Fall, 1995. Presentation of preliminary findings concerning issues regarding suspension and students with disabilities. Safe Schools Conference, Charleston, WV.

\section{Memberships and Honors:}

1999 Gustav Ohaus Innovations in Science Teaching--College Level Award, National Science Teachers Association, Boston, MA. With Dr. Eric Pyle and Dr. Gretchen Butera.

April 20, 1997. Phi Delta Kappa WVU Chapter, Outstanding Student Research Award, with Holly Klein and Brenda Wilson.

Student Memberships: Phi Delta Kappa, WV Council for Exceptional Children, American Educational Research Association 